\title{
Symptoms, Causes, and Coping Strategies for Performance Anxiety in Singers: A Synthesis of Research
}

\author{
Kristina Driskill \\ West Virginia University
}

Follow this and additional works at: https://researchrepository.wvu.edu/etd

\section{Recommended Citation}

Driskill, Kristina, "Symptoms, Causes, and Coping Strategies for Performance Anxiety in Singers: A Synthesis of Research" (2012). Graduate Theses, Dissertations, and Problem Reports. 3585.

https://researchrepository.wvu.edu/etd/3585

This Dissertation is protected by copyright and/or related rights. It has been brought to you by the The Research Repository @ WVU with permission from the rights-holder(s). You are free to use this Dissertation in any way that is permitted by the copyright and related rights legislation that applies to your use. For other uses you must obtain permission from the rights-holder(s) directly, unless additional rights are indicated by a Creative Commons license in the record and/ or on the work itself. This Dissertation has been accepted for inclusion in WVU Graduate Theses, Dissertations, and Problem Reports collection by an authorized administrator of The Research Repository @ WVU.

For more information, please contact researchrepository@mail.wvu.edu. 
Symptoms, Causes, and Coping Strategies for Performance Anxiety in Singers:

A Synthesis of Research

Kristina Driskill

Dissertation submitted to the

College of Creative Arts

at West Virginia University

in partial fulfillment of the requirements

for the degree of

Doctor of Musical Arts

in

Vocal Performance

Christopher Wilkinson, Ph.D., Chair

Jay Malarcher, Ph.D.

Nicholas Perna, D.M.A.

Janet Robbins, Ph.D.

Robert Thieme

Division of Music

Morgantown, West Virginia

2012

Keywords: Music Performance Anxiety; MPA; Performance Anxiety;

Singers; Stage Fright; Voice Teachers

Copyright 2012 Kristina Driskill 


\section{SYMPTOMS, CAUSES, AND COPING STRATEGIES FOR PERFORMANCE ANXIETY IN SINGERS: \\ A SYNTHESIS OF RESEARCH}

\section{Kristina Driskill}

Dissertation submitted to the

College of Creative Arts at West Virginia University

in partial fulfillment of the requirements for the degree of

Doctor of Musical Arts

in

Vocal Performance

Department of Music

\section{APPROVAL OF THE EXAMINIX'G COMMITTEE}

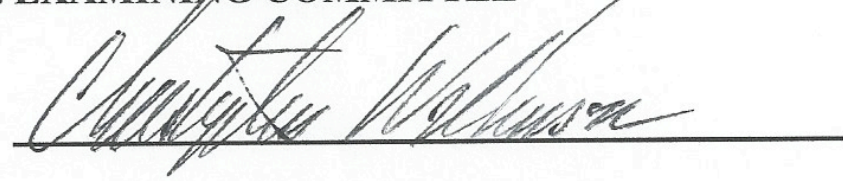

Christopher Wilkinson, Ph.D.

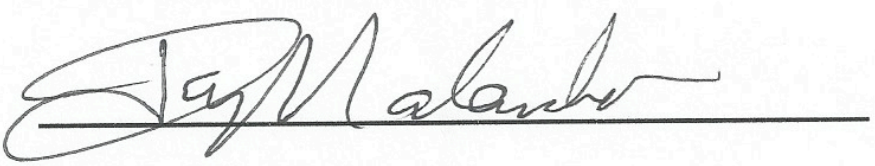

Jay Malarcher, Ph.D.

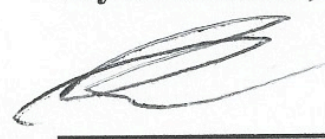

Nicholas Perna, D.M.A.

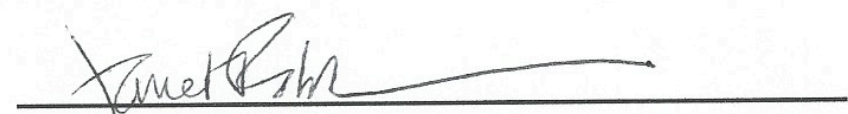

Janet Robbins, Ph.D.

$2 / 8 / 2012$

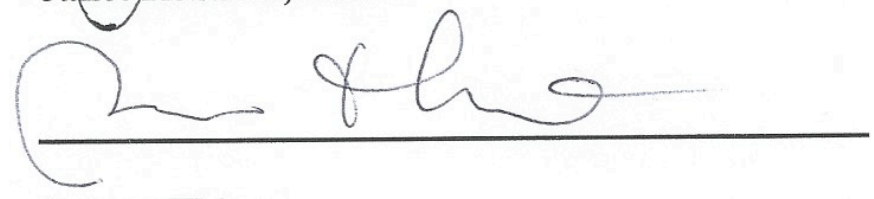

Date

Robert Thieme 


\section{ABSTRACT \\ Symptoms, Causes, and Coping Strategies for Performance Anxiety in Singers: A Synthesis of Research}

\section{Kristina Driskill}

A multitude of studies exists concerning performance anxiety, yet the number specifically focused upon singers is lacking in the literature. This study, intended as a reference guide for singers and singing instructors, discusses the symptoms, possible causes, and currently accepted coping strategies for music performance anxiety (MPA). An analysis of the published scholarship and correspondence from singers and professionals are included, as well as an appendix listing self-help sources and an extensive bibliography for further research. The study serves as an aid to singers and singing instructors seeking concise information on the topic. Specific steps within each coping method are not included, as the effectiveness of these can be unique to each individual. A survey of the most recent research suggests that more studies focused on singers are needed, as the voice is unlike any other instrument due to the fact that it resides within the body, and thus the efficacy of various treatments may be different for singers. 


\section{TABLE OF CONTENTS}

Forward iv

Chapter 1: $\quad$ The Nature of Performance Anxiety 1

$\begin{array}{lll}\text { Chapter 2: } & \text { Symptoms } & 11\end{array}$

$\begin{array}{lll}\text { Chapter 3: } & \text { Causes } & 23\end{array}$

Chapter 4: $\quad$ Coping Strategies: Movement-Oriented 40

Alexander Technique and Feldenkrais Method 41

$\begin{array}{ll}\text { Exercise } & 53\end{array}$

Chapter 5: $\quad$ Coping Strategies: Psychophysical 58

$\begin{array}{ll}\text { Biofeedback } & 58\end{array}$

$\begin{array}{ll}\text { Yoga } & 62\end{array}$

Chapter 6: Coping Strategies: Biochemical 76

Pharmaceuticals, Nutraceuticals, and $\quad 76$

Recreational Substances

$\begin{array}{ll}\text { Nutrition } & 86\end{array}$

Chapter 7: $\quad$ Coping Strategies: Cognitive-Behavioral Techniques 89

$\begin{array}{ll}\text { Visualization } & 90\end{array}$

Cognitive Behavioral Therapy 94

Hypnotherapy $\quad 98$

$\begin{array}{lll}\text { Chapter 8: } & \text { Conclusions } & 102\end{array}$

Appendix I: $\quad$ Transcriptions of Selected Correspondence 107

$\begin{array}{ll}\text { Appendix II: } & \text { Self-help Sources for Further Study }\end{array}$

$\begin{array}{lr}\text { Bibliography } & 114\end{array}$ 


\section{FORWARD}

This study will analyze the published scholarship on performance anxiety, presented in the form of monographs, articles, and web sources. In addition to the published material, this study will cite relevant correspondence from professionals as well as from singers who have experienced chronic performance anxiety and/or have feedback about their experiences with one of the coping strategies. ${ }^{1}$

The information contained within shall include a discussion of the common symptoms of performance anxiety including physical, mental, and behavioral symptoms caused by what has been termed "state anxiety," arising from thoughts concerning performance and the event itself. It shall not discuss the propensity for performance anxiety caused by what is known as "trait anxiety," a term describing an individual's general propensity for anxiety as part of one's psychopathology. While there is much research concerning the measured levels of both trait and state anxiety as they pertain to performance anxiety, the discussion of trait anxiety shall be omitted due to data suggesting that trait anxiety, while evidenced as a correlate, is not a prerequisite for music performance anxiety. ${ }^{2}$ “A person's long-standing personality traits are less relevant to producing [a] good...performance than are the individual states of mind, like anxiety...that the [performer] can bring about at particular times.",3

Trait anxiety is a personal matter, not necessarily open to discussion within a performance/study environment, and so it does not lie within the purpose of this study. The scholarship shall refer to "music performance anxiety," or MPA, as it is defined by Warren

\footnotetext{
${ }^{1}$ The term "professionals" shall refer to those qualified to speak authoritatively about a coping strategy within their field of expertise. "Professional singers" will identify those who have completed formal training and who have spent a significant part of their careers performing.

${ }^{2}$ Charlotte McKercher, F. Martin, and K.C. Kirkby, “Attentional Bias in Music Performance Anxiety?” supplement, Australian Journal of Psychology (2003): 196-197.

${ }^{3}$ David Krauss, Peak Performance (Englewood Cliffs, New Jersey: Prentice-Hall, 1980), 3.
} 
Brodsky, who refers to the condition as it pertains to the occupation of music performance. ${ }^{4}$ Performers should be aware that trait anxiety can have an affect on performance anxiety and on well being in general, and they should have their trait anxiety evaluated if they feel it may be affecting their ability to perform.

The symptoms and coping strategies examined, analyzed, and discussed are so common that, among psychologists, there is a consensus regarding their defining characteristics and an array of effective coping strategies. Symptoms will be defined and their impact upon a singer's physical and psychological state shall be discussed. The author acknowledges that while the list of symptoms is extensive, it may not be comprehensive, as some may experience symptoms that are not commonly discussed within existing sources. Within this essay, attention will be given to the coping strategies most frequently cited. The author is also aware that additional options exist, particularly in the psychological field, and that not all coping methods will be discussed. This study is intended as a resource for awareness, from which further individual exploration would be necessary to employ a coping strategy. The initial chapter shall discuss the nature of performance anxiety as it pertains to music.

\footnotetext{
${ }^{4}$ Warren Brodsky, "Music Performance Anxiety Reconceptualized: A Critique of Current Research Practices and Findings," Medical Problems of Performing Artists 11, no. 3 (September 1996): 88.
} 


\section{CHAPTER 1}

\section{The Nature Of Performance Anxiety}

For many people who perform in public, whether as amateurs or professionals and regardless of the nature of their performance, anxiety can be a part of those experiences. The term "performance anxiety" arises from the mental, behavioral, and physiological indicators of anxiety as they pertain to performing of any kind, while in front of an audience of any size (or that which may be perceived as an audience, such as a camera, microphone, or listeners that may be able to hear outside of a practice room), and it encompasses a myriad of possible symptoms with a vast range of physical and/or emotional responses. The presence of these indicators can be an asset or a hindrance based on individual experiences. For some, the release of adrenaline in anticipation of a performance can give a helpful boost of energy, while for others, it can have a negative effect. While some of the symptoms experienced seem rather non-threatening, other symptoms can be so debilitating as to cause individuals to perform at a substandard level or to stop performing completely. Whether perceptible to others or not, to those experiencing performance anxiety none of the symptoms is trivial, and many struggle with them throughout the entirety of their careers. The great Spanish cellist Pablo Casals said, "Throughout my career, nervousness and stage-fright have never left me before playing. And each of the thousands of concerts I have played at, I feel as bad as I did the very first time.".5

Often referred to as "stage fright," the condition discussed here within has more recently been labeled by scholars as "music performance anxiety." This is defined as "the experience of marked and anxious apprehension related to musical performance that has arisen through specific anxiety-conditioning experiences and which is manifested through combinations of affective,

\footnotetext{
${ }^{5}$ José Corredor, Conversations with Pablo Casals (New York: E.P. Dutton, 1956), ix.
} 
cognitive, somatic, and behavioral symptoms." ${ }^{\prime 6}$ Many sources use the terms interchangeably, but there are some sources that refer to stage fright as a separate condition, with performance anxiety encompassing a larger scope of issues and stage fright pertaining specifically to debilitating physiological symptoms occurring on stage during a performance. The symptoms of music performance anxiety can arise hours, days, or even weeks in advance of a performance, and many suffer its effects during the performance itself. It has been noted that some believe a certain level of anxiety is beneficial, but there is a distinction to be made between the potentially beneficial feelings of anticipation and the unproductive feelings of anxiety associated with what is termed performance anxiety. "The issue is not whether or not anxiety is good or bad; the issue is determining which direction [one's] anxiety level needs to go...to put [one] in the best range to perform well."7

Different types of anxiety typically fall into one of two categories: state anxiety or trait anxiety. "State anxiety" can be described as a temporary condition caused by a specific event occurring in one's environment that is perceived as being threatening. The feelings caused by state anxiety subside once the event has passed. Performance anxiety is a form of state anxiety, with the specific event being a public performance of any kind. Generalized anxiety is known as “trait anxiety," which concerns a person's inherent disposition for anxiety in daily life as it is related to one's psychopathology. While the causes of these different kinds of anxiety vary, the symptoms discovered through examination of both kinds are similar. ${ }^{8}$ Anxiety is an innate part of human behavior; it was originally defined as being part of a means of survival, and in cases

\footnotetext{
${ }^{6}$ Ariadna Ortiz Brugués, "Music Performance Anxiety - Part 1. A Review of Its Epidemiology,” Medical Problems of Performing Artists 26, no. 2 (June 2011): 102.

${ }^{7}$ David Krauss, Peak Performance (Englewood Cliffs, New Jersey: Prentice-Hall, Inc., 1980), 3.

${ }^{8}$ Melissa Brontons, "Effects of Performing Conditions on Music Performance Anxiety and Performance Quality," Journal of Music Therapy 31, no. 1 (1994): 63-81; Mark C. Ely, "Stop Performance Anxiety!” Music Educators Journal 78, no. 2 (October 1991): 35 .
} 
when one's well-being is truly in danger, the physiological responses of the body characterized as anxiety are indeed necessary and helpful. ${ }^{9}$

Rationality would dictate that performing is not the same thing as a life-threatening situation, and yet any anxiety experienced can feel the same: the nervous system cannot discern between actual endangering situations and those only perceived to be so, and thus it reacts based upon perception, whether or not that perception is based in reality. ${ }^{10}$ In the field of psychology, Aaron T. Beck's cognitive model of emotion is widely accepted as the basis for understanding the body's mental and physiological responses to events: emotions occur based upon one's perception of an event, and not the event itself. ${ }^{11}$ This explains why the same event affects different individuals in different ways.

The reason performance is so easily perceived as a threat is intrinsic and can be traced to humans' primitive, animal-like instincts for survival. ${ }^{12}$ Acceptance by others in a group was essential; one's best chance at survival entailed being with others (hence the popular phrase "safety in numbers"). With so many large predators in the wild, to be alone was to heighten one's risk of death greatly. Weakness and non-conformity were seen as detriments that could lead to being excluded or left behind, and so one did one's best to avoid being perceived as a potential problem for the group. ${ }^{13}$ In modern society, most people no longer have to contend with these kinds of survival issues, but the instinctual behavior is still part of the human psyche, and the perceived need to be accepted by anyone who could be considered part of one's group, be it an instructor, a colleague, an audition panel, or an audience, remains intact.

\footnotetext{
${ }^{9}$ Health Foundation Publications, "How to overcome fear and anxiety," Mental Health Foundation, http://www.mentalhealth.org.uk/publications/overcome-fear-anxiety (accessed November 11, 2011).

${ }_{10}$ Stuart Edward Dunkel, The Audition Process: Anxiety Management and Coping Strategies (Stuyvesant, NY: Pendragon Press, 1989), 4; Maxwell Maltz, Psycho-Cybernetics (New York: Prentice-Hall, Inc., 1960), 200.

${ }^{11}$ Paul M. Salkovskis, "The Cognitive Approach to Anxiety: Threat Beliefs, Safety-Seeking Behavior, and the Special Case of Health Anxiety and Obsessions," in Frontiers of Cognitive Therapy (New York: The Guilford Press, 1996), 48.

${ }^{12}$ Aaron T. Beck, "Beyond Belief: A Theory of Modes, Personality, and Psychopathology," in Frontiers of Cognitive Therapy (New York: The Guilford Press, 1996), 2.

${ }^{13}$ Edward O. Wilson, Sociobiology: The New Synthesis (Cambridge: Belknap Press of Harvard University Press, 1975 ), 562.
} 
Based on the scholarship of Beck, Emery, and Greenberg in Anxiety Disorders and Phobias, Paul Salkovskis asserts that the varying degree of anxiety experienced by an individual can be determined based on the following equation:

\section{Anxiety $\propto \frac{\text { Perceived probability of threat } x \text { Perceived cost/Awfulness of danger }}{\text { Perceived ability to cope with danger + Perceived "rescue factors"14 }}$}

Take, for example, a singer who is afraid she might trip on her dress as she walks out in front of an audience. The degree to which this thought will affect her anxiety level will be based upon her perception of how likely that is to happen ("I've already tripped on it twice") multiplied by the perception of how terrible the outcome would be if it occurred ("What if I break my ankle and I can't sing, I'll fail my recital"), reduced by her perception of coping ("Well if I fall I could just smile and take a bow") plus any perceived rescue factors ("My accompanist will help me up if I fall"). The higher the perception of threat/cost and the lower the perceived coping/safety mechanisms are, the higher the level of anxiety.

The term "performance anxiety" can refer to a performance of any kind. Many sources discussing this condition as it applies to music define it in general terms as performance anxiety, but in others the specific term "music performance anxiety," commonly referred to as MPA, has arisen so as to clarify its meaning. There does not seem to be any consistency throughout the source material concerning music as to which term is used, possibly because the matter discussed can be applied so easily across discipline lines: the symptoms experienced by a cellist may be identical to those of a singer or a dancer. While the physical execution of performance varies from one discipline to another, the causes and symptoms of performance anxiety are not unique

\footnotetext{
${ }^{14}$ Salkovskis, 51.
} 
to each field. Thus, much of the following information may be applied to performers of any discipline. It will, in this case, focus on the terms and conditions as they relate to singing. This is not a new problem; public speaking has been acknowledged by many sources as the most common fear among adult Americans. This anxiety manifests the same symptoms as those experienced by musicians or anyone giving any kind of public performance. The presence of performance anxiety is so prevalent that an abundance of literature has surfaced on the subject. The origin of its study stems from the performance psychology of sports, the earliest examples of which come from the late 1890s. During the first half of the twentieth century, the development of sports psychology and the study of performance grew and other disciplines, including education, business, personal living, and the performing arts, adopted its methods. However, in an interview with pianist Dylan Savage, renowned performance psychologist Don Greene cited musicians as having the greatest difficulty managing performance anxiety, more so than any other group with which he has worked. ${ }^{15}$

Performance anxiety can be considered a component of performance psychology, and a significant amount of research has appeared on this subject, particularly in the past twenty-five years. There are hundreds of articles in scholarly journals, trade magazines, professional journals, and newspapers that pertain to performance anxiety as it applies to the performing arts. There are over one hundred monographs on the subject and numerous websites and self-help workbooks. With the presence of so much information, it is evident that there is a demand for its existence. Knowing this, one would expect to see the acknowledgement of the subject within the curricula of institutions granting music performance degrees, but this is not yet a standard within post-secondary education.

\footnotetext{
${ }^{15}$ Dylan Savage, “An Answer to Performance Psychology: Don Greene,” American Music Teacher (February/March 2009): 29.
} 
The adoption of performance psychology as it pertains to sports by the music profession is quite logical. Musicians can be likened to athletes with respect to training: learning a technique that involves conditioning parts of the body, performing in front of a large crowd, taking direction and staying focused, and acquiring a balance that must exist between one's personal life and the training and commitment required to be successful. Many universities work with sports psychologists to assist their athletes with these matters in order to help them achieve better performance. There are even youth sports groups associated with sports psychology. The use of sports performance psychology has become increasingly popular at the educational level, yet the psychological aspects of being a musician do not seem to be a standard part of discussion within academic and conservatory environments. ${ }^{16}$

Professionals associated with opera companies have frequently commented on singers' general lack of skill and confidence required for a singing career when they complete their formal education. Although not the only possible cause, the issue of confidence can be linked to music performance anxiety, which is not formally addressed within an academic environment. A singer's curriculum can include voice lessons, acting lessons, master classes, coaching, opera theatre class, and other courses in which a singer might be asked to perform, including those in song literature and diction. It would seem logical to leave the task of addressing performance anxiety issues to the voice instructor, who spends the most amount of individual time with the student. But with all that needs to be accomplished, instructors may not take the time within the course of a lesson or other class to cultivate discussions with students about their background, personal issues, and anxieties. And in many cases, collegiate instructors are discouraged from inquiring about a student's personal conditions. Though commenting upon another topic often

\footnotetext{
${ }^{16}$ While there are numerous schools that employ sports psychologists as part of their staff to work with athletes, to the author's knowledge there are no Schools of Music that employ performance psychologists as a regular part of their staff to work with musicians as needed.
} 
neglected in performance curricula, namely marketing strategies for singers when embarking upon a professional career, Mark Stoddard's observation pertains just as much to the issue of performance anxiety: "Why this is not taught in music schools is understandable. Music schools teach music and it takes so long to teach the [vocal] techniques that they can focus on little else. ${ }^{n 17}$

With there being an apparent absence of courses or seminars offered on the subject of dealing with performance anxiety within a collegiate curriculum, it is not surprising that many singers are unaware of the frequency of this condition. In fact, most musicians believe that natural ability, rather than a method of practice and a strategic approach to performance, is the main factor in one's success. ${ }^{18}$ While some will attempt to overcome less debilitating symptoms by themselves, singers with incapacitating symptoms may feel like outcasts among their peers. The feelings of anxiety and inadequacy that result over time can quell a students' desire to sing and even diminish their joy for music. Since these issues can affect a singer's ability to progress, instructors are subject to dealing with them as well.

The word "instructor" within this research shall refer to anyone who guides a singer's study of performance, such as a voice teacher, a coach, a conductor, a stage director, or an adjudicator. Although many times instructors find themselves being asked for advice, they cannot be expected to solve the non-musical issues brought into the studio by their students. But by their pedagogy, instructors can directly influence a student's gain or loss of confidence in spite of this. There is an implied responsibility of instructors to be able to recognize behaviors that might be attributed to performance anxiety. Knowing this would allow them to communicate in such a way that encourages students, and this would suggest the need for an understanding of

\footnotetext{
${ }^{17}$ Mark Stoddard, Marketing Singers - Creating a Perpetual Job Machine (Lindon, Utah: Alexander Press, 2007$), 3$.

${ }^{18}$ Antoinette Felsky, The Musician's Mind (New York: Pioneer Publishing Company, 1921), 5.
} 
performance psychology. Singers' internal dialogues and how they receive information from others can have a great impact on whether they develop, maintain, or decrease their levels of performance anxiety. An instructor's negative or careless comment can trigger an old or current insecurity or create an entirely new one, typically unbeknownst to that instructor. Likewise, a positive, encouraging comment might help to assuage a fear of which the instructor has no knowledge. The nature of anxiety resides within a person's mental health and/or the current external influences of a person's life; anything that causes a thought that something bad might happen has the ability to produce feelings of anxiety. ${ }^{19}$

However, the ability to recognize and understand symptoms of performance anxiety appears to be as absent in training among teachers as it is among students. Unless they have taken personal time to educate themselves on the multitude of issues associated with performance anxiety, teachers may be unaware that a student's behavior could be a symptom of performance anxiety rather than a personality trait. Therefore it seems logical that both instructors and students alike need to become educated on the symptoms, causes, and possible coping strategies associated with performance anxiety.

It should be noted that experiencing this kind of anxiety cannot be linked to the level of talent or experience or to a specific style of music: many singers from all different vocal styles from amateurs to those who have enjoyed successful careers are known to have experienced performance anxiety. One of the most well known examples is that of Broadway star and recording artist Barbra Streisand, whose bout with performance anxiety kept her from singing in front of a live audience for twenty-seven years. There are many others, including pop/rock singers Carly Simon and Rod Stewart and world famous opera singers Luciano Pavarotti and

\footnotetext{
${ }^{19}$ Christian Nordqvist, "What is Anxiety? What Causes Anxiety? What To Do About It," Medical News Today, February 10 , 2009, http://www.medicalnewstoday.com/releases/7603.php (accessed November 30, 2011).
} 
Renée Fleming, who have suffered from various symptoms of performance anxiety. Even the highly successful classical pop star Andrea Bocelli refuses to perform at Teatro de La Scala because of his acute stage fright. ${ }^{20}$ And although performers such as these were able to cope with their symptoms and produce exceptional performances, others are plagued by their symptoms to the point that they become mentally and/or physically blocked, keeping them from being able to perform to their ability or to perform at all. Singing becomes an unappealing, laborious task that the performer dreads, and eventually singers may question why they sing or perform at all.

But surely the vast majority of performing singers do not enter into music performance as an academic major or career path already consumed by feelings of displeasure for their craft. It is understandable that state anxiety may cause feelings of uneasiness about performing and it is common for even those who enjoy performing to have symptoms of performance anxiety, but for some there comes a time when the symptoms become so prevalent that they lose all pleasure in performing. Compliments from colleagues and audience members are not perceived as sincere, the work is not satisfying, and the product is never good enough. In a case such as this, is the student perhaps just in the wrong field? During a discussion concerning performance anxiety in singers and coping, a professional singing colleague remarked, "Singers are thrown out into the water, and they either sink or swim."

This does not have to be the case, and there is much evidence to suggest it need not be so, as has been demonstrated in the summer intensive training programs at OperaWorks ${ }^{\mathrm{TM}}$ in Los Angeles for the past twenty-five years. Each summer many talented singers arrive to the program with stories of personal struggles that in various ways restrain them from feeling connected with themselves, and thus their singing. Many of them do not know what it is that holds them back.

\footnotetext{
${ }^{20}$ Patrick Enright, "Even Stars Get Stage Fright,” msnbc.com, September 12, 2007, http://www.msnbc.msn.com/id/20727420/ns/health-mental_health/t/even-stars-get-stage-fright/ (accessed November 30, 2011).
} 
Personal discoveries are often made during the course of the program, and without any voice lessons as part of its curriculum, every summer singers leave the program performing and singing better than when they arrived. Many of these singers felt as if they were indeed sinking, and yet many continued on to become prominent performers all over the world.

Singers are often told that once they get more experience, once they are in front of people more often, then the symptoms will subside. And while this may be true in some instances, it is also possible that the performance ability improves while the symptoms remain. This may be because the brain allows for an illogical pattern that can refuse to normalize after repeated exposure to the same situation, even though an experience takes place and no tragedy occurred. ${ }^{21}$ Along with the propensity to take place repeatedly, there are factors that cause the anxiety to be maintained. Paul Salkovskis describes these as 1) selective attention, where one becomes sensitive to stimulus that resonates with the perceived emotion; 2) physiological change, where the arousal state incited by the perceived threat of the event is experienced, and 3) changes in behavior, where the perception of threat causes an increase in avoidance behavior. These factors influence the levels of threat/cost/coping/safety perception as seen in the anxiety proportionality equation, and as they fluctuate, the maintenance of anxiety can continue, creating a prolonged cycle. $^{22}$ Thus, while evidence shows that singers with more experience consistently give better performances, ${ }^{23}$ it also shows that the symptoms experienced by the singer do not subside based upon experience level. ${ }^{24}$ In order to understand the true nature of performance anxiety, a discussion on the symptoms associated with this condition is necessary.

\footnotetext{
${ }^{21}$ Hans J. Eysenck, "The Conditioning Model of Neurosis," Behavioral and Brain Sciences, 2, no. 2 (June 1979): 155.

${ }^{22}$ Salkovskis, 52-53.

${ }^{23}$ Donald Lee Hamann, “An Assessment of Anxiety in Instrumental and Vocal Performances," Journal of Research in Music Education 30, no. 2 (Summer 1982): 88.

${ }^{24}$ Brugués, 102 .
} 


\section{CHAPTER 2}

\section{Symptoms}

There is a long list of possible symptoms associated with performance anxiety, including those that are physical, mental (cognitive and psychological), and/or behavioral. It is common for most performers to experience more than one of these manifestations, though the experience is unique for each individual. ${ }^{25}$ The anxieties concerning performance "can be distinguished from situational or phobic anxieties that are primarily contingent on external situational cues (e.g., heights, snakes), rather than the individual's own problematic behavior."26

\section{Physiological Symptoms}

A vital component of music performance is the functionality of the body's muscular, skeletal, and nervous systems, which collectively orchestrate movement and motor coordination. Physiologically, symptoms that inhibit these systems are associated with the body's response to threat and are commonly referred to as "fight or flight," defined as the body's physical response to being put into a state of danger. ${ }^{27}$ While public performance is not the same as a lifethreatening event, the central nervous system does not distinguish between real and conceived occurrences, and it is the brain's perception of an event that sends the body into this protection/action mode. ${ }^{28}$ According to Maxwell Maltz, "the subconscious mind prompts us to act in accordance with the 'truth' as we see it, based on our conditioned beliefs." ${ }^{29}$ As part of its survival instincts, "the body prepares for threat by activating systems and sub-systems which

\footnotetext{
${ }^{25}$ Eric Maisel, Performance Anxiety (New York: Backstage Books, 2005), 46.

${ }^{26}$ Dale O. Dogle, "Toward Effective Treatment for Music Performance Anxiety," Psychotherapy: Theory, Research and Practice 19, no. 3 (Fall 1982): 368.

${ }^{27}$ Walter B. Cannon, Bodily Changes in Pain, Hunger, Fear and Rage: An Account of Recent Research Into the Function of Emotional Excitement, 2nd ed. (New York: Appleton-Century-Crofts, 1929), 277.

${ }^{28}$ Kenneth Baum, The Mental Edge (New York: Berkeley Publishing Group, 1999), 28.

${ }^{29}$ Baum, 33.
} 
support and enhance physical performance and by shutting down systems which are not contributing to physical performance. ${ }^{30}$ The neurological pathways within the brain send messages throughout the body that explain many of the following physiological responses:

- Blushing: The skin becomes flushed as oxygen is moved quickly throughout the body

- Cold extremities: Blood leaves the extremities and heads for the major organs in order to protect them and minimize blood loss if an extremity is lost in an attack

- Increase in heart rate: Blood pressure is raised to maximize the dissemination of nutrients and oxygen while flushing out any potential toxins

- Sweating/Clamminess: Higher blood pressure creates a build-up of heat where the major organs exist: the head, chest, and stomach, which may cause the body to sweat in order to release the heat, thus making cold hands clammy

- Shortness of breath: The breath becomes rapid and shallow, as this provides the most steady, quickest supply of oxygen to the body

- Hyperventilation: A combination of shortness of breath, tension, and an increased heart rate becomes uncontrolled and sends the body into an overactive breathing state

- Nausea, Dry mouth: The digestive system is seen as a low priority and thus temporarily shuts down, causing dry mouth as the salivary glands stop working and causing nausea, as any food sitting in the stomach is no longer being digested

- Tension, Trembling, Twitching, Vocal distortion: Muscles contract (especially the neck and shoulders) to prepare for action and also to protect the organs - this contracting action causes the muscles to tremble (and trying to hold contracted muscles still makes them tremble more)

- Blurred near-sighted vision: The pupils dilate in order to see long distance in order to anticipate what may be ahead

- Hypervigilance: Brain wave frequency increases, as information needs to be processed more quickly (hence things seem to need to move faster, manifesting as speaking faster, pacing, and fidgeting)

- Sense of fatigue: Muscle tension can increase and then decrease accompanied by feelings of weakness

${ }^{30}$ Bryant J. Cratty, Social Psychology in Athletics (Ithaca, NY: Mouvement Publications, 1984), 82. 
- Need to eliminate bodily fluids (urine, bowel, stomach): The body looks to get rid of anything it doesn't need that might weigh it down and inhibit its ability to escape ${ }^{31}$

In 2004, a group of psychologists conducting research on the psychological conditions of war veterans suggested that the well-known "fight or flight" phrase should also include "freeze" and "fright," since many clinical advancements had occurred since the phrase came into existence in $1929 .^{32}$ Psychologist Jeffrey A. Gray asserted that "the freeze response" is the initial reaction, allowing the subject not only to assess the danger, but also to become immobilized so as not to be detected. ${ }^{33}$ The inclination to freeze is then followed by "flight." In the original phrase, fight was placed in the primary position, but clinical research has proved that the desire to flee follows the signal to stop, look, and listen. This explains why a performer does not have the "fight" instinct initially: humans are hard-wired to run first and fight only if they cannot escape. Fight follows flight in the sequence, and if fighting is not successful, then "fright," referring to immobility, may occur. Sociobiologist Edward O. Wilson describes these symptoms as naturally occurring, based upon our primitive instincts. ${ }^{34}$

The majority of studies seeking to confirm the existence of performance anxiety have done so by focusing upon the physiological symptoms; of all possible symptoms, they are the easiest to measure and from which quantitative data can be shown. It should be noted that most have been conducted using instrumentalists as the subjects and not singers. While the symptoms experienced can be the same regardless of the discipline, only singers are dealing with a living instrument that must resonate and produce sound within their bodies, and "physical disorders

\footnotetext{
${ }^{31}$ Dale Cyphert, "Managing Stage Fright," University of Northern Iowa College of Business Administration, http://business.uni.edu/buscomm/Presentations/stagefright.html (accessed November 30, 2011); Cratty, 82.

${ }^{32}$ H. Stefan Bracha, et al., "Does 'Fight or Flight' Need Updating?" Psychosomatics 45, no. 5 (September 2004): $448-449$.

33 Jeffrey A. Gray, The Psychology of Fear and Stress, 2nd ed. (Cambridge: Cambridge University Press, 1988), 93.

${ }^{34}$ Edward O. Wilson, Sociobiology: The New Synthesis (Cambridge: Belknap Press of Harvard University Press, 1975$), 18$.
} 
among singers differ from those of other musicians, due to the nature of their instrument." ${ }^{, 35}$ To date, the author is unaware of any research studies that have sought to analyze the possible differences between the effects of physiological symptoms on singers as compared to instrumentalists.

\section{Cognitive and Psychological Symptoms}

In accord with the functionality of muscular, skeletal, and nervous systems are reasoning and emotional elements necessary for optimal performance. ${ }^{36}$ The mind's competence is crucial for successful execution, but oftentimes the ego creates inefficient processes due to its desire to maintain self-preservation. ${ }^{37}$ Mental manifestations can include both cognitive and psychological (or emotional) symptoms. Cognitive symptoms concern thoughts about a performance (whether current or in the future) or the possibility of a performance. When these thoughts become irrationally negative, they are known as "distortions." ${ }^{38}$ Cognitive therapists list the following different kinds of distortions:

- All-or-Nothing Thinking: Everything must be right/good or it is considered worthless; there is no credit given for effort or parts that may have been good

- Labeling: Negative labels ("I'm a failure" or "I'm so ungraceful") are used to describe oneself rather than a task or situation and imply that one is categorized as such in all situations

- Overgeneralizing: Phrases using "always," "never," "everybody," and "nobody" are used to describe a situation ("Everybody is better than me")

- Assuming: Future-predicting or mind-reading without any proof ("Even if I sing well I'll never win" or "My teacher hates me")

\footnotetext{
${ }^{35}$ Ariadna Ortiz Brugués, "Music Performance Anxiety - Part 1. A Review of Its Epidemiology," Medical Problems of Performing Artists 26, no. 2 (June 2011): 105.

${ }^{36}$ David Pargman, Stress and Motor Performance (Ithaca, NY: Mouvement Publications, 1986), 8.

${ }^{37}$ As stated by Sigmund Freud in Maisel, Performance Anxiety, 39.

${ }^{38}$ Glenn R. Schiraldi, 10 Simple Solutions for Building Self-Esteem (Oakland: New Harbinger Publications, 2007$), 28$.
} 
- Emotional Reasoning: Thoughts that associate feelings with reality to justify an emotional connection in a situation ("I feel stupid so I must be stupid")

- Dwelling on the Negative: Only giving attention to flaws or mistakes regardless of the big picture (such as thinking about one note that was not good and dismissing the rest of a performance that was otherwise excellent)

- Rejecting the Positive: The inability to accept compliments at face value; many times an excuse will be given as to why something should not have been seen as good ("Thanks, but I should have been able to hold the end longer")

- Making Unfavorable Comparisons: Self-judging comparisons to others regardless of circumstances, like another being older or having more experience ("She is a better singer than I am")

- "Should" Statements: Thoughts that are used to compensate for a lack of perfection ("I should have been better," "It ought to be perfect," "I must get it right this time")

- Catastrophizing or Magnifying: A fearful thought leading to a negative conclusion that expects the worst or takes a situation out of proportion ("If I forget the words I might freeze up and faint," "If I make a mistake my teacher will kill me")

- Personalizing: Thoughts that attempt to give one more control or responsibility than what is reasonable ("The whole show was ruined because I missed that entrance")

- Blaming: Thoughts that place too much responsibility on other people or circumstances ("That guy in the audience ruined my performance") 39

In addition, one may experience a lack of focus, which can include decreased concentration, increased distractibility, memory lapses, confusion, and/or indecision. ${ }^{40}$ This tends to be caused by an overactive mind concentrating on the result rather than the process that leads to the result. ${ }^{41}$ When the mind is busy with concern over the outcome, the ability to focus on thoughts designed to produce the desired outcome is decreased, which in turn can diminish the quality of the performance.

\footnotetext{
${ }^{39}$ Judith S. Beck, Cognitive Therapy: Basics and Beyond (New York: Guillford Press, 1995), 181-182; Albert Ellis and Robert A. Harper, A New Guide to Rational Living (North Hollywood: Wilshire Book Co., 1975), in Schiraldi, 30-37; David Burns, Ten Days to Self Esteem: The Leader's Manual (New York: William Morrow, 1993), 50.

40 Test Medical Symptoms, "Performance Anxiety Symptoms," Test Medical Symptoms at Home, Inc., http://www.testsymptomsathome.com/sym_performance.asp (accessed November 30, 2011).

41 James Traverse, "Performance Anxiety: Mental Impotence,” Being Yoga, http://www.beingyoga.com/Performance\%20Anxiety.htm (accessed November 30, 2011).
} 
Many of these thoughts are associated with psychological symptoms. One of the primary emotions involved is fear - not the fear of the performance itself, but fear associated with public performing. ${ }^{42}$ In his workbook entitled Performance Anxiety, psychologist and creativity coach

Eric Maisel lists the following fears as being associated with performance anxiety:

- Fear of annihilation

- Fear of being ignored

- Fear of being in power

- Fear of being seen as flawed

- Fear of criticism

- Fear of diminished self-esteem

- Fear of disappointing people

- Fear of dying

- Fear of embarrassment/humiliation

- Fear of evaluation

- Fear of failure

- Fear of fear itself

- Fear of imperfection

- Fear of inauthenticity

- Fear of lack of preparation

- Fear of looking foolish or stupid

- Fear of loss of control

- Fear of loss of love or approval

- Fear of loss of the dream

- Fear of luck running out

- Fear of meaninglessness

- Fear of mediocrity

- Fear of memory loss

- Fear of not being clear/being misunderstood

- Fear of not repeating past success

- Fear of rejection

- Fear of retribution

- Fear of success

- Fear of strangers

- Fear of unexpected/unknown ${ }^{43}$

In addition to fear, worry can cause "what if" questioning ("What if I forget the words?"), which has the possibility of leading to distortional thinking. Other emotional symptoms can

\footnotetext{
${ }^{42}$ Elizabeth Valentine, "The Fear of Performance," in Musical Performance: A Guide to Understanding, edited by John Rink (Cambridge: Cambridge University, 2002), 176.

${ }^{43}$ Maisel, Performance Anxiety, 64.
} 
include feeling irritable, overwhelmed, vulnerable, helpless, worthless, guilty, ashamed, envious, or inadequate. ${ }^{44}$ While these are real and should be recognized, Stuart Dunkel summarizes David Viscott's comments on feelings:

The way you handle them determines whether you live in honesty or by a lie. You may discover that you use defenses to try to manage feelings. Though this may distort your perception of the truth, it does not alter the truth. You may be one who explains feelings away, but they must be dealt with head-on. Keep in mind that a painful feeling will not go away until it has run its natural course, for when a feeling is avoided, its painful effects are prolonged. Dealing with it, then, becomes increasingly difficult. ${ }^{45}$

Mental symptoms can only be recognized outwardly when they are verbalized. Sports psychologist and tennis coach Judy Van Raalte observed that players with these kinds of thoughts (known to her because of the players' audible negative comments to themselves) "were more likely to perform poorly" when they played. ${ }^{46}$ Furthermore, it has been proven that conscious self-criticism produces an inferior result. ${ }^{47}$ Negative thoughts and irrational emotions tend to produce a shift in conduct, which can be seen as behavioral symptoms.

\section{Behavioral Symptoms}

The behaviors rooted in this condition can vary greatly. Some behavioral symptoms are outwardly noticeable, such as arrogance and/or verbal responses of the sort, as described below. Ego self-protection may lead to more aggressive behavior, such as being irrationally defensive when criticized and projecting anger or frustration toward an innocent party. Other behaviors can

\footnotetext{
${ }^{44}$ Shirlee Emmons and Alma Thomas, "Shirlee Emmons: The Various Faces of Performance Anxiety," http://www.shirleeemmons.com/anxiety.html (accessed November 30, 2011); Stuart Dunkel, The Audition Process: Anxiety Management and Coping Strategies (Stuyvesant, NY: Pendragon Press, 1989) 79.

45 David Viscott, Risking (New York: Simon and Schuster, 1977), 21-22.

${ }^{46}$ Baum, 30.

${ }^{47}$ Dunkel, 88. An experiment conducted by Dr. E. Collon Cherry proved that stutterers showed dramatic improvement when they could not hear themselves speak.
} 
be more internal and subtle, such as avoiding situations that may cause hurt. ${ }^{48}$ Performers may also express opposite reactions for true feelings, such as saying that a performance was a waste of time or unimportant when it was indeed important. One may experience the symptoms for various amounts of time ranging from in the moment (during the event itself) to days or weeks ahead of the performance, and some underlying mental and/or behavioral symptoms may be continuously present.

Avoidance behavior, such as procrastination and/or avoiding practicing, auditioning, or performing, can be the result of "safety-seeking" behavior, where one looks for ways to reduce the level of threat. While this is a necessary instinctual response in an actual situation involving danger, in a non-threatening situation it can prevent one from learning that there is no cause for the fear. ${ }^{49}$ It is also difficult sometimes for people to acknowledge this kind of conduct, and so a defensive tactic is employed. The following are different behavioral symptoms associated with avoidance and defensive behavior:

- Denial of Reality/Escapism: A form of self-preservation that seeks to avoid reality by refusing to acknowledge it or to deal with it (such as by finding other activities to do rather than spending time on preparation)

- Compensation: Attempting to conceal a feeling of insecurity by projecting what is thought to be a preferable or superior identity (such as by speaking in an affected voice to sound more important) or making up for frustration in one area (not getting hired/not understanding) by over-gratification of another (indulgent eating/provocative dress/constantly talking about a subject that is familiar)

- Identification: Identifying oneself with famous or prestigious people/places by namedropping and story telling, typically taken out of proportion (such as mentioning a part singing with a leading role star and not mentioning that it was a chorus/background part)

- Fantasy: Spending time imagining being successful or having a star-like career but not doing any of the work to make it happen

\footnotetext{
${ }^{48}$ Maisel, Performance Anxiety, 51.

${ }^{49}$ Salkovskis, 55.
} 
- Introjection: The assimilation of external values or standards into one's own personality so that they are no longer perceived as external threats (such as protecting oneself from the pain of being criticized by liberally criticizing others)

- Projection: Projecting feelings onto others to avoid the actual issue (such as singers not understanding a teacher and thus saying the teacher is out to get them)

- Rationalization: Validating thoughts in order to defend them when they may be unreasonable or untrue (such as singers arguing that they could not practice because they do not have time)

- Repression: Inhibiting personality traits, thoughts, or memories in order to escape the feelings of discomfort, pain, or anxiety with which they are associated (such as repressing thoughts of being talented as to avoid the fear that others may think of it as being conceited)

- Reaction Formation: The expression of contradictory thoughts or behaviors to conceal actual thoughts (such as degrading another singer's talents because of jealousy)

- Displacement: Expressing feelings of hostility toward people/things less threatening than the actual cause (such as picking a fight with a friend because a practice didn't go well with the conductor)

- Emotional Insulation and Isolation: Self-protection by withdrawal into passivity (such as refraining from auditioning to avoid pain associated with a previous audition experience)

- Regression: An attempt to revert to an earlier stage of growth so as to relieve responsibility and/or feelings of being overwhelmed, such as behaving immaturely or operating on a diminished level of ambition (such as resorting to old technique or performance habits because it feels safer)

- Sympathism: An attempt to gain pity from others to boost self-esteem (such as singers telling people that they cannot get ahead in their careers because they do not have any money)

- Undoing: Purposely sabotaging work so that a negative outcome is not a surprise when it occurs (such as not practicing/memorizing music until the last minute)

- Acting Out: Engaging in combative behavior in order to avoid dealing with the task at hand (such as returning an accusation when being confronted with an issue) $)^{50}$

\footnotetext{
${ }^{50}$ Maisel, Performance Anxiety, 52-60, as adapted from Coleman, Abnormal Psychology and Modern Life (Glenview, IL: Pearson Scott Foresman, 1988).
} 
It is crucial for an instructor to understand the conduct that exists as a result of performance anxiety; only once a behavior is recognized can the teacher understand whether or not it may be associated with performance anxiety and how the issue might be affecting the student's performance ability and/or progress. This is especially important since many singers who employ these behaviors are unaware of their existence or, if they are, why they engage in them. If students are confronted about why they are employing a specific undesirable behavior, many times they will respond without honestly considering the origin, or they may sheepishly answer, "I don't know." Becoming aware of the behavioral indicators of performance anxiety can help instructors determine whether symptoms are characteristic of a student's personality or if they are signs of low self-confidence and/or fear related to performance anxiety.

\section{$\underline{\text { Research Findings and Acknowledgement of Symptoms }}$}

In a study completed in 2004, both student musicians and their teachers were asked to complete performance evaluations concerning the student's performance quality, perceived levels of anxiety, and the perceived impact of that anxiety on the performance during a lesson, a mock jury, and a jury performance. The evaluations after the mock jury and jury performances revealed that teacher and student perceptions varied greatly from one another, with student perceptions rating the impact of their anxiety significantly higher than the ratings of their instructors. The study suggested that there are "challenges associated with how teachers may or may not recognize the existence and subsequent impact of performance anxiety among college students." 51

\footnotetext{
${ }^{51}$ Staci Renee Miller and Kris Chesky, "The Multidimensional Anxiety Theory: An Assessment of and Relationships Between Intensity and Direction of Cognitive Anxiety, Somatic Anxiety, and Self-Confidence over Multiple Performance Requirements among College Students," Medical Problems of Performing Artists 19, no. 1 (March 2004): 18-19.
} 
Research studies concerning music performance anxiety vary greatly in size, length, and format. While some have claimed definitive findings, many have been criticized for their poor methodology or unsatisfactory implementation. In his critique of the research literature published, Warren Brodsky lists the "diversity of conceptual theories, inferior sampling procedures, invalid screening criteria, and use of unreliable assessment measures" as concerns regarding the validity of conclusions of various studies. Irrespective of this and although the symptoms investigated differed among these studies, all of the research acknowledged the existence of music performance anxiety and the existence of an array of physiological, cognitive, psychological, and behavioral symptoms with which it is associated.

Among the findings of a number of these studies was a discovery that focused upon the relationship between gender and the experience of performance anxiety. And although the various studies yielded differing percentages, the research has consistently shown that females are more affected by performance anxiety, and that adolescent musicians experience symptoms in the same manner as adults. ${ }^{52}$ The observation concerning gender is widely accepted, perhaps because it is known that social anxieties are more common in women, and performance anxiety is considered a form of social anxiety. However, the reason for this gender favoring is unknown. ${ }^{53}$

Although the percentage of those who experience music performance anxiety is not agreed upon, the lowest figures range from fifteen percent to twenty-five percent, while the highest are between seventy and one hundred percent. Since the studies conducted have so many variables, including gender, level of proficiency/expertise, performance conditions, individual

\footnotetext{
${ }^{52}$ Dianna T. Kenny and Margaret S. Osborne, "Music Performance Anxiety - New Insights from Young Musicians," Advanced Cognitive Psychology, 2, no. 2-3 (2006): 106-108.

53 James C. Ballenger, et al., "Consensus Statement on Social Anxiety Disorder from the International Consensus Group on Depression and Anxiety." Journal of Clinical Psychiatry 59, supplement 17 (1998): 54-60.
} 
personality traits, and whether the performer is an ensemble performer (such as an orchestral or choral member) or a soloist, there are complications involved in determining an accurate figure.

Even though a plethora of information exists on the subject of performance anxiety, to date there has not been a significant body of work from which to draw definitive conclusions. According to a review of music performance anxiety literature seeking to analyze research that involved the use of clinical evidence, only sixteen studies were found to be relevant, and of those, none qualified as what was termed a "Level I" study, meaning that none of the "evidence was obtained from a well-constructed, long-term cohort study." The review states in its conclusions that as of yet "there are no gold standard studies," and that further research is necessary. ${ }^{54}$

As with any issue, recognizing the symptoms of performance anxiety is prerequisite to finding a path toward resolution. While the physiological symptoms are plainly obvious to identify, mental and behavioral symptoms - even when outwardly obvious - may not be known to the performer or to the instructor unless they have been informed as to the symptoms' existence. Once they have been identified, it is then necessary to examine the possible causes for the condition that led to their appearance.

\footnotetext{
${ }^{54}$ Brugués, 105.
} 


\section{CHAPTER 3}

\section{$\underline{\text { Causes }}$}

The causes of performance anxiety may have numerous origins and can be assessed by surveying a combination of three factors: the individual's trait anxiety, the task's level of difficulty, and the level of situational stress. ${ }^{55}$ Situational stress can be something as basic as a lack of preparation or the difference between judgmental and non-judgmental conditions, such as singing in front of a non-threatening audience versus singing in front of an audience perceived as threatening, such as an audition panel. A key component is this perception, which in this case can be defined as "a single unified awareness derived from sensory processes while a stimulus is present.. ${ }^{, 56}$ Jazz singer Kevin Mahogany described the commonality of this among artists:

Even when there is no problem whatsoever, the mind of an artist will imagine something. Even when I sing every note perfectly, everything goes smoothly, and I get to sing many encores, I will still find something I don't quite like about my performance. ${ }^{57}$

As stated in Chapter 1, the mind creates truths based upon perception, whether or not the perception is based on fact. The way one assesses an event or situation is critical to the presence of anxiety, and it can deepen or lessen one's reaction. Anxiety is typified by a state of helplessness due to a perceived inability to predict, control, or obtain desired results. ${ }^{58}$ Alexander Technique instructor Geórgia Diaz echoes this primary psychological issue: "The internal voice

\footnotetext{
${ }^{55}$ Elizabeth Valentine, “The Fear of Performance,” in Musical Performance: A Guide to Understanding, ed. John Rink (Cambridge: Cambridge University, 2002), 172.

${ }^{56}$ Random House Dictionary, "Perception,” Dictionary.com, http://dictionary.reference.com/browse/Perception (accessed November 30, 2011).

${ }^{57}$ Barry Green, The Mastery of Music (New York: Broadway Books, 2003), 218.

${ }^{58}$ David H. Barlow, Bruce F. Chorpita, and Julia Turovsky, "Fear, Panic, Anxiety, and Disorders of Emotion," in Perspectives on Anxiety, Panic, and Fear (The 43 ${ }^{\text {rd }}$ Annual Nebraska Symposium on Motivation), ed. Debra A. Hope (Lincoln: Nebraska University Press, 1996), 251; George R. Thorn, et al., "Psychological Theories of Panic Disorder," in Panic Disorder: Clinical Diagnosis, Management, and Mechanisms, ed. David J. Nutt (London: Martin Dunitz, 1999), 94.
} 
is bound to bring about one's habitual patterns. ${ }^{, 59}$ If the brain has learned to associate a certain kind of event or situation with a particular perception, it will gladly retain the information so as to repeat the pattern learned. And since the brain likes to learn in this manner, it picks up whatever patterns it is given, whether those come from external sources such as instructors, classes, or performances, or from an internal source, such as self-talk. ${ }^{60}$

Neurotransmitters are responsible for carrying neurological messages from one part of the brain to another and can cause, among many other psychological and physiological processes, changes in mood, anxiety levels, heart rate, and fear. Their primary purpose is to allow the body's nerves to excite or inhibit their impulses. ${ }^{61}$ The perception of threat causes alterations among some of these chemicals, including adenosine, dopamine, epinephrine, gamma-aminobutyric acid (GABA), glutamate, histamine, norepinephrine, PEA, and serotonin. ${ }^{62}$ The following table illustrates a basic description of these neurotransmitters' functions:

\footnotetext{
${ }^{59}$ Geórgia Diaz, "Voice Work in the Alexander Technique," http://www.bodyandmind-at.nl/06e-media\&articles.html (accessed November 30, 2011).

${ }^{60}$ Leslie A. Hart, Human Brain and Human Learning (New York: Longman, 1983), 178-179.

${ }^{61}$ Pediatric Neurotransmitter Disease Association, "What are neurotransmitters?" http://www.pndassoc.org/site/c.iuLWJdMRKpH/b.689419/k.8000/What_Are_Neurotransmitters.htm (accessed November 30, 2011).

${ }^{62}$ Jeremy D. Coplan and R. Bruce Lydiard, "Brain Circuits in Panic Disorder," Biological Psychiatry 44, no. 12 (1998): 1264; A.J. Rush, et al., "Neurobiological Bases for Psychiatric Disorders," in Comprehensive Neurology, 2nd ed., Roger N. Rosenberg and David E. Pleasure, (New York: John Wiley and Sons, 1998), 555.
} 


\begin{tabular}{|l|l|l|}
\hline Neurotransmitter & Inhibitory/Excitatory & Function/Responsibility \\
\hline Adenosine & Inhibitory & $\begin{array}{l}\text { Heart-rate reduction, decreases stress } \\
\text { response }\end{array}$ \\
\hline Dopamine & $\begin{array}{l}\text { Inhibitory \& } \\
\text { Excitatory }\end{array}$ & $\begin{array}{l}\text { Focus, motivation, interest, drive, positive } \\
\text { stress, makes norepinephrine }\end{array}$ \\
\hline Epinephrine (Adrenaline) & Excitatory & $\begin{array}{l}\text { Metabolism, attention, mental focus, } \\
\text { arousal, cognition, heart rate, blood } \\
\text { pressure }\end{array}$ \\
\hline GABA & Inhibitory (main) & $\begin{array}{l}\text { Reduces anxiety and stress, regulates other } \\
\text { neurotransmitters }\end{array}$ \\
\hline Glutamate & Excitatory (main) & Learning, memory \\
\hline Histamine & Excitatory & $\begin{array}{l}\text { Sleep-wake cycle, regulates other } \\
\text { neurotransmitters }\end{array}$ \\
\hline Norepinephrine & Excitatory & $\begin{array}{l}\text { High levels = anxiety, stress, high blood } \\
\text { pressure, hyperactivity; Low levels = lack } \\
\text { of energy, focus, and motivation }\end{array}$ \\
\hline PEA & Excitatory & Focus, concentration \\
\hline Serotonin & Inhibitory & Defends against anxiety and depression \\
\hline
\end{tabular}

It has been suggested that anxiety (and other mood disorders) is closely related to an imbalance among neurotransmitters. ${ }^{64} \mathrm{~A}$ change in one can cause a reactionary chain of alterations among many other neurotransmitters associated with anxiety responses, such as cholecystokinin (CCK), corticotropin releasing factor (CRF), and neurokinins, also known as Substance P. ${ }^{65}$ Because the functionality of these chemicals is intricately linked and they are responsible for regulating so many biochemical and physiological reactions, it is evident why the body has so many possible reactions to fear-provoking thoughts.

Since perception is based upon individual assessment, it can be described as an internal cause; it can be connected with other internal causes, and it can also be linked to external origins.

\footnotetext{
${ }^{63}$ Jamie Al-Nasir, “Anxiety - Evidence of Involvement of the Neurotransmitter GABA (Gamma-Amino-Butyric-Acid) and Other Implicated Neurotransmitters," Jamie Al-Nasir, http://www.al-nasir.com/www/Jamie/Articles/Pharmacy/anxiety_gaba_neurotransmitters.shtml (accessed November 30, 2011). ${ }^{64}$ Valerie Balandra and David Sheiderer, "The Four Major Neurotransmitters," Integrative Psychiatry, http://www.integrativepsychiatry.net/neurotransmitter.html (accessed November 30, 2011).

${ }^{65}$ Al-Nasir, http://www.al-nasir.com/www/Jamie/Articles/Pharmacy/anxiety_gaba_neurotransmitters.shtml
} 
Examples of internal causes can include:

- One's inherent need for acceptance

- Self-criticism and negative self-talk

- Attentional focus

- Perfectionism

- Improvement

Examples of external stimuli that could initiate feelings of performance anxiety based on perception would include:

- Previous experiences that have been perceived as being negative (bad lesson/coaching/rehearsal/audition/performance)

- Lack of support: comments/behaviors from instructors, family members, peers, or friends perceived as being negative

- Poor health choices (although choices are made internally, nutrition is an external addition to the body)

- Learning in a comfortable environment if the singer was initially ignorant of the profession and not informed of its standards, or learning in an environment where the standard of everyone is consistently very high (Big Fish Little Pond Effect)

These influences will now be discussed in greater detail.

\section{The inherent human need to be accepted for survival}

As discussed in Chapter 1, a human's need for acceptance in order to survive is a primal, inherent quality that still remains as part of the human psyche, even though human living conditions have changed drastically. Any situation in which humans could possibly subject themselves to rejection by others is naturally perceived as threatening. The nature of performing 
dictates that virtually all practice (practice rooms where others can hear/see, lessons, coachings, rehearsals) and all performances are executed in front of others, and therefore the probability of one or more of these situations triggering anxiety symptoms would be expected.

\section{$\underline{\text { Self-criticism and negative self-talk }}$}

Self-criticism, or negative self-talk, is common among those afflicted with performance anxiety ${ }^{66}$ While this is seen as a symptom of performance anxiety and can be the result of another cause, a person continuously clouded with negativity can also develop poorer results from consistently providing a destructive cognitive environment.

Mental self-sabotage can cause distress before a performance, but it is especially damaging for singers during the performance itself. It is essential that singers remain present while producing sound. Not only are they the only musicians who directly face the audience without an external instrument in front of them, they are the also the only musicians whose instrument resides within. When the mind begins to dwell on unproductive thoughts such as any of those described in Chapter 2 or a reactionary thought formed as a result of what is happening at the moment ("That sounded terrible!" or "My legs won't stop shaking”), it cannot concentrate on the task at hand. The mind must be able to remain focused on proper breathing and communication of the poetry and music. When idle thoughts take over, a singer will almost always take an inefficient breath, and/or the face will display a blank or inappropriate expression.

\footnotetext{
${ }^{66}$ Glenn D. Wilson and David Roland, "Performance Anxiety," in The Science and Psychology of Music Performance: Creative Strategies for Teaching and Learning, ed. Richard Parncutt and Gary McPherson (New York: Oxford University Press, 2002), 47-48.
} 


\section{$\underline{\text { Attentional Focus }}$}

"Attentional focus" involves directing one's attention toward something specific, either internal or external. Internal focus can relate to thoughts about oneself or to the physical control of parts of the body as the instrument. External focus can involve thoughts that do not concern the immediacy of self and the use of one's peripheral energy. Attentional focus is vital to a high quality performance; it can be used in a productive way to one's advantage or in an unproductive way to one's detriment, and a poor use can contribute to performance anxiety. ${ }^{67}$

Result-oriented thoughts are an example of misappropriated attentional focus. There is an inherent mentality that product should be the main focus and should supersede any thought of process. The outcome of the sound or the performance itself becomes the object on which to concentrate, and whether it is good or successful becomes the consummate project. This relates back to the ego and its survival instinct to protect: the mind fears that any possibility of being "wrong" will equal failure, and failure may be followed by a lack of acceptance, which may threaten one's well-being. So the mind becomes obsessed with perfection and being correct in order to "save" itself. Ironically, this thought process typically yields lower quality results, because the mind is not focused on the task at hand; rather, it is focused upon a future event: the outcome.

This can produce the same yo-yo effect as questionable self-worth. Oboist Stuart Edward Dunkel said of his experiences, "I noticed that my ups and downs, my frustrations, and my depressions were subject to how I perceived the end result of winning or losing." As he began to study about anxiety in musicians, he discovered that there was a correlation between how

\footnotetext{
${ }^{67}$ Gabriele Wulf, “Attention and Motor Skill Learning,” Human Kinetics, http://www.humankinetics.com/products/allproducts/attention-and-motor-skill-learning (accessed November 30, 2011).
} 
performers perceive their work and their value of self-worth. ${ }^{68}$ When the mind and emotions are not coordinated, it is possible for irrational thoughts to interfere with rational knowledge, and in this state one must choose between the two. And although solely obeying one or the other is not a reasonable choice for a course of action, all too often emotions are indulged over logic. In fact, studies show that ninety percent of decisions are based on emotion rather than logic. ${ }^{69}$

Other examples of troublesome attentional focus include: concentration on the audience, acoustics of the performance space, or external environmental factors (noises, temperature, dress/costume); worrisome thoughts such as the possibility of forgetting the words or an entrance; non-beneficial, body-specific focus (shaky limbs, tight muscles, uncommitted gestures); and non-performance related circumstances, such as an illness in the family or an argument that occurred before the performance.

\section{$\underline{\text { Perfectionism }}$}

Perfection as a general standard carries a stigma of failure if anything is perceived as less than so. ${ }^{70}$ Most performers are familiar with the phrase "practice makes perfect," which later was enhanced by some to be "perfect practice makes perfect." The reasoning for such adages can be understood; one cannot become highly skilled at a craft without a lot of practice, and students that wish to become experts must be fully committed to practicing. Indeed, to become a successful performer, one must strive for excellence. But the word "perfect" carries a heavy responsibility, and what was intended to be a phrase of instructional encouragement can be quite destructive. A performer that aims solely for perfection cannot experiment or risk because of the

\footnotetext{
${ }^{68}$ Stuart Edward Dunkel, The Audition Process: Anxiety Management and Coping Strategies (Stuyvesant, NY: Pendragon Press, 1989), 9.

${ }^{69}$ Kurt Mortensen, Maximum Influence: The 12 Universal Laws of Power Persuasion (New York: AMACOM, 2004$), 184$.

${ }^{70}$ Bonnie Blanchard, Making Music and Having a Blast! (Bloomington: Indiana University Press, 2009), 222.
} 
possibility of failure, and if an attempt is perceived as less than perfect, than it was a failure anyway. "Perfectionist expectations lead to detachment from one's body and a tendency to apologize preemptively for one's efforts, knowing from experience that there is sure to be something wrong with them...Perfectionism can really get in the way of communication and perception, to say nothing of enjoyment and ultimate mastery."71

In his manual Ten Days to Self-Esteem: The Leader's Manual, psychologist David Burns lists nine different kinds of perfectionism:

- Physical - must have a perfect face/figure to be worthy and/or desirable

- Achievement - cannot make mistakes, fail, or fall short

- Perceived - must impress everyone and be liked by all

- Emotional - should always be happy and in control

- Self-Esteem - people who are more intelligent/attractive/successful are better

- Relationship - relationships should not have any conflict

- Entitlement - everything else should be perfect in one's environment

- Obsessive compulsive - things must be done until they are considered perfect

Burns states, "There is little or no evidence to support the belief that perfectionism motivates people to achieve. Because perfection can lead to anxiety and depression, it may have the opposite effect of reducing creativity and productivity. Many perfectionists probably achieve success in spite of their perfectionism, not because of it." ${ }^{, 72}$

A study of eighty-seven professional performers showed that those with high levels of “self-oriented perfectionism [and] socially prescribed perfectionism" were connected to more

\footnotetext{
${ }^{71}$ William Westney, The Perfect Wrong Note: Learning to Trust Your Musical Self(Pompton Plains, NJ: Amadeus Press, 2003), 132.

${ }^{72}$ David Burns, Ten Days to Self-Esteem: The Leader's Manual (New York: William Morrow, 1993), 42.
} 
debilitating levels of performance anxiety ${ }^{73}$ Furthermore, research studies show that there is a significant link between perfectionism beliefs and a number of clinical psychiatric disorders, such as depression, anxiety, eating disorders, and substance abuse, and non-clinical issues including less satisfaction with performance, attitudinal inflexibility, higher levels of stress, procrastination, and the propensity for persistent worry and fear of failure. ${ }^{74}$ Jonathan Dunsby said, "An idealistic approach to music making can be a blinkered one that is of no use to either the professional or the amateur., 75

\section{Improvement}

Most people would not associate improvement with performance anxiety, but there are two crucial factors associated with skill progression that may cause symptoms. The first of these concerns the necessity of a focus on process versus a focus on product. When students develop a fine motor skill, they will typically go through stages where progress will be evident or where practicing or performing will be difficult or yield less than desirable results. When these events are obvious, it is easier to comprehend them at face value. But when students must undo a habit that has become an inherent part of technique or performance in order to improve, a productoriented focus will leave them feeling as if they are getting worse. In an article entitled "Change for the Better," athletic coach Doug Reese explains that athletes like Michael Jordan and Tiger Woods, when they were already considered highly successful, were courageously willing to get

\footnotetext{
${ }^{73}$ Shulamit Mor, Hy I. Day, and Gordon L. Flett, "Perfectionism, Control, and Components of Performance Anxiety in Professional Artists," Cognitive Therapy and Research 19, no. 2: 207.

${ }^{74}$ Hugh Kearns, Angus Forbes, and Maria Gardiner, "A Cognitive Behavioral Coaching Intervention for the Treatment of Perfectionism and Self-Handicapping in a Non-clinical Population," Behavior Change 24, No. 3 (2007): 157-159.

${ }^{75}$ Jonathan Dunsby, "Performing Music: Shared Concerns (New York: Oxford University Press, 1995), 31.
} 
worse at their games in order to get better. He states, "Changing the basics of your game is hard enough to do when you are losing; doing it when you are winning is almost unprecedented.”76

As stated in Chapter 1, while the brain enjoys challenge and stimulation, it also enjoys its patterns, and when comfortable patterns are disrupted, anxiety can appear if this is not perceived as being a positive experience. This can be especially personal for singers since their instrument is also part of the body. "One should be aware of the strong identification one has with the sound of the voice. When it changes there is the risk of not recognizing [oneself] and feeling lost. The temptation to go back to what the debauched sensorial mechanism considers as right will be very much present."77

The second factor involves higher expectations derived from the improvement. Once better sound is made, more musicality is displayed, and/or a higher performance level is reached, a student typically hears overwhelming responses from instructors and colleagues that applaud the progress. Singers may then develop the belief that the new and improved skill level must be displayed each and every time, that they must not show any sign of regression, and as a result, an irrational (and unnecessary) expectation of self ensues. This is confirmed in The Art \& Technique of Performance, in a discussion about practice:

The more successful we become, the more times we continue to repeat the piece. As soon as we make an error (one is bound to happen), we now assume we can't play the piece. We feel the need to increase our practice... The more successful we are in playing the piece, the more pressure we put on ourselves to play better. ${ }^{78}$

\footnotetext{
${ }^{76}$ Doug Reese, "Change For the Better," To The Next Level Sports Network, http://www.tothenextlevel.org/docs/features/change_for_the_better/default.asp (accessed November 30, 2011).

${ }^{77}$ Diaz, "Voice Work in the Alexander Technique,"

${ }^{78}$ Richard Provost, The Art \& Technique of Performance (San Francisco: Guitar Solo Publication, 1994), 18.
} 


\section{The Connection Between Self-Worth and Experiences}

For many, self-worth has been socially formed as higher or lower based on performance, status, or events. ${ }^{79}$ Self-worth should not be dependent upon external sources, yet as described earlier in Dunkel's observations, this is a common occurrence. In a correspondence to the author, a young singer described an experience that had a profound impact on him:

I entered a competition and made it through the semi-final round into the finals. I was feeling so good about myself and how I was singing, that in my mind I had already won.

I decided to sing "Una furtiva lagrima" for the final round of a competition; I was so nervous, because I had not performed this aria in public and it is considered a risk to do such a thing. However, with encouragement of both my teacher and pianist, I decided to do it. When I finished, there was dead silence in the room. Suddenly, I was jarred back to "real life" by a boisterous "BRAVO!" I felt accomplished. I put myself out there and exposed a part of my soul and life.

What I was most looking forward to in the competition was the comments from the judges, but what I read that day from one particular judge was so hurtful that it brought me to tears: "You have a great sound, but you look quite GAY." I felt harassed and bullied on paper. He probably did not know how much those words hurt, no matter the circumstance.

None of the other judges had a comment that was close to this; in fact, they were very positive, but this comment stripped me down. After the competition, I started having major self-doubts about my singing and performance practice. It even penetrated how I went about my daily life. I did not want to look "quite gay." His poor word choice invaded my mind with thoughts of self-doubt, a loss of self worth, and a self-esteem that reached an all time low. ${ }^{80}$

When singers allow themselves to garner self-worth based upon external factors, such as a good/bad lesson, rehearsal, competition, audition, or performance experience, it will inevitably lead to a psychological yo-yo effect, always leaving them to question whether they are "good enough" at any moment. And while that question may need to be addressed honestly when it

\footnotetext{
${ }^{79}$ Glenn Schiraldi, 10 Simple Solutions for Building Self-Esteem (Oakland: New Harbinger Publications, 2007), 5.

${ }^{80}$ Confidential e-mail message to the author, August 10, 2011.
} 
comes to a career path, it should never be in question as it pertains to the individual. Allowing this kind of perception to enter the thought process on a personal level will indeed affect one as a performer, as the uncertainty it creates can cause singers to question their capacity as artists, interfering with a committed and authentic performance. The inability to connect with the music due to these factors can commonly lead one to acquire symptoms of performance anxiety. The world of music making may be filled with competition, but self-worth should not be competitive; it should not increase or decrease based on the perception of being better or worse than others or based on the perception of whether a performance was good or bad. Music educator William Westney writes, "Self-contempt in any form is toxic. In this tainted atmosphere [one's] honest musical soul [does] not feel safe emerging. ${ }^{, 81}$

As in the aforementioned case, an unsettling comment, feedback, or review can be just as detrimental if allowed to define self-worth. When polling people in a wide base of professions, teaching artist Eric Booth noticed that feedback topped their lists of what was most supportive and also of what hindered them most. ${ }^{82}$

\section{$\underline{\text { Lack of Support }}$}

The cases of external events affecting a singer's confidence are numerous, and they can be either positive or negative. In a message to the author, a singer explained the different experiences she had as an undergraduate student, as a participant in the OperaWorks Summer Intensive Program, and as a graduate student:

I feel my undergraduate voice teacher was instrumental in damaging my self-confidence, although I'm pretty sure this was unintentional on her part. I do believe she was trying to help me in her own way, but I heard things like, "I don't understand why you can't get

\footnotetext{
${ }^{81}$ Westney, 126.

${ }^{82}$ Eric Booth, The Music Teaching Artist's Bible (New York: Oxford University Press, 2009), 175.
} 
this," "You're my most difficult student," "Can't you do anything right?" "Quit being stupid," etc., for five years. I was vulnerable and hurt coming to school because of family issues at home and this kind of language hindered me to the point of emotional breakdown in every lesson. She would constantly tell all of us, "There's nothing special about you; you're very replaceable." Then I came to OperaWorks and you told me something completely different, "Many people sing this role, but nobody can sing your Komponist." This...helped change my thought pattern about singing, and now I don't worry when I go on stage, something that's never happened before!

My grad school voice teacher was wonderfully nurturing and supportive. The kind of language he used was, "Your Gs are beautiful, could you try that through your middle voice?" My technique improved instantly not only because of the content of vocal technique, but because I was no longer bursting into tears every lesson. I use the supportive/positive reinforcement approach with my own students and it works beautifully! There were a couple of intense coaches/directors in grad school that used a lot of the same negative language as my teacher from undergrad, but much, much less often. Nonetheless this still affected me and I found my body to be considerably tenser during those coachings/rehearsals than in voice lessons. ${ }^{83}$

Those who did not receive parental support in activities as a child may feel that they are not a worthy talent before they ever start. A sense of confidence and commitment can also be compromised by the words of others, including friends, family members, colleagues, strangers, and/or instructors. ${ }^{84}$

\section{$\underline{\text { Poor Health Choices }}$}

Because singers' bodies are also their instruments, the whole body must be employed to perform, and all aspects of a singer's life affect the instrument, including one's health choices. Good nutrition is often overlooked as a possible cause of performance anxiety. ${ }^{85}$ Since the body's systems rely on a balance of blood sugar (glucose) for well being, it is important to establish an eating regimen that seeks to optimize blood sugar levels and keep them in balance.

\footnotetext{
${ }^{83}$ Confidential e-mail message to the author, July 30, 2009.

${ }^{84}$ Anthony G. Greenwald and Mahzarin R. Banaji, "Implicit Social Cognition: Attitudes, Self-Esteem, and Stereotypes," Psychological Review 102, no. 1 (January 1995): 13.

${ }^{85}$ Dunkel, 114.
} 
When the body receives too much sugar at one time, the blood stream becomes over-flooded and the pancreas reacts by releasing insulin, which pulls the sugar out of the blood stream. Because the body sees this as an emergency, the insulin overcompensates and the blood sugar drops dramatically. Then the adrenal glands become stressed because there is not enough glucose, and they release adrenalin. This creates a vicious cycle; the body is given too much sugar, then it is all taken away, and so the brain sends a message to acquire more sugar, and typically too much is ingested again, which causes the process to repeat. This explains why, for many people, eating sugar results in a heightened state of excitement (too much sugar in the blood) followed by what is referred to as a "sugar crash" (not enough sugar in the blood). ${ }^{86}$

Low blood sugar can also be caused by not eating enough. In both of these cases, the absence of enough glucose can cause fatigue, sluggishness, and cloudy thinking, headache, and depression, along with the following symptoms that are similar to those of performance anxiety: irritability, lack of concentration, forgetfulness, confusion, body tremors, cold extremities, faster heartbeat, restlessness, and insomnia (the last three being results from an adrenaline release). ${ }^{87}$

While there are many foods such as desserts, candy, and soda that are obviously sugar based, there are also many high-sugar foods that are commonly included in meals, such as corn, white rice and white potatoes, anything made with refined flours, dried fruit, fruit juices, and honey. These and other simple carbohydrates convert to sugar quickly, especially if they are not eaten with fiber or protein, both of which help to slow down the metabolic process that converts foods to glucose. ${ }^{88}$

\footnotetext{
${ }^{86}$ Susan Driskill (Ph.D., Nutritional Counseling), e-mail message to the author, October 5, 2011.

${ }^{87}$ April Khan, “Anxiety and Eating," Livestrong.com, http://www.livestrong.com/article/331540-anxiety-eating/ (accessed December 1, 2011).

${ }^{88}$ Susan Driskill, e-mail message to the author, October 5, 2011.
} 
For some, stimulants such as caffeine can also cause an increase in blood pressure and heart rate, restlessness, nausea, diarrhea, and insomnia. Alcohol, which is normally thought to be a relaxant, can also trigger anxiety symptoms. Many forms of alcohol contain sugar, which quickly affects glucose levels in the blood. ${ }^{89}$

While having trouble sleeping is a symptom of performance anxiety, an insufficient amount of sleep can also contribute to the disorder. The body must sleep in order to repair itself from daily stress and any injury. Without a proper amount of sleep, the mind's ability to think clearly or to effectively make decisions is diminished. ${ }^{90}$ In a study that reviewed the effects of adolescents' sleep patterns on school performance, it was found that "adolescents who report inadequate sleep, irregular sleep patterns and/or poor sleep quality as a group tend to do poorly in school in comparison to other adolescents." ${ }^{91}$

Along with affecting mental acuity, sleep can also influence physical ability. According to former NASA scientist Mark Rosekind, sleep loss creates "significant detriments in performance. ${ }^{.92}$ Glucose and cortisol (a steroid hormone) levels are also affected by sleep deprivation. Because the regulation of these is important to optimal physiological function, an imbalance can cause a reduction in physical performance ability. ${ }^{93}$ This has been proven in studies involving athletes; because the use of the body during singing can be likened to athletic energy, a lack of sleep would most likely affect singers in a similar way.

\footnotetext{
${ }^{89}$ Shelly Guillory, "Foods that Trigger Anxiety," Livestrong.com, http://www.livestrong.com/article/273839-foods-that-triggeranxiety/ (accessed December 1, 2011).

${ }^{90}$ American Psychological Association, “Why Sleep is Important and What Happens When You Don't Get Enough,” APA, http://www.apa.org/topics/sleep/why.aspx (accessed December 1, 2011).

${ }_{91}$ Amy R. Wolfson and Mary A. Carskadon, "Understanding Adolescents' Sleep Patterns and School Performance: A Critical Appraisal," Sleep Medicine Reviews 7, no. 6 (2003): 503.

${ }_{92}$ Heather Hatfield, "How to Sleep Like an Olympic Athlete," WebMD, http://www.webmd.com/sleep-disorders/guide/sleeplike-an-olympian (accessed December 1, 2011).

${ }^{93}$ Elizabeth Quinn, "Sleep Deprivation Can Hinder Athletic Performance," About.com Sports Medicine, http://sportsmedicine.about.com/cs/conditioning/a/aa062800a.htm (accessed December 1, 2011).
} 


\section{$\underline{\text { Big Fish Little Pond Effect and Self-Concept }}$}

Herb Marsh, director of the SELF Research Center and professor of Educational Psychology, has performed extensive research on what is known as the Big Fish Little Pond Effect (BFLPE), which states that "equally able students have lower academic self-concepts when attending schools where the average ability levels of classmates is high, and higher academic self-concepts when attending schools where the school-average ability is low." 94 This effect was tested in both academic and extra-curricular settings.

The possible implications of this on acquiring symptoms of music performance anxiety are two-fold. First, for successful singers who are trained in environments where there is a lower level of talent overall, there may be a high sense of talent level concept established that is challenged when the singer enters into a mainstream environment, such as a regional or national audition. When exposed to this kind of competition, singers are subject to the realization that what is considered a high level of talent in their environment may be considered average among the mainstream. A singer that has not been introduced to the national standard of competition can be shocked upon entering a competition with singers from other areas, and discovery of this can lead to anxiety and a lower level of self-concept. This is not true in all cases, but many times a good sense of confidence exists until the realization of performing's true competitive nature raises self-doubt. ${ }^{95}$

Conversely, those who study within a specialized environment may deal with this kind of competition on a daily basis, with consistent exposure to the mainstream standard and constantly under the pressure of comparison to others with high levels of talent. According to the BFLPE,

\footnotetext{
${ }^{94}$ Herbert W. Marsh, "Big Fish Little Pond Effect on Academic Self-Concept: Cross-Cultural and Cross-Disciplinary Generalizability," Australian Association for Research in Education, www.aare.edu.au/05pap/mar05389.pdf (accessed December 1, 2011). The acronym SELF stands for Self-Concept Enhancement and Learning Facilitation.

95 Jacquelynne S. Eccles, "School and Family Effects on the Ontogeny of Children's Interests, Self-Perceptions, and Activity Choices," Nebraska Symposium on Motivation 1992, ed. Janis E. Jacobs (Lincoln: University of Nebraska Press, 1993 ), 159.
} 
these students may have a lower self-concept in these conditions, and therefore singers within these environments may develop self-confidence issues and anxiety as part of their learning environment.

While some causes of anxiety cannot be changed, such as negative events that occurred during one's childhood, or previous negative performing or learning experiences, it is possible for singers to reform their thoughts and behaviors, and thus their physical reactions, by learning how use one or more coping strategies. The following chapters will discuss the most common of these. 


\section{CHAPTER 4}

\section{Coping Strategies: Movement-Oriented}

Because there are so many possible symptoms and causes and combinations thereof associated with performance anxiety, and because every individual is unique, it is impossible to suggest a single coping method that would be helpful in all cases. There is a range of proven strategies, and what is effective for one person may be more or less effective for another. However, methods do exist that have been known to help reduce symptoms and modify behavior. Alexander Technique, Feldenkrais Method, and exercise, all discussed in this chapter, are what may be called "movement-oriented strategies." The studies of biofeedback and yoga, while associated with movement, can also include cognitive and behavioral adaptation, and therefore they will be discussed separately in the following chapter, termed "psychophysical strategies." The effects of biochemical strategies, including the use of pharmaceuticals, nutraceuticals, and recreational substances, as well as nutrition, are the subjects of Chapter 6 . Strategies dealing purely with mental symptoms include visualization, cognitive behavioral therapy, and hypnotherapy, and these are discussed in Chapter 7. Readers seeking information on a specific strategy may consult the Table of Contents to locate the relevant discussion.

It should be noted that, before any solution or combination thereof can be employed, one must be aware of the presence of performance anxiety. Self-denial may play a role in awareness and in a lack of improvement, and this is one of the reasons that self-inventories designed to calculate a performer's anxiety level (and the percentage of performers that are affected by the disorder) may be inaccurate. Once aware, performers should make an attempt to understand the symptoms and their possible causes in order to identify behavioral patterns. In an executive summary on fear and anxiety published by the United Kingdom's Mental Health Foundation, it 
is stated that, "if we don't understand the connection between feelings, thought, and behaviour, we have little ability to change the way we think, feel, and act. ${ }^{, 96}$ Once the identification of symptoms and possible causes has occurred, then an exploration of the coping strategies can begin.

\section{$\underline{\text { Alexander Technique and Feldenkrais Method }}$}

Although the Alexander Technique and the Feldenkrais Method are different modalities, they are both considered strategies that seek to heighten one's awareness of the body while in motion, whether it be movement during daily life activities or during a specialized task such as performing. ${ }^{97}$ While not as widely adopted by singers as the Alexander Technique, the Feldenkrais Method is also recognized as a useful tool for singers and should be considered. Because of their analogous qualities, it is appropriate to discuss each of them separately as well as in a comparative manner.

The Alexander Technique was born out of necessity by its creator, Fredrick Matthias Alexander. A gifted young actor, Alexander began having chronic vocal problems that occurred as a result of performing. Vocal rest only alleviated the issue until he performed again, and at the age of nineteen, he lost his voice midway through a performance and could not continue. This event led him to begin an investigation of his physical movements as they pertained to his speaking, and through careful self-observation, Alexander was able to discover movements that

\footnotetext{
${ }^{96}$ Mental Health Foundation, "In the Face of Fear: How Fear and Anxiety Affect Our Health and Society, and What We Can Do About It," Mental Heath Foundation Executive Summary 2009, http://www.mentalhealth.org.uk (accessed November 5, 2011).

${ }^{97}$ Sanjiv Jain, Kristy Janssen, and Sharon DeCelle, "Alexander Technique and Feldenkrais Method: A Critical Overview,"

Physical Medicine and Rehabilitation Clinics of North America 15 (2004): 811.
} 
were prohibiting vocal freedom. He realized that he could inhibit these actions and replace the unnecessary tensions by means of adopting more efficient behavioral habits. ${ }^{98}$

The Alexander Technique is utilized globally and "enables improved mobility, posture, performance, and alertness along with relief of chronic stiffness, tension and stress." While the most common reason the technique is utilized now is for the relief of pain, it is also commonly used in many disciplines as a means to improve performance. ${ }^{99}$ Because its original purpose was to solve an issue concerning the voice, the Alexander Technique is naturally connected to vocal performers as a means for solving vocal issues. It seeks to maximize the usage efficiency of the body.

The American Society for the Alexander Technique lists the following as the basic concepts of practicing the Technique:

- Recognition of the Force of Habit - The awareness of habitual reactions

- Faulty Sensory Appreciation - Understanding how lack of awareness of unproductive habits limits the ability to make changes

- Inhibition - Learning to break the pattern of automatic reaction involving an inefficient habit

- Direction - Giving the body a new instruction that replaces the ineffective habit response

- Primary Control - The relationship between the head, neck, and back as it pertains to overall movement and functioning ${ }^{100}$

Practice of the Alexander Technique is purported to improve one's ability to deal with stress. Because the body learns to react to events in a way that limits tension, stress is managed

\footnotetext{
${ }^{98}$ Lisa Jo Sagolla, "Keeping Up with Alexander," American Society for the Alexander Technique, http://www.amsatonline.org (accessed November 10, 2011); Jain, Janssen, and DeCelle, 812.

${ }_{99}$ American Society for the Alexander Technique, "The Alexander Technique," American Society for the Alexander Technique, http://www.amsatonline.org (accessed November 10, 2011).

${ }^{100}$ American Society for the Alexander Technique, "What are the basic concepts?" American Society for the Alexander Technique, http://www.amsatonline.org (accessed November 10, 2011).
} 
with a diminished level of ineffective physical movement. ${ }^{101}$ Some of the major physical symptoms of performance anxiety for singers involve muscular tension; learning a method that allows a less physical reaction to stress would inevitably improve the quality of one's performance. Specific to vocal performers, alleviating neck and back tension has been reported to produce fuller breathing and better vocal quality. ${ }^{102}$ Although these methods are typically suggested for those dealing with physical symptoms, the benefits from relieving these could have a positive effect on any correlated mental symptoms as well.

Learning the Alexander Technique typically involves taking lessons from a certified Alexander Technique instructor. These sessions are referred to as lessons because of their educational association; the focus is on acquiring the ability to re-educate oneself in order to affect change rather than to "fix" something. ${ }^{103}$ Alexander lessons can involve two different kinds of work: table or chair work, and verbal and/or manual direction during active movement. ${ }^{104}$ Table work allows the student to learn how to incorporate the concepts of the Technique while lying down. Here, the effects of gravity are lessened, and the student has the ability to focus on function with limited activity. In this position, awareness of how performers use their muscles during basic movements is heightened.

The semi-supine position of the body in table work (lying on the back with the knees bent and feet flat on the table) is also the position for what is called "Active Rest." Students are encouraged to perform active rest in order to bring the body to a state of awareness while resting and to alleviate spinal pressure and muscle and joint tension, to allow the body and mind to

\footnotetext{
${ }^{101}$ American Society for the Alexander Technique, "What are the benefits of the Alexander Technique?" American Society for the Alexander Technique, http://www.amsatonline.org (accessed November 10, 2011).

${ }^{102}$ American Society for the Alexander Technique, "How can the Alexander Technique help performers?" American Society for the Alexander Technique, http://www.amsatonline.org (accessed November 10, 2011).

${ }^{103}$ Nancy Crego, "What Is the Alexander Technique?" Nancy Crego: Alexander Technique, http://www.at-toledo.com (accessed November 10, 2011).

${ }^{104}$ American Society for the Alexander Technique, "What happens in a lesson?" American Society for the Alexander Technique, http://www.amsatonline.org (accessed November 10, 2011).
} 
become calm, and to allow breathing to become regulated. It is suggested that active rest take place at least once a day for ten to twenty minutes, although if there is a time constraint, even as little as five minutes can make a difference in the body's ability to handle physical and mental stress. ${ }^{105}$

Active Rest requires lying on a flat surface with something firm like a book (or books) underneath the head, allowing the head and spine to be supported without the head falling back and compressing the back of the neck or having the chin tucked toward the throat. According to Alexander Technique instructor Pamela Blanc, students learn how to recognize the quality of the body in active rest and then retain that feeling when sitting, standing, or walking, while remaining aware of their physical, mental, and emotional states and discovering if any function needs to be inhibited and redirected. ${ }^{106}$

The act of sitting is a large part of daily life. Students sit for large parts of a day in classrooms, and many people sit at desks throughout the day at work. Chair work seeks to evaluate the body's habitual responses while sitting and when getting into and out of a chair and also serves as the basis, along with table work, for learning the Technique. During floor and chair work, an Alexander instructor works both through verbal suggestion and through gentle hand contact. Along with visual observation, the hands are used to gather further information about how the student's joints and muscles are functioning and also as guides that suggest the direction of release from tension.

Working with the breath is also a core component of the Alexander Technique. Professional singer and Alexander teacher Geórgia Diaz remarks, "The effects of poor breathing

\footnotetext{
${ }^{105}$ Imogen Ragone, “Alexander Technique Self-Help Information,” Alexander Technique with Imogen Ragone, http://www.imogenragone.com (accessed November 10, 2011).

${ }^{106}$ Pamela Blanc, "Bringing the Semi-Supine to Life." Pamela Blanc: Lessons in the Alexander Technique, http://www.pamelablanc.com (accessed November 12, 2011).
} 
affect every body's movement, poise, and balance. If legs, knees, ankles, or any other parts of the body are blocked, breathing will be restrained. ${ }^{, 107}$ Natural breathing is inherent at birth; it is not a skill that humans need to learn. But over time, habits of posture (particularly those learned in adolescence) tend to reframe the efficacy of the breath, and when a person begins performance work that involves the voice, the breath support can be affected by maladaptive posture. According to Blanc, "Breathing coordination [is] taught within the context of the principles of the Alexander Technique and is aimed to re-educate the respiratory system for maximum efficiency with minimum effort." 108

Blanc works with singers of all ages both in private practice and as a faculty member within the music and theatre departments in Southern California academic environments. In correspondence with the author, she listed the following as focal points of unnecessary tension among singers:

- Over-tightening the neck in such a way as to cause compression of the head onto the spine

- Locking the knees - this causes the lower back to tighten and impedes the movement of the lower ribs in the back and the excursion of the diaphragm

- Lifting the chest to inhale (a mismanagement of the breath)

- Compressing the chest and overly engaging the shoulders (rounding/squeezing) to exhale (another mismanagement of the breath)

- Overworking the neck and throat to sing

- Using the muscles of the throat to pull air in

- Tightening the lower back - this is often accompanied by lifting the chest and locking the knees

\footnotetext{
${ }^{107}$ Geórgia Diaz, "Voice Work in the Alexander Technique," Geórgia Diaz, http://www.bodyandmind-at.nl/06emedia\&articles.html (accessed November 30, 2011).

${ }^{108}$ Pamela Blanc, "The Alexander Technique/Respiratory Re-Education and the Art of Breathing," Pamela Blanc: Lessons in the Alexander Technique, http://www.pamelablanc.com (accessed November 12, 2011).
} 
She describes the issue of tension in the body and how it affects the voice:

Unnecessary tension found in other parts of the body affects the voice because the body is the instrument of sound in singing. Sound resounds, and it resounds more efficiently and effectively when it does not have blocks in the way. The voice comes out of the human organism as a vibration, producing sound. The diaphragm is the primary muscle of respiration; it lowers for the inhalation and it rises for the exhalation. If there is holding or bracing of muscles in the torso, this can interfere with the working of the diaphragm. This being said, a singer needs the muscles of the torso to be toned and to respond to the demand of the diaphragm and of the voice. ${ }^{109}$

Alexander's Technique was based on his own observations and discoveries and not on any medical standards, but scientific studies have connected the efficacy of the Alexander Technique with the principles of neurology. People with chronic pain, particularly those associated with the neck, shoulders, and back, are being referred by physicians to Alexander instructors, and some medical communities are offering the Alexander Technique as an alternative therapy. In a 2008 publication of the British Medical Journal, twenty-four Alexander Technique lessons proved to be more effective treatment for low back pain than walking or massage. ${ }^{110}$

While studies exist concerning the efficacy of the Alexander Technique, only one has been performed as it pertains to performance anxiety. In 1995, a study of twenty-one students (twelve in an experimental group and nine in a control group) showed that those given fifteen Alexander lessons were scored higher in technical quality, and the subjects showed an improved attitude toward performance in a self-assessment survey. While the authors admit that the study was perhaps too small in scope and that fifteen Alexander lessons may not have been enough to develop the ability to apply the skills learned, the analysis suggested that Alexander lessons "may have beneficial effects on the quality of performance, the mental state of the performer,

\footnotetext{
${ }^{109}$ Pamela Blanc, e-mail message to the author, October 5, 2011.

${ }^{110}$ Sagolla, http://www.amsatonline.org.
} 
and may help to modulate increased variability of heart rate under stress." ${ }^{111}$ In a summary of music performance anxiety including its origins, phenomenology, assessment, and treatment, Dianna T. Kenny criticized the study for having a "weak design" and suggested that, because of the lack of studies completed concerning Alexander Technique and music performance anxiety, "conclusions must at this stage be tentative."

But the number of singers who attest to the improvements acquired due to Alexander study is large. While there is an obvious lack of scientific research showing a reduction in symptoms associated with MPA, many studies have shown the positive effects of Alexander Technique on pain, inefficient movement, stiffness, and stress, all of which have been associated with performance anxiety. About her first encounter with the Technique, singing voice specialist Dr. Sharon Radionoff remarked, "I went to my first session when I was in graduate school...the way that the concept of body alignment was presented made a huge impact on my mindfulness of the interconnectedness of the skeletal frame and sound production from that moment on."113

In the field of music, the Technique has become widely accepted, as seen by the fact that colleges, universities, and conservatories throughout the United States are employing Alexander Technique instructors to give Alexander lessons as part of their course offerings. The following are comments made to the author by singers through correspondence that inquired as to whether Alexander study had a positive impact on their singing and performing:

[I] find that my alignment allows for a much more open, freer sound. Something in the improved posture makes me feel more confident about everything in life, not just about my singing. In my singing, I never feel as if I need to worry about if that high note will come out, or if the coloratura will be fast enough. I know that my body will allow the sound to come out of me, and freely, easily, and beautifully, at that.

\footnotetext{
${ }^{111}$ Valentine, et al., "The Effect of Lessons in the Alexander Technique on Music Performance in High and Low Stress Situations," Psychology of Music 23, No. 2 (October 1995): 131, 138-139.

${ }_{112}$ Dianna T. Kenny, "Music Performance Anxiety: Its Origins, Phenomenology, Assessment and Treatment," Context: Journal of Music Research 31 (2006): 62.

${ }^{113}$ Sharon L. Radionoff, e-mail message to the author, November 6, 2011.
} 
I learned more in those [Alexander] private lessons about my body than I have in any other course. Alexander Technique improved my posture and singing, as well as my health and the way I perform onstage, all by keeping myself aware of my body and how I was restricting myself. It goes into breathing as well, with singing. I can sit and observe my breathing...but I am also aware of my lack of breathing whenever I get nervous. I don't think Alexander Technique is something you acquire overnight; you really have to commit to it... and observe your body and where you've been holding tension. Tension is a part of our lives and is all around us...the more we become aware and allow ourselves to release unnecessary tension, the better we are for it in all aspects.

I always incorporate what I learned about Alexander Technique into the work I do with my singers. It has an almost magical affect on bringing everything together organically and softly without tension. It is also a great way to encourage good deep breathing for singing.

I have continued to use what I learned in my Alexander training from five years ago. Through my awareness of the voice and the body, I am able to discover new things as my voice constantly evolves. ${ }^{114}$

In order to learn the Alexander Technique and to apply it to one's daily and performance activities, students must be willing to let go of accustomed patterns and accept new habits. ${ }^{115}$ Many times, the more established a habit is, the more difficult it is to unlearn. Alexander himself said, "Change involves carrying out an activity against the habit of life. When anything is pointed out, our only idea is to go from wrong to right in spite of the fact that is has taken us years to get wrong - we try to get right in a moment."116 Study of the Alexander Technique involves a commitment to awareness, and singers looking for "quick fix" solutions may become impatient, as they must take the time to learn new habits and do the work themselves. Just as in learning vocal technique, the teacher is a guide and can offer insight and instruction, after which students must work on their own to continue to apply what was learned in a lesson.

\footnotetext{
${ }^{114}$ Confidential e-mail messages to the author, November 10-18, 2011.

${ }^{115}$ Robert Rickover, "What Can Go Wrong with Alexander Technique Lessons?” AltMD.com Health and Wellness Community, http://www.altmd.com/Articles/What-Can-Go-Wrong-with-Alexander-Technique-Lessons (accessed December 2, 2011).

${ }^{116}$ Nancy Crego, "A Collection of the Saying and Aphorisms of F.M. Alexander," Nancy Crego: Alexander Technique, http://www.at-toledo.com/aphorisms/index.html (accessed December 2, 2011).
} 
When looking for someone with whom to study, singers should always ensure that an Alexander teacher is certified by the American Society for the Alexander Technique, also known as AmSAT. ${ }^{117}$ To be certified to teach the Technique, one must undergo a 1600-hour program, at least three years of training at a school approved by AmSAT; claiming experience in Alexander Technique does not constitute qualification. Students can verify certification by searching for the instructor's name on the AmSAT website.

Just as Alexander developed his Technique as a means to resolve his own issue, Moshe Feldenkrais created the Feldenkrais Method in response to injuries he acquired in the 1940 s. ${ }^{118} \mathrm{~A}$ nuclear physicist and engineer, Feldenkrais was also an avid athlete who excelled in soccer, JiuJitsu, and Judo. Knee injuries that occurred as a result of these high-impact sports crippled his ability to walk, and when conventional medicine was unable to resolve the issue, he began his own exploration. $^{119}$

Unlike Alexander, who derived his method solely through self-study, Feldenkrais researched many different techniques and disciplines; he developed his method from his research and from his knowledge of science and martial arts. One of the methods he studied was the Alexander Technique. Feldenkrais met Alexander and found that his principles related well to Judo; when the body is rigid, it must be released in order to execute movement, and so more efficient movement can occur if the body does not become locked in the first place. Because he was injured at the time, Feldenkrais experimented with minute adjustments, and he discovered

\footnotetext{
${ }^{117}$ Alexander Techniques societies are found throughout the world; those living in countries other than the United States may find certification under another country's organization.

${ }^{118}$ Alan Fraser in Barbara Lewis, "Feldenkrais Method - Some Tips and Insight for Singers from an Interview with Alan Fraser," Singing Tips with Barbara Lewis, http://singing-tips-with-barbara-lewis.com (accessed November 6, 2011).

119 Jain, Janssen, and DeCelle, 812 .
} 
that very small movements could make a significant impact on one's neurology. ${ }^{120}$ Through his work, he was able to avoid surgery and to improve his condition enough to walk again. ${ }^{121}$

While both methods are based on the assumption that inefficient habitual patterns are the cause of dysfunction and that the re-education of the psychophysical system is the solution, the Alexander Technique works through habitual motion and activities, and the Feldenkrais method works through movement sequences and manipulation. The two main components of Feldenkrais are termed "Awareness Through Movement" and "Functional Integration." The first takes place either as a group (more common) setting or within an individual lesson. The teacher uses verbal instruction to guide students through a sequence of exploratory movements, where the students are encouraged to become aware of their own movements without direction. Awareness Through Movement teaching is mainly verbal, and there are hundreds of "structured movement explorations." 122 Because there is no precise means to an end and the instructions evolve throughout the session, students are not able to predict outcomes, and as a result, the mind is able to focus on how the body is performing kinesthetically in the present moment. ${ }^{123}$

Functional Integration's main instructional technique is direction through touch. Spontaneous, rather than controlled, movement is encouraged. ${ }^{124}$ Like the chair and table work of the Alexander Technique, Functional Integration ordinarily takes place on a table, sitting, or standing. The instructor develops the lesson according to the individual's needs at the moment. $^{125}$

Both methods invite the student to become curious about movement and action. In an

\footnotetext{
${ }^{120}$ Fraser, http://singing-tips-with-barbara-lewis.com.

${ }^{121}$ Jain, Janssen, and DeCelle, 813.

122 Jain, Janssen, and DeCelle, 818; The Feldenkrais Method of Somatic Education, http://www.feldenkrais.com (accessed November 8, 2011).

${ }^{123}$ Jill Anna Ponasik, "Continuing Education: One More Conversation about the Feldenkrais Method with Master Teacher Maxine Davis," Classical Singer, January 2009, 15.

${ }^{124}$ Jain, Janssen, and DeCelle, 818.

${ }^{125}$ The Feldenkrais Method of Somatic Education, http://www.feldenkrais.com.
} 
article that discusses the use of the Feldenkrais Method for singers, Feldenkrais instructor Maxine Davis said, "We expect that if we've spent three hours a day practicing, we should improve, just because we've put in the time. Yet the reality is that you may have spent the time in hours, but you haven't really been present to receive the learning. There might be a short in the circuit somewhere. Curiosity can help us close the circuit." ${ }^{126}$ The author of the article, Jill Anna Ponasik, made the following self-observations as a result of taking two lessons with Davis and meeting with her to write a four-part article:

- By focusing on making minute changes in her physical movement she was able to resolve problems she had when singing without thinking about them

- She felt more connected to her body

- Although the new habit felt very good, giving up the old habit was somewhat scary because it felt different and wasn't what she was used to doing, and it didn't feel as if she were "trying" as much

- Practicing and performing were more fun, daily tasks were easier and more enjoyable

- She reacted differently to frustration and tension ${ }^{127}$

Like the Alexander Technique, scientific data supporting the efficacy of the Method is lacking. It has been suggested that this is due to a variety of factors that make studies difficult to conduct, such as the length of time that would be necessary to validate the experiment, maintaining a control group when the treatment involves hands-on work, possible technique variation among instructors, securing a large enough subject group, and effective standardized

\footnotetext{
${ }^{126}$ Ponasik, 16.

127 Jill Anna Ponasik, "Learning to Let Go: A Discussion about the Inner Game of Singing with Feldenkrais Teacher Maxine Davis," Classical Singer, December 2008, 22-24; Ponasik, "Continuing Education," 14-17.
} 
measures. $^{128}$

The Feldenkrais Method has its own training program as well, certified through the Feldenkrais Guild of North America, which falls under the International Feldenkrais Federation, an organization that oversees Feldenkrais Guilds and Associations worldwide. Certification involves approximately 800 hours of training over three to four years, and qualified practitioners can be found on the Feldenkrais Guild of North America's website.

The following chart shows the similarities of and differences between the Alexander Technique and the Feldenkrais Method and can be used as a summarized reference of the above information:

\begin{tabular}{|c|c|}
\hline Alexander Technique & Feldenkrais Method \\
\hline Created by Frederick M. Alexander $\sim 1890$ & Created by Moshe Feldenkrais $\sim 1950$ \\
\hline $\begin{array}{l}\text { Developed as a result of personal injury to the } \\
\text { voice }\end{array}$ & $\begin{array}{l}\text { Developed as a result of personal injury to the } \\
\text { knee }\end{array}$ \\
\hline \multicolumn{2}{|c|}{ Practice is both mental and physical } \\
\hline $\begin{array}{l}\text { Key terms: Primary Control, Inhibition, Faulty } \\
\text { Sensory Appreciation, Direction }\end{array}$ & $\begin{array}{l}\text { Key Terms: Awareness Through Movement, } \\
\text { Functional Integration }\end{array}$ \\
\hline \multicolumn{2}{|c|}{ Re-education of movement functionality - minimum effort with maximum efficiency } \\
\hline Clear instruction toward a specific outcome & $\begin{array}{l}\text { Avoid direction toward a specific outcome in } \\
\text { favor of spontaneity }\end{array}$ \\
\hline \multicolumn{2}{|c|}{ Teacher/student relationship vs. therapist/patient } \\
\hline Typically taught one-on-one & Taught one-on-one and in groups \\
\hline \multicolumn{2}{|c|}{ Work is done is comfortable clothing } \\
\hline $\begin{array}{l}\text { Requires } \sim 1600 \text { hours in a } 3 \text { year program for } \\
\text { certification }\end{array}$ & $\begin{array}{l}\text { Requires } \sim 800 \text { hours in a 3-4 year program for } \\
\text { certification }\end{array}$ \\
\hline
\end{tabular}

\footnotetext{
${ }^{128}$ Jain, Janssen, and DeCelle, 819.
} 
Practitioners of Alexander Technique and Feldenkrais Method agree that, since each individual's experience is unique, the best way to determine which modality would be most beneficial can only be discovered through exploration of both methods.

\section{$\underline{\text { Exercise }}$}

The benefits of exercise for stress relief are well documented. For singers, the fact that the vocal instrument is contained within the body should be an obvious reason to include physical maintenance within a weekly regimen. Yet its importance is often overlooked and many people only associate exercise with its outwardly aesthetic benefits. Exercise improves one's strength and stamina, and while changing the outside shape of the body should be seen more as a fringe benefit and not necessarily the main goal, it has its advantage as well: when body shape improves, one's mental self-image improves, and that can improve self-confidence. ${ }^{129}$

Cardiovascular exercise oxygenates the blood, and strength training helps give the body a sense of control. Studies concerning exercise and anxiety confirm the value of incorporating cardiovascular activity as a part of state anxiety resolution. ${ }^{130}$ The first of these studies, performed by William P. Morgan of the University of Wisconsin in 1973, showed that forty-five minutes of vigorous exercise slightly raised anxiety levels from the onset through five minutes following completion, at which time the anxiety returned to pre-exercise levels. Twenty to fortyfive minutes after exercise was completed, however, anxiety levels dropped significantly. ${ }^{131}$ But exhaustive exercise was not a necessitating factor; another study showed that twenty minutes of

\footnotetext{
${ }^{129}$ C. Barr Taylor, James F. Sallis, and Richard Needle, "The Relation of Physical Activity and Exercise to Mental Health," Public Health Reports 100, no. 2 (Mar-Apr 1985): 196.

${ }^{130}$ Rod K. Dishman, Richard A. Washburn, and Gregory W. Heath, Physical Activity Epidemiology (Champaign: Human Kinetics, 2004), 338.

${ }^{131}$ William P. Morgan, “Anxiety Reduction Following Acute Physical Activity,” Psychiatric Annals 9, no. 3 (March 1979 ): 36.
} 
cardiovascular activity at seventy percent of able capacity resulted in a reduction in anxiety

levels similar to that achieved through meditation or quiet rest in a group. ${ }^{132}$

Furthermore, a lack of exercise can actually induce stress in some, resulting in irritability, boredom, restlessness, and unfulfillment. ${ }^{133}$ A Public Health Report published in 1985 listed the following as psychological benefits of exercise:

\begin{tabular}{|l|l|}
\hline \multicolumn{1}{|c|}{ Increases: } & \multicolumn{1}{c|}{ Decreases: } \\
\hline Academic performance & Absenteeism at work \\
Assertiveness & Alcohol abuse \\
Confidence & Anger \\
Emotional stability & Anxiety \\
Independence & Confusion \\
Intellectual functioning & Depression \\
Internal locus of control & Dysmenorrhea \\
Memory & Headaches \\
Mood & Hostility \\
Perception & Phobias \\
Positive body image & Psychotic behavior \\
Self-control & Stress response \\
Sexual satisfaction & Tension \\
Well-being & Type A behavior \\
Work efficiency & Work errors \\
\hline
\end{tabular}

Because different personalities need different levels of stimulation, the exercise routine should be chosen based on individual need, as a mismatched regimen can contribute to stress rather than alleviate it. ${ }^{135}$ Singers should take care when choosing high-adventure or full contact/high impact sport for exercise, however, since there is a higher potential for injury, which can have a significant effect on singing.

\footnotetext{
${ }^{132}$ Michael S. Bahrke and William P. Morgan, “Anxiety Reduction Following Exercise and Meditation," Cognitive Therapy and Research 2, no. 4 (1978): 323.

${ }^{133}$ Pargman, 161.

${ }^{134}$ Taylor, Sallis, and Needle, 196.

${ }^{135}$ Marvin Zuckerman, "The Search for High Sensation,” Psychology Today 11, no. 9 (1978): 46.
} 
Regardless of the form of exercise, consistent use of the body is optimal. In Stress and Motor Performance, David Pargman lists the following as benefits acquired from exercising at least thirty-five minutes, three times a week:

- Ability to release oxygen is strengthened

- The lungs' ability to inhale and exhale improves

- The heart becomes stronger and more efficient

- Blood pressure is lowered

- Stored body fat is diminished; as a result the circulatory system supports less living tissue

- When strengthened, the body is physiologically able to better handle the biological reactions to stress ${ }^{136}$

Pargman also states that psychological fatigue may be lessened by gross motor performance. Fine motor movement causes fatigue and creates waste products in the body; a high level of activity can move waste out of the body and also relieves residual fatigue. ${ }^{137}$

The execution of strength training should be done with caution. In many current productions, singers are required to maintain a certain physique in order to be cast. Strength training must be done with extreme caution, as the extrinsic and intrinsic laryngeal muscles can become very tense if the exercises are not performed properly with constant attention to the neck, shoulders, and throat.

There are also possible psychological harms associated with exercise. Some people have been known to become obsessed with the effects of exercise, which can lead to the following:

\footnotetext{
${ }^{136}$ Pargman, 154-155.

${ }^{137}$ Pargman, 118.
} 
- Addiction to exercise

- Compulsiveness

- Decreased involvement in other activities and relationships

- Avoidance of problems

- Exacerbation of anorexia nervosa

- Fatigue

- Overcompetitiveness

- Overexertion

- Poor eating habits

- Preoccupation with fitness, diet, and body image

- Self-centeredness ${ }^{138}$

It is unknown whether the exercise contributes to these issues, or whether one's predisposed mental condition is responsible. While these issues should be noted, studies agree that the mental and physiological benefits of exercise overwhelmingly outweigh the possible negative concerns.

Since one's anxiety level can be significantly lowered by exercise, it would be advantageous for a singer to get some exercise the day of a performance, although caution should be taken. If a performer does not typically exercise, it would be unwise to begin a new regimen close to the day of a performance. The body's joints and muscles should be gradually introduced into physical activity, even if one has been previously active; anyone who has taken a hiatus from exercise and overworked the body when starting up again knows the muscular soreness that can result. Through social media, the author asked singers who exercise regularly if they exercised the day of a performance, and if so whether that exercise was helpful to their singing. Out of thirty-four singers who responded, all but two performed light cardiovascular exercise on a performance day or a more strenuous workout the day before and agreed that this contributed to a more successful performance. ${ }^{139}$

Many times when the physiological symptoms such as shaky limbs appear immediately

\footnotetext{
${ }^{138}$ Taylor, Sallis, and Needle, 199.

${ }^{139}$ E-mail correspondence via Athletic Performers group, Facebook, https://www.facebook.com/groups/146143598794863/ (accessed November 18, 2011); E-mail correspondence via Singers and Singing, Public Group, https://www.facebook.com/groups/183665261687124/ (accessed November 19, 2011).
} 
before a performance, singers will try to quell this by trying to hold the body still. Since the muscles tensing up cause the shaking, this action actually magnifies the tension, making the symptom worse. Instead of trying to move less, the body should engage in gross motor movement. Examples of gross motor movement include push-ups, jumping jacks, squatting up and down, and large arm circles. In an interview with Barry Green, trumpet player and band leader Carl Hilding "Doc" Severinsen remedied a difficult recording session by going back stage during his breaks and doing push-ups, which relieved his tension and worry and gave him strength and confidence. ${ }^{140}$ Simply stated, exercise contributes to a stronger body and greater stamina, which will inevitably improve performance ability, and thus one's self-confidence.

${ }^{140}$ Barry Green, The Mastery of Music: Ten Pathways to True Artistry (New York: Broadway Books, 2003), 206. 


\section{CHAPTER 5}

\section{Coping Strategies: Psychophysical}

This chapter will discuss two strategies: biofeedback and yoga. While both can be considered psychophysical strategies, they are called so for different reasons. Biofeedback uses instrumentation to measure physiological readings given by the body, and in order to make changes in these, the mind is trained to react in a different way. Yoga is known as a physical exercise, but the study of yoga also includes a prescribed mentality and meditation.

\section{$\underline{\text { Biofeedback }}$}

The purpose of biofeedback is to enable a person to access biological information that is typically unavailable to the conscious mind. ${ }^{141}$ Originating in the 1940 s, "biofeedback" (the term was coined in the 1960s) can be described as "a treatment technique in which people are trained to improve their health by using signals from their own bodies." ${ }^{, 142}$ Information from these physiological indicators is gathered by some kind of instrument that processes the data into a form that can be interpreted by a health professional or by the individual using the instrument.

A very simplistic example of a biofeedback instrument would be a thermometer; people may feel hot or cold but they cannot assess their actual body temperature on their own, so an instrument is used to gather data from the body, which it processes into a number that can be read. The instruments used to give biofeedback as it pertains to tension and stress can measure one's heart rate, muscle tension, brain wave activity (called neurofeedback), blood pressure, and

\footnotetext{
${ }^{141}$ David Pargman, Stress and Motor Performance (Ithaca, New York: Mouvement Publications, 1986), 167.

${ }^{142}$ Bette Runck, "What Is Biofeedback?” Arizona Behavioral Health Associates, P.C., http://www.psychotherapy.com/bio.html (accessed November 10, 2011).
} 
peripheral skin temperature. ${ }^{143}$

Biofeedback training is not intended to diminish the symptoms, rather its goal is to help the individual control the responses to them so that unwanted reactions can be regulated when necessary. ${ }^{144}$ This process typically occurs in sessions with a professional therapist. Electrode sensors are attached to the corresponding area of the body from which information is to be received; a program then interprets the data gathered by the sensors, and these readings can be used in comparison with additional outcomes.

There are numerous forms of biofeedback; the following is a partial list of different kinds of sensor modalities:

- Electromyography (EMG) - shows muscle activity through auditory or visual perception

- Electroencephalography (EEG) - provides awareness of the brain's electrical activity; since brain waves vary according to activity, they can be measured in Hertz

- Electrocardiograph (EKG or ECG) - measures electrical currents measured by the heart

- Galvanic skin response (GSR) - measures the electric currents conducted by the water found in sweat

- Thermistor - measures peripheral skin temperature and the vasoconstriction of the small blood vessels (causes cold hands/feet)

- Gastrointestinal biofeedback - measures stomach nervousness, cramps, spasms, diarrhea, rumbling (sensor must be placed in the digestive tract)

- Photoplethysmograph (PPG) - measures peripheral blood flow and heart rate

- Electrodermograph (EDG) - measures the skin's electrical activity

- Pneumograph - measures respiratory strain and respiration rate

\footnotetext{
${ }^{143}$ Pargman, 167.

${ }^{144}$ Pargman, 167.
} 
- Capnometer - measures end-tidal carbon dioxide (levels correspond to shallow/deep, rapid/slow, and effortful/effortless breathing) ${ }^{145}$

While it is unknown exactly how or why biofeedback works, those who can benefit from it the most are people whose issues have been created or worsened by stress. ${ }^{146}$ If the session takes place in an office, the therapist works with the client by moving through a series of mental exercises, suggesting situations that may raise or lower perceived stress. The client is able to see or hear changes in the results, which correlate to the raising or lowering of the physiological activities that are being measured.

The advantage to biofeedback involves receiving immediate results that assist in awareness. One can learn how to control certain physiological behaviors by seeing how the body responds based on thoughts and actions. While it is not typically suggested as a coping strategy for performance anxiety within the medical world, biofeedback is listed as a potential recommendation for generalized anxiety and has been used to help regulate breathing, peripheral temperature, sweating, and stiffness, all of which are associated with the physiological symptoms of performance anxiety. It has also been used to treat performance-related pain in musicians. ${ }^{147}$

Like the Alexander Technique and the Feldenkrais Method, experimental studies providing scientific data to support biofeedback's effectiveness, as it pertains to performance anxiety, are lacking. This is possibly due to many of the same factors, such as the cost and time involved: a study intending to conduct research using biofeedback sent 772 music students a survey, of which 163 were completed and returned. Based on the scores of the survey, students

\footnotetext{
${ }^{145}$ Barbara B. Brown, Stress and the Art of Biofeedback (New York: Harper \& Row, 1977), 51, 112, 142, 146; Pargman, 170175; Natural Healing for All, "Types of Biofeedback," Natural-healing-for-all.com, http://www.natural-healing-forall.com/biofeedback-2.html (accessed December 2, 2011).

${ }^{146}$ University of Maryland Medical Center, "Biofeedback," http://www.umm.edu/altmed/articles/biofeedback-000349.htm (accessed November 12, 2011).

${ }^{147}$ Brand Keola Niemann, Rosalie R. Pratt, and Michael Maughan, "Biofeedback Training, Selected Coping Strategies, and Music Relaxation Interventions to Reduce Debilitative Musical Performance Anxiety," International Journal of Arts Medicine 2 , no. 2 (Fall 1993): 9.
} 
were invited to participate in the study, but because the biofeedback lab could only accommodate a limited amount of hours, only 21 participants were accepted. Of those, three dropped out of the study due to conflicts within the six-week study time frame, and so the experimental group contained only nine participants, with the other nine assigned to a control group. While the study was based on too limited a sample to provide a solid foundation of scientific evidence to support the researchers' hypotheses, a self-evaluation by the participants overwhelmingly agreed that the biofeedback and relaxation exercises were helpful to them for performance and other life situations. $^{148}$

The most reliable organization providing certification for biofeedback professionals is the Biofeedback Certification Institute of America (BCIA). Very few states require certification to administer biofeedback, but this ensures that the therapist has agreed to abide by a code of ethics and applicable laws as they pertain to this practice. Certified practitioners also complete supervised personal and client training, and they must pass a written exam. While having certification is not the same as being licensed in a practice, it can at the least assure the client that a standards committee has approved the therapist to use biofeedback within the scope of his or her profession. ${ }^{149}$ In an article concerning ethics and the performing arts, Sebastian Streifel confirms, "Individuals who are seeking biofeedback and other support for stress related problems in performance should also look at the training, certification, reputation, licensing, and successes of those they consider employing to help them achieve their goals. Not all members of AAPB are equally qualified to help a client achieve peak performance in a performing art."150

\footnotetext{
${ }^{148}$ Niemann, Pratt, and Maughan, 14.

${ }^{149}$ Fred Schaffer, Judy Crawford, and Randy Neblett, "Biofeedback Certification 101," Biofeedback 36, no. 2 (2008): 49-51.

${ }^{150}$ Sebastian Streifel, "Ethics and the Performing Arts," Biofeedback 30, no. $3 / 4$ (2002): 7. AAPB stands for the Association of Applied Psychophysiology and Biofeedback.
} 


\section{$\underline{\text { Yoga }}$}

Yoga's psycho-physiological combination of exercise, breathing, and meditation helps to create a better mood and a sense of calmness, which can reduce anxiety and stress. ${ }^{151}$ Originating in India thousands of years ago, the intention of yoga was to cultivate a philosophy of living that could bring one closer to God through mental and physical practices. These are divided into different components called "limbs," which include ethical standards, self-discipline and spiritual observation, postures, mastery of the respiratory process, withdrawal from the external, concentration, meditation, and transcendence of self.

Coming from the ancient Sanskrit language, the word "yoga" has many meanings, including "union" and also "contemplation." In order to meditate properly, preparation of the body and mind is necessary. This occurs through different poses, called "asanas" (Sanskrit, "to sit"), and through breath control and coordination, called "pranayama” (Sanskrit - prana, meaning "life force" and ayama, "to regulate," referring to the breath). When a certain level of mastery with these is achieved, then one can begin working toward a practice of meditation. Because asanas and pranayama employ body balance and use of the muscles through prolonged holding of each pose and/or movement coordinated with the breath, there were physical advantages to practicing yoga as well, and these were seen as a fringe benefit.

Although only one of the eight limbs of yoga, the physical benefit of practicing asanas is what first attracted many Westerners to yoga as a form of exercise. Asanas can be gentle or challenging, and they seek equilibrium between stretching and balance using one's own body as resistance. In the United States there are currently over fifty versions of yoga, all stemming from

\footnotetext{
${ }^{151}$ Richard P. Brown and Patricia L. Gerbarg, "Sudarshan Kriya Yogic Breathing in the Treatment of Stress, Anxiety, and Depression: Part II - Clinical Applications and Guidelines." Journal of Alternative and Complementary Medicine 11, no. 4 (Aug 2005): 716 .
} 
Hatha yoga (which established a variety of asanas), each having its own focus and purpose. A version popular with Western practitioners comes from a form called "Ashtanga," commonly known in the United States as "power yoga." This kind has become a standard offering at many fitness clubs; it is typically moderate or fast-paced and focuses mainly on the physical benefits for the body. While power yoga is beneficial as a form of physical exercise, it has perhaps given many Westerners the impression that yoga was meant to be about exercise.

Ashtanga and power yoga are typically not the kinds of classes that would be most beneficial to someone looking for relief from anxiety, although the combination of strength and stamina acquired from taking more intensive classes has been quite beneficial for some.

Professional operatic baritone Christopher Holloway said this of his practice:

Not only has [yoga] strengthened the core muscles used for powerful singing, it also has helped me release tension in other areas. I have found that I sing now with considerably more power, confidence, and strength than if I hadn't begun to strengthen the abdominal muscles, which are the basis for the support mechanism of the voice. When the core/yoga muscles are engaged (abdominally), a better release in the laryngeal area can happen because those muscles are strong and engaged. Furthermore, the nervous energy I feel prior to going on stage/into an audition room are calmed considerably by doing Kundalini Yoga "Breath of Fire" exercises. ${ }^{152}$

In addition to Hatha, Kundalini, and Ashtanga, other major forms of yoga include Bhakti, Iyengar, Kripalu, Bikram, Anusara, and Yoga Nidra, among others.

One of the most important components of yoga practice focuses on breathing (pranayama), with the goal of maintaining control over the breath while executing different postures. Paramahansa Yogananda described one advantage of yogic breathing like this: "Yoga teaches how, through breath-control, to still the mind and attain higher states of awareness." ${ }^{153}$ When a singer experiences performance anxiety, the ability to control one's breath in order to

\footnotetext{
${ }^{152}$ Christopher Holloway, e-mail message to the author, December 5, 2009.

${ }^{153}$ Paramahansa Yogananda, The Essence of Self-Realization (Nevada City: Crystal Clarity Publishers, 1990), 110.
} 
assuage shallow breathing and heart palpitations could lead to an overall feeling of being in control of the anxiety-causing situation and therefore prompting a resurgence of confidence. Yogic breathing should be a welcome familiarity to singers; it requires the same low breath allowing the diaphragm to release and the lungs to open completely.

The practice of yoga also suggests a certain way of thinking and living in accordance with its principles, one of which is to live in the present moment, releasing thoughts of the past and the future in order to increase the ability to focus and concentrate on the present moment. This lifestyle also addresses the importance of respect for and honor to one's self. Those who respect and honor their feelings and abilities find it difficult to be adversely affected by negative thoughts. The concept of never winning is also prevalent; this non-competitive attitude allows one to focus on the task at hand rather than the outcome. Thoughts become more productive because there are fewer projections concerning the past or the future. If the mind's focus does not concern an issue that may have occurred in the past, or what might happen in the future, time management and problem solving can be much more effective and efficient.

It is suggested that receiving proper training from a certified yoga instructor and a committed practice consisting of at least thirty minutes a day will maximize the benefits of yoga. Studies have shown that yoga techniques can improve one's mood, attention, mental focus, and stress tolerance. ${ }^{154}$

Professional operatic soprano Priti Gandhi explains why yoga became such an integral part of her life:

I wasn't a dedicated practitioner until I became a singer, when I realized that after about a week of practicing yoga regularly...I had bigger and more frequent breakthroughs in my voice lessons and my singing practice suddenly became easier. The feeling of support in my body seemed to happen more naturally and unconsciously than usual, and there was a feeling of lightness and ease when I sang. Many things just seemed to kick in without my

\footnotetext{
${ }^{154}$ Brown and Gerbarg, 711.
} 
having to make them kick in, and I felt freer to emote and to express - there was more joy in producing sound this way. It felt more naturally produced than otherwise. And when I sang, everything seemed to line up better than usual. I didn't have to think about technique so much (always a challenge for the singer, since our mind gets in the way so much of the time). The weeks that I didn't practice [yoga], I noticed that all those things that had made singing easier slowly disappeared. Technique was more on my mind. I had to think about my breath support more. There was more mental chatter to get in the way of the process of easy-flowing technique. Organic expression suddenly became more contrived. And it just felt like work. After a few months, I realized the connection and suddenly, it became very obvious to me why yoga would be important to my lifestyle as a singer.

After discovering the benefits of yoga in her own singing, Gandhi became a certified yoga instructor, with the goal of sharing her newfound knowledge with other singers.

Violinist Yehudi Menuhin embraced the teachings of the famous yoga guru Bellur Krishnamachar Sundararaja Iyengar (commonly referred to as B.K.S. Iyengar), calling him his "best violin teacher." 156 Menuhin considered the body to be his "first instrument,"157 and believed that the body needed to be played, "drawing from it maximum resonance and harmony." "158 Thanks to Iyengar's introduction of yoga to the West, musicians have been discovering the connection between yoga and the quality of their ability to communicate musically since the 1960s. ${ }^{159}$ Instrumentalist and certified yoga instructor John P. Giunta created one of the first yoga workshops specifically tailored for musicians. In correspondence with the author, he described his classes, called Yoga for Musicians ${ }^{\circledR}$ :

Through yoga, we learn to minimize our concerns about ego and "just play the music." Musicians are notoriously terrible at taking care of themselves. I always have to cut through their misconceptions in order to get at the emotional heart of their sources of

\footnotetext{
${ }^{155}$ Priti Gandhi, e-mail message to the author, November 23, 2009.

${ }^{156}$ Jesse Stacken, "Yoga for Musicians: The Benefit of Daily Yoga Practice," Bloomingdale School of Music, http://www.bsmny.org/features/yoga/index.php (accessed December 31, 2009).

${ }^{157}$ Evelyn Lee Soen, "Yoga Within the Music Studio," American Music Teacher (August/September 2004): 36.

${ }^{158}$ B.K.S. Iyengar, Light on Yoga: The Bible of Modern Yoga - Its Philosophy and Practice - by the World's Foremost Teacher. (Schoeken Books, 1979), 11.

${ }^{159}$ Jesse Stacken, "Yoga for Musicians: The Benefit of Daily Yoga Practice." Bloomingdale School of Music, http://www.bsmny.org/features/yoga/index.php (accessed December 31, 2009).
} 
anxiety. Most musicians really need this work, but they sometimes believe that practicing yoga means putting your legs behind your head. In a group, I use the terms and life circumstances that musicians, teachers, and artists use in their daily lives. Daily yoga postures and breathing show us the places in the body where we are holding tension, and meditation releases the stress from the mind. ${ }^{160}$

Among the benefits Giunta lists for musicians are performance anxiety control and stress management, breath control, posture and stage poise improvement, concentration and memory improvement, meditation and visualization that is deeper and clearer, emotion management, healthier goal orientation, and a more realistic life review. Numerous university music programs, music societies, and professional music organizations have invited Giunta to present workshops. ${ }^{161}$ For vocalists, OperaWorks was the first summer training program to incorporate yoga into the singer curriculum. The organization's current instructor, Vida Alikani, describes how singers gain a heightened sense of body awareness through taking yoga in the programs:

[Singers] tell me that yoga helps them feel more in tune with their bodies and more comfortable inhabiting their bodies. They tell me that they develop the ability to get "centered" and focused for performing. Many of them have told me that before exploring yoga, they felt "cut off" from their legs and their lower bodies in general. I've seen how yoga helps them find more space inside their bodies so that energy circulates more freely throughout the body rather than being concentrated in the upper body (especially the head!). Yoga...helps them become aware of and utilize the whole body (rather than just the voice) as their instrument. In effect, each student is encouraged to express his or her "whole" person, his or her unique essence in singing. ${ }^{162}$

OperaWorks includes Hatha yoga classes in its summer programs five days a week.

There are two programs: a two-week Emerging Artist program which includes eleven sessions of yoga, and four-week Advanced Artist program, which includes twenty sessions of yoga.

Although some singers have come into contact with yoga and a few are regular practitioners,

\footnotetext{
${ }^{160}$ Reverend John P. Giunta, e-mail message to the author, December 31, 2009. Many organizations are using the name Yoga for Musicians, and it should be noted that Giunta owns the registration of this trademark.

${ }^{161}$ John P. Giunta, "Yoga for Musicians," Yoga for Musicians, http://specialmind.com/yogamus.htm (accessed December 3, 2011).

${ }^{162}$ Vida Alikani, e-mail message to the author, August 11, 2011.
} 
most of the singers in the program are exposed to taking daily, consistent yoga for the first time.

OperaWorks participants responded to an open question posted by the author on Facebook®, asking if their experience with yoga at OperaWorks had an impact on their singing and if they noticed any overall changes to their well-being from practicing yoga. ${ }^{163}$ Some of their responses are stated here, which included both male and female singers from both programs and at different career levels:

[Yoga] had an INCREDIBLE effect on my singing and overall state of being. I was so much more relaxed. My mind was much clearer after practicing yoga. I also felt a connection to my body that I hadn't previously felt... all of these things contributed to a healthier mental and physical state while singing and performing. Yoga basically revolutionized the way I handle stressful, trying situations.

When I practice yoga, I feel different...more energetic, calmer, focused, clear about thoughts, patient, not to mention how physically I feel balanced and strong. Sometimes it is hard for me to stay focused but I love how I get to connect with my body, listen to it, and within my limits challenge myself. Practicing yoga a couple of hours before [an audition] helped me in feeling more connected to my breath. I am thinking of becoming a certified yoga teacher!

I have practiced slightly more athletic yoga, and although it changed my body more, it wasn't as helpful to my overall mental health. [With hatha yoga] I was generally calmer, aware of my body, and satisfied with myself.

I am able to process life in a calmer, and overall more efficient manner. I am able to work through stressful situations or times in a healthier way, and can maintain better emotional balance. I became aware of how I brace certain parts of my body that prevent me from truly using my breath to release into postures. This also enabled me to become more flexible, and to utilize yoga not merely for the physical benefits, but also to begin to truly practice releasing the body and mind within the postures. Yoga also reminds me that every day is different, and that each time I practice it is not going to be or feel the same. This is beneficial for singers to recognize that the voice is not always going to "behave" and to see this in a more objective and more stable perspective. Thus, "having a bad day" is not nearly as emotionally or mentally crippling.

\footnotetext{
${ }^{163}$ Posted August 9, 2011 in OperaWorks Emerging Artist Program and OperaWorks Advanced Artist Program, closed groups on Facebook.
} 
The simple act of meditation and deep breathing had a tremendous calming effect on my nerves and anxiety. A couple of times I was crying through the first fifteen minutes because of things that had happened earlier in the day and I was able to work through them in yoga. Also, on the day of the first performance I was experiencing quite a bit of anxiety that was manifesting itself in mini panic attacks that were hitting about every ten minutes. After yoga, I was able to calm myself and focus on breathing and the panic attacks went away. I also used this strategy during the program when I was experiencing attacks and was able to work through them much more productively than before yoga. Another added benefit was becoming more flexible and confident in my own body. After about two days I started to realize that it didn't matter what anybody else was thinking about my skill level, and me, because no one was thinking about that. Everyone was doing what he or she could and not judging. That made me more confident in my body and capabilities. Overall I am much calmer after yoga. It allows me to center and to feel connected to my body. It also centers all of the restless energy and focuses it into one place, that place of relaxed readiness.

Daily yoga practice has had a SIGNIFICANT impact on my singing ability, and my ability to perform in general. Before yoga, I always found myself lacking the breath line that I desired to sing through lengthy passages of music. After doing yoga at OperaWorks though, and continuing it at home after the program ended, I found my breathing has increased ten fold and my stamina in general is heightened and improved. I especially love poses that open the chest, like "Camel" (Ustrasana) and "Fish" (Matasyasana). When I get into them, I feel breath pouring into my chest and I feel I never had a good grasp on FULL breathing. Or, what I thought was a good grasp was just the tip of the iceberg. I have learned to let [my] perfectionist thought silence itself when I practice. Now, I am more comfortable with my body and with my thoughts; I feel so much calmer and in the moment.

Musician-specific yoga classes and seminars have since become part of other programs and yoga for singers has even become popular as its own entity. Mark Moliterno (a member of the voice faculty at Rider University and a certified yoga instructor) created YogaVoice ${ }^{\mathrm{TM}}$, in which the classic principles of yoga (ethical living, postures, breathing, and meditation) are combined with vocal study. Designed for any kind of voice professional, the method seeks to assist the performer in connecting to honesty in performance by removing mental and physical blocks. This is done through self-evaluation, after which vocalists apply the knowledge acquired 
from yoga study to singing and/or performance work. ${ }^{164}$ Along with providing his own workshops, his method has been adapted as part of the CoOPERAtive's summer program at Westminster Choir College at Rider University.

Classically trained vocalist Suzanne Jackson created a program designed specifically for singers and public speakers called "YogaSing." The study, available in DVD format, is divided into five sections, including a yoga routine designed for singers, poses for working in a chair, breathwork, kriyas (vocalizations), and poses to help with sleep. ${ }^{165}$ An Internet search reveals many yoga workshops tailored for musicians being offered across the United States, and there are also books that detail yoga practice for performers, such as Linda Lister's Yoga for Singers: Freeing Your Voice and Spirit Through Yoga (Lulu.com) and Mia Olson's Musician's Yoga: A Guide to Practice, Performance, and Inspiration (Berklee Press).

A voice instructor with a yoga background can be a great asset to a student's study. Tenor Jeremy Hunt, who teaches on the voice faculty at the University of Central Florida, is also a certified yoga instructor. He says, "I would say that yoga is extremely helpful to those with performance anxiety. Most people who suffer from [it] are worried about what 'might' or 'could' happen, while yoga teaches us to be present and in the moment." $" 166$

The appeal of yoga for singers extends beyond yoga instructors and the singers themselves. Alexandra Bacon is the Vice President of Barrett Vantage Artists' vocal division, and she is also an advocate of yoga both for herself and for singers. In an email dialogue with the author, Bacon discussed her thoughts on how yoga can be beneficial to singers:

\footnotetext{
${ }^{164}$ Mark Moliterno, "What is YogaVoice?” Facebook, November 19, 2009. https://www.facebook.com/note.php?note_id=201188711411(accessed August 12, 2011).

${ }^{165}$ Suzanne Jackson, "YogaSing," YogaSing.com: Yoga for Singers and Performers, http://www.yogasing.com (accessed November 15, 2011).

166 Jeremy Hunt, e-mail message to the author, January 1, 2010.
} 
I find yoga philosophy challenging, moving, inspiring, helpful, and practical. A good yoga class makes me feel invigorated and serene at the same time. [Yoga instills] awareness! My busy urban life is tempered by introspection, even when doing a difficult pose. Consistent yoga brings my body, mind and spirit onto a higher plane of excellence. ${ }^{167}$

Bacon prefers the form of yoga known as Kripalu. Being in the business of representing singing artists, she often asks singers why they practice yoga, and they seem to have common answers, including: it helps with breathing, posture alignment, performance anxiety, stress, and concentration; it is a good warm up before an audition or performance; it instills a sense of body awareness; it helps keep muscles supple and flexible, and it just feels good! She concluded her discussion:

Being a singer, or an artist in general, can be stressful for reasons including money, competition, general stress, etc. Isn't it lovely that there is an avenue for all of us to pursue that is within our reach - that can provide good exercise along with serenity, perspective, focus in the present moment, and so much more! ${ }^{168}$

Another integral part of yoga study is meditation. Priti Gandhi explains the process and its pertinence to singing:

One of the most important parts of a yoga practice (that is often overlooked in favor of yoga as a purely physical practice) is the regular practice of meditation. Yoga helps to clear energy blocks and infuse the body with new oxygen, or 'prana,' as the life-force aspect of energy is called in yoga. In meditation, the practitioner sits and focuses on breathing evenly and deeply, eventually breathing without 'controlling' the breath, but in essence, 'watching' the body breathe. This process then helps one to eventually detach from the chaos of the mind, to step back from identification with whirlwind thoughts. In regularly steeping oneself in these periods of detachment, quiet, and breathing, one starts to find greater periods of peace of mind in daily life. This is why doctors and psychologists in the West are increasingly suggesting meditation as a way to dissipate stress and tension.

For the singer, this means greater concentration in performance, less performance

\footnotetext{
${ }^{167}$ Alexandra Bacon, e-mail message to the author, March 31, 2010.

${ }^{168}$ Bacon, e-mail message to the author, April 10, 2010.
} 
anxiety, and a slow but sure building of self-confidence in one's singing practice. There is less of the post-mortem that most singers go through after an audition or performance, which can involve mentally beating up one's self for all the things we did 'wrong.' This is surely one of the most damaging processes a singer engages in throughout her lifetime. This psychological 'beating' is usually what undoes a singer's confidence in her technique, her potential, and her happiness with her singing path.

For these reasons, I believe that yoga, and then subsequently meditation, becomes an absolutely necessary part of a singer's regular curriculum of learning along the path of building a vocal technique. For what is often overlooked in most music conservatories or standard university vocal programs is the building of the singer's self as an artist, rather than just the technique. Singers often leave programs feeling prepared on the surface level, and unprepared on the emotional level. The level of competition in this industry creates great amounts of anxiety that cannot be met with surface preparation alone. ${ }^{169}$

Further correspondence from yoga professionals about yoga and performing are cited in Appendix I.

While the correspondence from participants, instructors, and pro-yoga professionals in the singing business is convincing, there is much scientific evidence that supports their claims. Examples of these include a Harvard Medical School study, which concluded that those who participated in yoga showed an inclination towards a lower level of performance anxiety as well as a significant decrease in general anxiety and tension, depression, and anger. ${ }^{170} \mathrm{~A}$ larger study conducted by some of the same researchers three years later yielded similar results. ${ }^{171}$ And a study performed in 2006 supports the OperaWorks singers' claims that even ten days of yoga is enough to cause a reduction in anxiety: conducted to examine how yoga can have an impact on reducing anxiety associated with a number of disorders, the study suggested that anxiety levels were significantly lower after ten days of yoga practice. $^{172}$

\footnotetext{
${ }^{169}$ Priti Gandhi, e-mail message to the author, November 23, 2009.

${ }^{170}$ Sat Bir Khalsa and Steven Cope, "Effects of Yoga Lifestyle Intervention on Performance-Related Characteristics of Musicians: A Preliminary Study.” Medical Science Monitor 12, No. 8 (Aug 2006): 325-331.

${ }^{171}$ Sat Bir Khalsa, et al., "Yoga Ameliorates Performance Anxiety and Mood Disturbance in Young Professional Musicians," Applied Psychological Biofeedback 34, No. 4 (Dec 2009): 279-89.

${ }^{172}$ Nidhi Gupta, et al., "Effect of Yoga Based Lifestyle Intervention on State and Trait Anxiety," Indian Journal of Physiology and Pharmacology 50, No.1 (Jan-Mar 2006): 41-47.
} 
It is important to be aware of issues that may hinder a singer from reaping the benefits of a yoga practice. Interestingly, many of these are similar to things that people are recommended to avoid in daily life:

Recognizing limitations: Of her yoga experience at OperaWorks, one singer observed, "I found that there were days when I could do a certain posture and days when I couldn't. I had to be aware of what I could do that day or I could risk injury." Self-awareness is crucial to ensuring that yoga does not become a painful experience. Stretching too far or trying to accomplish a pose for which the body is not ready can lead to unnecessary soreness and injury. This leads to another one of yoga's primary principles, which is acceptance - acceptance of self, surroundings, situations, and of others. ${ }^{173}$

Competitiveness: This applies both to competition with others and competition with oneself. There is no winner in yoga; according to yoga's principles, one cannot execute a pose better than another person, and one does not gain worth by being able to execute a pose. As a yoga instructor, Priti Gandhi tells her students, "no matter how their pose looks...if they are involved in the moment to moment awareness of the breath and paying attention to present moment awareness of how their body feels, then they will be reaping the same benefits of that yoga as someone who seems to be doing a pose 'perfectly' (though there is really no such thing)."174

Perfection: As Gandhi stated, yogic principles do not allow for perfection, only for what is at that moment. People who seek perfection in their practice often miss the point of yoga, and can strain muscles while holding a pose in order to make it look 'right,' rather than releasing those muscles and letting go while in the pose. Yoga proposes that instead of setting a goal of

\footnotetext{
${ }^{173}$ Marisa Lowenstein, "Stretching Your Abilities: Yoga for Musicians," Star Polish: Helping Artists Help Themselves, http://www.starpolish.com/features/columns/article.asp?ID=46, March 9, 2001 (accessed December 31, 2009).

${ }^{174}$ Priti Gandhi, e-mail message to the author, November 23, 2009.
} 
being perfect, or right, or winning, that one set an intention. This sets a path toward a desired outcome rather than solely the outcome itself. Therefore, if the desired outcome is not immediately achieved, one simply continues on a path toward the desired outcome rather than announcing a point of perceived failure. ${ }^{175}$

One should also be aware of the difference between locations where yoga classes are offered; typically, yoga offered in a community center or gym will be centered around achieving physical results, and there is usually a large number of people in a class. ${ }^{176}$ Yoga classes taught in a private studio are often much smaller and more intimate. There is a greater chance of receiving individual attention from the instructor at a studio, and although classes that focus on yoga for physical results may exist within the studio, there are usually a variety of classes offered in the one location. The exception to this is yoga studios specifically created around power yoga, such as CorePower Yogå, a franchise which has over fifty locations.

While practicing yoga will garner feelings of relaxation and calmness in the moment, it is important that one practice consistently in order to bring that feeling into daily life. In her article "Singing the Praises of Yoga," singer Dagmar Morgan describes a performance experience in which she did not prepare in her customary way:

Because I didn't do my breathing I wasn't in position to sing and I had the jitters but wasn't grounded in my breathing to settle them down. The audience didn't seem to notice but I did and felt off my game the whole performance. When I was done my throat was a little hoarse and I didn't get to enjoy my time on stage with the other musicians. I was too busy thinking about just pulling it together. I wasn't relaxed at all and realized regardless of distractions I need to spend time getting relaxed and grounded. If I had done yoga and my breathing before I got up this wouldn't have happened and I would have felt good about my performance, enjoyed myself, and had fun. ${ }^{177}$

\footnotetext{
${ }^{175}$ Lowenstein, http://www.starpolish.com/features/columns/article.asp?ID=46

${ }^{176}$ Dagmar Morgan, "Singing the Praises of Yoga." The Muse's Muse, November 22, 2002. http://www.musesmuse.com/00000337.html (accessed December 31, 2009).

${ }_{177}$ Morgan, http://www.musesmuse.com/00000337.html
} 
While daily yoga might be of the most benefit, this is not to suggest that practice must be daily in order to show behavioral improvement. A study of sixty-five women showed that taking a ninety-minute yoga class twice a week for two months significantly reduced both trait and state anxiety in the experimental group as opposed to the control group. ${ }^{178}$

As can be concluded from the correspondence cited, not everyone will find the same kind of yoga to be most beneficial. Because each person is unique, it is important to become educated on the different kinds of yoga and to experience ones of interest before making an assumption about which would be best. It is also possible that more than one kind is beneficial. In her article entitled "Yoga and Singing," Sarah Whitten describes the experiences of three classically trained singers, one of which practices Bikram yoga, another Iyengar yoga, and the third practices power yoga. And all three find that their particular form works best for them, and all three cite a strong connection between yoga and their singing. ${ }^{179}$ In trying different forms, one will come to know which kinds are beneficial and which may not be suitable. A singer described an experience she had with yoga:

I had gone to a class before and it was a more aggressive style (they didn't tell me what sort of yoga it was) and it was more of a workout, with a "no pain, no gain" mentality. While I was sweating at the end, I felt even more tied up in knots.

This same singer found Hatha yoga to be highly beneficial to her singing. Priti Gandhi corroborated this as well:

For my own path as a working singer and a yoga practitioner, I have found that certain lines of yoga are more beneficial to me personally than others. I have had many conversations with other singers who have found specific types of yoga to help them as

\footnotetext{
${ }^{178}$ M. Javanbakht, Kenari R. Hejazi, and Majid Ghasemi, "Effects of Yoga on Depression and Anxiety of Women," Complementary Therapies in Clinical Practice 15 (2009): 102-104.

${ }^{179}$ Sarah Whitten, "Yoga and Singing," Boston Singers' Resource, http://www.bostonsingersresource.com/yogaandsinging.asp (accessed December 31, 2009).
} 
well, and our experiences did not always concur. It is important to remember that as unique as each individual is, different yoga paths will appeal to different physical needs and emotional issues.

That said there are a few I always recommend to singers who have never practiced yoga before. Be aware that all yoga stems from the same practice and scripture in India. The different lines of yoga came through different teachers who highlighted different ways of approaching poses and energy movement. It simply becomes about which approach appeals to your specific mindset and physical body better.

I personally find Anusara to be of great benefit to my singing practice. The posture alignments it employs seem to be tailored to a singer's pitfalls in posture and singing practice, and the gentle awareness of opening the heart energy also seems perfect for the artistic sensibilities. I have personally found Anusara yoga to be my favorite when it comes to creating my best singing practice. ${ }^{180}$

Some sources suggest specific poses for singers, but they shall not be included in order to comply with the premise that while a pose may be quite beneficial to one singer, it may not be so for another. It is important to remember that asanas are only one component of yoga, and for those looking to reduce anxiety, the yogic principles of living and meditation can also have a profound influence.

${ }^{180}$ Priti Gandhi, e-mail message to the author, November 23, 2009. 


\section{CHAPTER 6}

Coping Strategies: Biochemical

Any substance introduced into the body produces a series of biochemical reactions. Some of these are beneficial and necessary for the body's overall health and function, and others work against the body's wellness, meaning its systems become stressed and must work hard to counteract what was introduced. Pharmaceuticals, nutraceuticals, recreational substances, and nutrition can be placed into both of these categories.

\section{$\underline{\text { Pharmaceuticals }}$}

Sometimes medication is needed for regulation of the body's biochemical functions, and other times it is taken unnecessarily, either as a "quick fix" or because it was prescribed frivolously. In a time when doctors' schedules are typically overbooked, medication is often prescribed as a solution, without further investigation into the symptoms and whether or not other remedies that may be available would be more suitable. An online educational source about anti-anxiety medication states, "many people use anti-anxiety medication when therapy, exercise, or self-help strategies would work just as well or better - minus the side effects and risks."181

Currently there are many anti-anxiety prescription medicines readily available, however many of them are not suitable for the treatment of performance anxiety due to their tranquilizing nature. Anti-anxiety drugs known as benzodiazepines have a fast reaction time, typically under

\footnotetext{
${ }^{181}$ Melinda Smith, Lawrence Robinson, and Jeanna Segal, “Anxiety Medication: What You Need to Know About Drugs for Anxiety," Helpguide.org, http://helpguide.org/mental/anxiety_medication_drugs_treatment.htm (accessed November 12, 2011); Sarah W. Book and Carrie L. Randall, "Social Anxiety Disorder and Alcohol Use," Under "Publications," National Institute on Alcohol Abuse and Alcoholism, http://pubs.niaaa.nih.gov/publications/arh26-2/130-135.htm (accessed November 12, 2011).
} 
an hour. While they provide quick relief to anxiety symptoms, the possible side effects from taking these drugs is overwhelming. Benzodiazepines reduce anxiety by reducing brain activity, the results of which can include slurred speech, forgetfulness, and emotional numbness, all of which would be counterproductive to performing. If the drug does not agree with one's system, it can even cause an increase in anxiety, and these drugs have a high risk of addiction. The continued use of benzodiazepines can also cause "physical dependency," meaning the longer they are taken, the higher the dosage needs to be in order for them to be effective.

This is not to say that benzodiazepines are not found to be effective for some. In correspondence with the author, a professional singer who normally has high levels of adrenaline described his experiences after he began having panic attacks later in his career:

Xanax made me feel more anxious than I was before I took it. Chlorazapate is meant to be taken as a preventative measure rather than treating an attack...I also sometimes don't take it depending on what the day is going to be like singing wise. I didn't audition well until I started taking chlorazapate and getting rid of that adrenaline that was crippling me. Even a slight attack of nervousness or anxiety/adrenaline spike would cause major dysfunction. I'm in the best shape of my life, pretty much anxiety free, and singing better than ever. ${ }^{182}$

Anti-depressant medication is also commonly prescribed to treat anxiety. These

medicines should only be prescribed for chronic trait anxiety and not for those with state anxiety issues. Anti-depressants typically take between four and six weeks to begin affecting the symptoms of anxiety, and like benzodiazepines, they are associated with a long list of potential side effects, including an increase in anxiety. The use of monoamine oxidase inhibitors (MAOIs) necessitates certain dietary restrictions that, if not adhered to, can cause serious reactions. The effectiveness of anti-depressants is disputed; they are often requested by patients and prescribed by doctors because of effective marketing designed by pharmaceutical companies. Advertising is used to boast about the effectiveness of a drug, but omitted is the fact that an overwhelmingly

${ }^{182}$ Confidential e-mail correspondence with the author, November 17, 2011. 
higher percentage of study participants also showed improvement when given a placebo. ${ }^{183}$

Busiprone has a milder tranquilizing effect compared to benzodiazepines and works faster than anti-depressants. It also has a low risk of addiction and does not affect memory or coordination. While it is purported to be effective for generalized anxiety disorder, is has not proven to be a successful solution for other forms of anxiety. ${ }^{184}$ In a study that compared the use of busiprone, cognitive behavioral therapy, and a combination of the two, busiprone was found to be an ineffective treatment. ${ }^{185}$

Beta-adrenergic blockers (known more commonly as beta-blockers) have been nicknamed the "musician's underground drug" and are considered highly controversial within the performance world. ${ }^{186}$ These drugs are praised by some, who claim they have significantly helped with their performing careers, and they are condemned by others, seen as giving performers an "unfair advantage" or as causing emotional indifference to the music. ${ }^{187}$ Betablockers are known to reduce the physiological symptoms associated with performance anxiety, including a rapid heartbeat, higher blood pressure, shakiness in the voice and limbs, and sweating, without causing sedation. They do not, however, have any effect on the psychological symptoms.

Beta-blockers are named for their function; the drug blocks the beta-adrenoreceptors that respond to threat by engaging the "flight or fight" physiological symptoms. The mind perceives a possibly threatening situation in exactly the same way as it normally would, but because the receptors are unable to receive the signals that would ordinarily cause the body to react, the

\footnotetext{
${ }^{183}$ David D. Burns, When Panic Attacks (New York: Morgan Road Books, 2006), 60.

${ }^{184} \mathrm{Smith}$, Robinson, and Segal, http://helpguide.org/mental/anxiety_medication_drugs_treatment.htm

${ }^{185}$ Duncan B. Clark and W. Stewart Agras, "The Assessment and Treatment of Performance Anxiety in Musicians," American Journal of Psychiatry 148, no. 5 (May 1991): 598.

${ }^{186}$ Stuart Dunkel, The Audition Process: Anxiety Management and Coping Strategies (Stuyvesant, NY: Pendragon Press, 1989), 122.

${ }^{187}$ Richard J. Lederman, "Medical Treatment of Performance Anxiety: A Statement in Favor," Medical Problems of Performing Artists 14, no. 3 (September 1999): 120.
} 
physiological symptoms can be reduced significantly. Physicians prescribe beta-blockers for performance anxiety "off-label;" this term is used to describe prescriptions written for symptoms other than those for which the medicine was approved. The Federal Drug Administration does not approve the use of beta-blockers for performance anxiety, but if clinical studies have been performed that show a medication is useful for an indication for which the FDA has not approved it, doctors may prescribe it for that particular condition as well. ${ }^{188}$

Although beta-blockers are only available by obtaining a prescription, research has shown that a surprising number of musicians get them from a colleague or other, without consulting a doctor. When discussing the wide spread use of beta-blockers among musicians, most sources quote a study conducted among members of the International Conference of Symphony and Opera Musicians. It states that approximately one-fifth of the musicians surveyed (out of over two thousand) have used beta-blockers in connection with performing. Of the twenty percent using beta-blockers, seventy percent were doing so without having obtained a prescription. ${ }^{189}$ As with any prescription medication, what is appropriate for one person may not be appropriate for another. There are different kinds of beta-blockers, and they can be prescribed in various doses. The amount of medication needed is unique to the individual and can only be discovered by trial. ${ }^{190}$ While not considered to be addictive, it is possible for one to become physically dependent as well as psychologically dependent on beta-blockers.

Singers should be wary of the research supporting the use of beta-blockers. While studies show impressive results, the "musicians" referred to in these major studies are all instrumentalists, and voice professionals have not shown the same level of positive results.

\footnotetext{
${ }^{188}$ Jürg Kesselring, "Music Performance Anxiety," in Music, Motor Control, and the Brain, ed. Jürg Kesselring (Oxford: Oxford University Press, 2006), 315.

${ }^{189}$ Martin Fishbein, et al., "Medical Problems Among ICSOM Musicians: Overview of a National Survey," Medical Problems of Performing Artists 3, no. 1 (January 1988): 1, 7.

${ }^{190}$ Kesselring, 314.
} 
According to laryngologist and voice specialist Robert Thayer Sataloff, "The laryngologic community generally agrees that beta-blockers should not be used for singers."191

\section{$\underline{\text { Alcohol }}$}

Alcohol has been used for performance anxiety relief for centuries. ${ }^{192}$ While this may seem like the quickest and most inexpensive solution, alcohol can impair one's ability to use the fine motor skills essential for musical performance. ${ }^{193}$ Excessive consumption of alcohol can cause serious health problems, and when used to assuage undesired feelings, some people begin to abuse alcohol, drinking larger quantities that what would be considered appropriate. Many public videos exist of singers who have abused alcohol before a performance; it is evident that the performance was not enhanced in a positive manner.

\section{$\underline{\text { Marijuana }}$}

Due to its wide use, the ingestion of cannabis should be mentioned briefly. The cannabis plant is used for a variety of purposes, from textiles to food and oils. The dried flowers and leaves of the cannabis plant have been used for thousands of years for medicinal purposes. ${ }^{194}$ Whether inhaled by smoking or ingested, the chemicals from the plant are absorbed into the bloodstream and the brain and then carried throughout the body.

Like alcohol, marijuana can affect one's ability to use fine motor skills effectively. This side effect, along with the possibility of impaired thinking ability, distorted perception, and short-term memory loss should be reason enough to avoid marijuana as a coping strategy for

\footnotetext{
${ }^{191}$ Robert Thayer Sataloff, Deborah Caputo Rosen, and Steven Levy, "Medical Treatment of Performance Anxiety: A Comprehensive Approach," Medical Problems of Performing Artists 14, no. 3 (September 1999): 124.

${ }^{192}$ Lederman, 119.

${ }^{193}$ Sataloff, Rosen, and Levy, 124.

${ }^{194}$ Kevin Bonsor, "How Marijuana Works," How Stuff Works, http://science.howstuffworks.com/marijuana1.htm (accessed November 15, 2011).
} 
performance anxiety. If smoked, the lung concerns associated with smoking and the coughing that typically occurs are obviously detrimental to a singer; in addition, the body ingests hundreds of additional chemicals when the leaves are burned. ${ }^{195}$ If used in combination with other drugs, including prescription medication and over the counter medicines, marijuana can cause the effects of these medications to be intensified. ${ }^{196}$ If a high level is ingested, anxiety, paranoia, and panic attacks may occur. ${ }^{197}$

The use of cannabis for medical purposes is currently considered legal in sixteen states and in Washington, D.C. and requires the user to obtain a Medical Marijuana card. Some states have rather strict conditions for which use is approved, while other states have a rather vague list of conditions. It should be noted that anxiety is not listed as an eligible condition in any state. ${ }^{198}$

The following chart provides a summary of substances that may be associated with relieving social anxiety (under which performance anxiety is categorized), their indications, and their possible side effects: ${ }^{199}$

\footnotetext{
${ }^{195}$ Bonsor, http://science.howstuffworks.com/marijuana4.htm

${ }^{196}$ Drugs.com, “What Is Cannabis?” Drugs.com http://www.drugs.com/cannabis.html (accessed November 15, 2011).

${ }^{197}$ Bonsor, http://science.howstuffworks.com/marijuana4.htm; Dianna T. Kenny, The Psychology of Music Performance Anxiety (Oxford: Oxford University Press, 2011), 227.

${ }^{198}$ ProCon.org, "Should Marijuana Be a Medical Option?” ProCon.org, http://medicalmarijuana.procon.org/ (accessed November 15, 2011).

${ }^{199}$ Melinda Smith, Lawrence Robinson, and Jeanna Segal, “Social Anxiety Disorder and Alcohol Use,” National Institute on Alcohol Abuse and Alcoholism, http://pubs.niaaa.nih.gov/publications/arh26-2/130-135.htm (accessed November 12, 2011); Karla Harby, et al., "Beta Blockers and Performance Anxiety in Musicians," http://www.ethanwiner.com/BetaBlox.html (accessed December 2, 2011); Dunkel, 120-122; Lederman, 119; Sataloff, Rosen, and Levy, 124; Bupa, "Beta-blockers," http://www.bupa.co.uk/individuals/health-information/directory/b/beta-blockers?intcmp=heart-circulation\%3abeta-blockers (accessed November 15, 2011).
} 


\begin{tabular}{|c|c|c|c|}
\hline Substance & Common Names & Indications & Possible Side Effects \\
\hline Benzodiazepines & $\begin{array}{l}\text { Ativan (lorazepam) } \\
\text { Klonopin (clonazepam) } \\
\text { Librium (chlodiazepoxide } \\
\text { hydrochloride) } \\
\text { Serax (oxazepam) } \\
\text { Tranxene (clorazepate) } \\
\text { Valium (diazepam) } \\
\text { Xanax (alprazolam) }\end{array}$ & $\begin{array}{l}\text { Anxiety, panic attacks, } \\
\text { insomnia, muscle } \\
\text { relaxants }\end{array}$ & $\begin{array}{l}\text { Agitation/Hostility } \\
\text { Blurred vision } \\
\text { Clumsiness/Slowed reactions } \\
\text { Depression } \\
\text { Dizziness/Lightheadedness } \\
\text { Impaired thinking/judgment } \\
\text { Memory loss/Forgetfulness } \\
\text { Drowsiness } \\
\text { Emotional numbness } \\
\text { High risk of dependency/abuse } \\
\text { Increased anxiety } \\
\text { Irritability } \\
\text { Lack of energy } \\
\text { Nausea } \\
\text { Slurred speech } \\
\text { Confusion/Disorientation } \\
\text { Suicidal thoughts }\end{array}$ \\
\hline $\begin{array}{l}\text { Antidepressants } \\
\text { including serotonin } \\
\text { reuptake inhibitors } \\
\text { (SSRIs), tricyclic } \\
\text { antidepressants } \\
\text { (TCAs), monoamine } \\
\text { oxidase inhibitors } \\
\text { (MAOIs) }\end{array}$ & $\begin{array}{l}\text { Anafranil (clomipramine) } \\
\text { Celexa (citalopram) } \\
\text { Desyrel (trazodone) } \\
\text { Lexapro (escitalopram) } \\
\text { Luvox (fluroxamine } \\
\text { maleate) } \\
\text { Nardil (phenelzine) } \\
\text { Pamelar (nortriptyline) } \\
\text { Paxil (paroxetine-HCl) } \\
\text { Prozac (fluoxatine-HCl) } \\
\text { Serzone (nefazodone) } \\
\text { Sinequan (doxepin) } \\
\text { Tofranil (imipramine) } \\
\text { Zoloft (sertraline-HCl) } \\
\end{array}$ & $\begin{array}{l}\text { Depression, Panic } \\
\text { disorder, Obsessive- } \\
\text { compulsive disorder, } \\
\text { Generalized anxiety } \\
\text { disorder }\end{array}$ & $\begin{array}{l}\text { Agitation/Hostility } \\
\text { Dizziness } \\
\text { Headaches } \\
\text { Increase in anxiety } \\
\text { Increase in depression } \\
\text { Moderate risk of dependency } \\
\text { Nausea } \\
\text { Nervousness } \\
\text { Sexual dysfunction } \\
\text { Sleepiness } \\
\text { Suicidal thoughts } \\
\text { Weight gain }\end{array}$ \\
\hline Busiprone & Buspar & $\begin{array}{l}\text { Generalized anxiety } \\
\text { disorder }\end{array}$ & $\begin{array}{l}\text { Constipation/Diarrhea } \\
\text { Dizziness } \\
\text { Drowsiness } \\
\text { Dry mouth } \\
\text { Headaches } \\
\text { Low risk of dependency } \\
\text { Nausea }\end{array}$ \\
\hline Beta-blockers & $\begin{array}{l}\text { Beta-Cardone, Sotacor } \\
\text { (sotalol) } \\
\text { Betaloc, Lopressor } \\
\text { (metoprolol) } \\
\text { Betim (timolol) } \\
\text { Brevibloc (esmolol) } \\
\text { Carditor, Emcor } \\
\text { (bisoprolol) } \\
\text { Celectol (celiprolol) } \\
\text { Corgard (nadolol) } \\
\text { Eucardic (carvedilol) } \\
\text { Inderal (propranolol) } \\
\text { Nebilet (nebivolol) } \\
\text { Sectral (acebutolol) } \\
\text { Tenormin (atenolol) } \\
\end{array}$ & $\begin{array}{l}\text { High blood pressure, } \\
\text { heart problems, angina, } \\
\text { migraines }\end{array}$ & $\begin{array}{l}\text { Anaphylactic shock } \\
\text { Bronchospasm/Cough/Wheezing } \\
\text { (can exacerbate asthma) } \\
\text { Cold hands/feet } \\
\text { Constipation/Diarrhea } \\
\text { Depression } \\
\text { Dizziness/lightheadedness } \\
\text { Dry mouth } \\
\text { Fainting } \\
\text { Fatigue } \\
\text { Hallucinations } \\
\text { Impotence } \\
\text { Low blood pressure } \\
\text { Nasal stuffiness } \\
\text { Nausea/Heartburn/Vomiting } \\
\end{array}$ \\
\hline
\end{tabular}




\begin{tabular}{|c|c|c|}
\hline & $\begin{array}{l}\text { Trandate (labetalol) } \\
\text { Trasicor (oxyprenaolol) } \\
\text { Visken (pindolol) }\end{array}$ & $\begin{array}{l}\text { Nightmares } \\
\text { Rash } \\
\text { Sleepiness } \\
\text { Unstable blood sugar } \\
\text { Unusually slow pulse }\end{array}$ \\
\hline Alcohol & & $\begin{array}{l}\text { Depressed immune system } \\
\text { Dizziness/lightheadedness } \\
\text { High blood pressure } \\
\text { Impaired coordination } \\
\text { Impaired judgment } \\
\text { Increased risk of anxiety attack } \\
\text { Risk of dependency } \\
\text { Slower reaction time } \\
\text { Slurred speech } \\
\text { Unpredictable behavior } \\
\text { Weight gain }\end{array}$ \\
\hline Cannabis & $\begin{array}{l}\text { Grass, Marijuana, Pot, } \\
\text { Reefer, Weed }\end{array}$ & $\begin{array}{l}\text { Distorted Perception } \\
\text { Dizziness } \\
\text { Drowsiness } \\
\text { Impaired coordination } \\
\text { Impaired judgment } \\
\text { Lung complications (smoking) } \\
\text { Rapid heart rate } \\
\text { Risk of dependency } \\
\text { Short term memory loss } \\
\text { Weakened immune system }\end{array}$ \\
\hline
\end{tabular}

If drug use of any kind is being considered, extensive research should be conducted to determine the potential benefits and risks, and a health professional should be consulted. While the degree is varied, all of the above substances dull the senses by depressing the central nervous system and altering one's state of consciousness. ${ }^{200}$ And while alleviating some of their anxiety symptoms, some musicians have also reported a loss of connection to their emotions and to their music while performing. If medication is sought in connection to performance anxiety, doctors agree that the use should be short-term. Robert Sataloff states, "Long term medication may be more necessary for more significant underlying psychological disorders in a performer who also has performance anxiety, but almost never as a treatment for performance anxiety alone... any performer who requires an ingested substance (alcohol or other medication) routinely to perform

${ }^{200}$ Lederman, 119. 
the daily activities of his or her chosen profession is revealing a significant problem."201

\section{Nutraceuticals}

Herbs and certain foods have been used for medicinal purposes for centuries. In 1989, the term "nutraceuticals," coined by Dr. Stephen DeFelice, is defined as "any substance that is a food or a part of a food and provides medical or health benefits, including the prevention and treatment of disease. ${ }^{202}$ These substances are typically extracted from plants (herbal and food) and formulated into supplements. A specific group of herbs called "nervines" are purported to support the nervous system and claim to diminish feelings of anxiety. ${ }^{203}$ Many of these herbs have are being marketed as a non-habit forming alternative to prescription anti-anxiety medications. They come in a variety of forms, including supplements, tinctures, and in dried forms for making teas.

Because there is a large market for these substances, which are represented as interventions for anxiety, studies concerning their effectiveness must be considered. Some studies show that they have been successful in reducing general anxiety, but the same studies typically report (like their pharmaceutical counterparts) a high rate of benefit from placebos. ${ }^{204}$ The following nutraceuticals have been highlighted in studies as being considered effective for reducing anxiety:

- California Poppy

- Hawthorn

- Hops

- Kava-Kava

\footnotetext{
${ }^{201}$ Sataloff, Rosen, and Levy, 126.

${ }^{202}$ American Nutraceutical Association, "What is a Nutraceutical?" http://www.ana-jana.org/nut_info_details.cfm?NutInfoID=4 (accessed November 17, 2011).

${ }^{203}$ Kathy Abascal and Eric Yarnell, "Nervine Herbs for Treating Anxiety," Alternative \& Complementary Therapies 10 , no. 6 (December 2004): 309.

${ }^{204}$ Abascal and Yarnell, 309.
} 
- Lavender

- Lemonbalm

- Linden

- Oat Seed

- Passion Flower

- Skullcap

- St. John's Wort

- Valerian ${ }^{205}$

A plethora of material is available about these and other nutraceuticals, but there is a lack of clinical research supporting their effectiveness. Marketers use the term rather broadly, and the FDA does not regulate products defined as nutraceuticals; indeed, their packaging often contains labels stating that the Food and Drug Administration has not evaluated their indication statements. While this is not a sign that the products are ineffective, thorough research should be conducted before taking these substances. Just like pharmaceutical medications, the dosage can have a significant impact on an herb's effectiveness, and contraindications exist for these as well.

All proponents of pharmaceutical and nutraceutical therapies recommend giving the substance a fair trial period before decided whether the substance is effective or not. A one-time dose, or even a month of taking the substance, may not be enough time to determine whether or not it is helpful to the individual, and the time frame may vary from one person to another.

${ }^{205}$ Abascal and Yarnell, 309-314. 


\section{Nutrition}

While nutrition alone cannot be claimed as a coping strategy for performance anxiety, its importance should not be overlooked. The body survives by its ability to convert food and liquids into glucose, which is absorbed into the bloodstream and carried throughout the body. This blood glucose, or blood sugar, must be maintained within a proper level in order for the body to function optimally. If there is not enough sugar in the blood, the body responds by showing symptoms such as getting a headache, having cold extremities, and/or feeling jittery, tired, irritable, anxious, depressed, or unable to concentrate. ${ }^{206}$ The body considers this to be a state of emergency, as if it is being starved, and so adrenaline is released as well, creating a faster heart rate and feelings of restlessness. ${ }^{207}$

If too much sugar is ingested at one time, the body is also sent into a state of emergency, because the blood has been over-saturated with sugar. Now the body must release insulin, which pulls the sugar out of the blood stream and stores it elsewhere in the body. Once the sugar is removed from the blood, the body signals that more sugar must be eaten because there is suddenly not enough. If too much sugar is ingested again, the cycle repeats, creating a high amount of stress on the body's physiological systems. This explains why many people feel an energy surge after eating sugar, which is followed by feelings of sluggishness. ${ }^{208}$

The kinds of food eaten and the combination of those foods can make a big difference: the more simple the sugar, the faster it is converted to glucose and made available to enter the bloodstream. Simple carbohydrates enter the bloodstream the fastest, followed by complex carbohydrates, then protein, and then fats. Fiber slows down the conversion process; this

\footnotetext{
${ }^{206}$ Joel H. Levitt, "Conquering Anxiety, Depression, and Fatigue Without Drugs - the Role of Hypoglycemia," Alternative Mental Health, http://www.alternativementalhealth.com/articles/hypoglycemia.htm (accessed November 19, 2011).

${ }^{207}$ Dunkel, 115.

${ }^{208}$ Levitt, http://www.alternativementalhealth.com/articles/hypoglycemia.htm
} 
explains why nutritionists prefer that clients eat fruit rather than drink fruit juice. ${ }^{209}$ While juice can contain many vitamins, minerals, and antioxidants that are good for the body, it contains no fiber, and while one piece of whole fruit is typically a sufficient serving, eight ounces of juice would be equivalent to eating three to four pieces of fruit, and the sugar enters the blood stream too rapidly. ${ }^{210}$

Besides being the cause of many health problems, unregulated blood sugar produces many of the same symptoms as performance anxiety, and if glucose levels are off when a performance is imminent, symptoms can be exacerbated. Sugar is also dehydrating, which can be detrimental. ${ }^{211}$ In a teleconference on April 6, 2010, nutritionist Jenny Donnelly explained that the body could only handle approximately thirty grams of carbohydrates at a time, which it can metabolize in three to four hours. If more food is not introduced after that time frame, when the body is finished metabolizing that meal, the body assumes that it is being starved and activates physiological processes to prepare for starvation.

In is not within the scope of this research to provide specific dietary suggestions. But many sources on performance anxiety suggest specific foods that may be helpful to alleviate anxiety symptoms, such as eating a banana because it contains potassium, which is purported to lower blood pressure. Eating a banana is an old adage that has been passed on by performers for years and is still mentioned on blogs and websites giving advice about performance anxiety, but there are other food sources that have higher levels of potassium without containing any sugar. Bananas have one of the highest sugar contents of any fruit; an avocado has two times the

\footnotetext{
${ }^{209}$ Anil Minocha, "Whole Fruit Versus Fruit Juice," Digestion, Health, and Nutrition: Dr. Anil Minocha, A Gastroenterologist and Nutritionist, http://minochahealth.typepad.com/gut/2010/08/fruit-juice.html (accessed November 19, 2011).

${ }^{210}$ Levitt, http://www.alternativementalhealth.com/articles/hypoglycemia.htm

${ }^{211}$ Kenny, The Psychology of Music Performance Anxiety, 290.
} 
potassium as a banana and contains no sugar. ${ }^{212}$

This example is mentioned to bring awareness to the necessity of gathering complete information before adopting a dietary suggestion that will "fix" anxiety symptoms. Performers should evaluate their current nutritional habits to see if overall changes can be made and any health conditions should be taken into consideration.

${ }^{212}$ McVitamins, "Potassium," McVitamins, http://www.mcvitamins.com/Vitamins/potassium.htm (accessed November 19, 2011). 


\section{CHAPTER 7}

\section{Coping Strategies: Cognitive-Behavioral Techniques}

Many of the physiological solutions discussed can also be considered cognitivebehavioral in manner; the Alexander Technique and Feldenkrais Method, biofeedback, and yoga have components that affect the mind and body through cognitive and behavioral change. While those methods focus upon physiological modification, strategies called cognitive-behavioral techniques focus upon reasoning and learning in order to affect positive growth. Studies have shown that psychological factors contribute more to the prediction of music performance anxiety than do somatic elements. ${ }^{213}$ David Pargman states, "If cognitive activity prior to or during performance is believed to induce anxiety or stress reactivity and thus disrupts performance behavior, then coping strategies that include cognitive emphases should receive serious consideration. ${ }^{214}$

The similarity between athletic performers and creative performers has already been established, and this remains true for mental training as well. In their writing concerning mental skills training, Christopher Connolly and Aaron Williamson confirm:

For decades, elite athletes have enhanced their performance by exploiting advancements in applied psychology and science. An important constituent of the training received by these performers has focused on the interplay between mental and physical skills. Indeed, any witness to elite sporting achievement can appreciate that physical exactitude and excellence go hand in hand with mental agility, determination, focus, and an unimpeded vision of the performance outcome. Thus, the potency and worth of pursuing holistic body-mind training approaches for developing both physical and mental skills have been taken as self-evident by sports trainers and coaches. Clearly, the same argument can be made for musical performance. ${ }^{215}$

\footnotetext{
${ }^{213}$ Ariadna Ortiz Brugués, "Music Performance Anxiety - Part 1. A Review of its Epidemiology," Medical Problems of Performing Artists 26, no. 2 (June 2011): 104.

${ }^{214}$ Pargman, 180.

${ }^{215}$ Christopher Connolly and Aaron Williamson, "Mental Skills Training," in Musical Excellence: Strategies and Techniques to Enhance Performance, Aaron Williamson, ed. (Oxford: Oxford University Press, 2004), 221.
} 
Although the extent to which mental training has a positive influence is disputed, many studies "provide support for the notion that combining physical and mental practice can be favorable for music learning." ${ }^{216}$ While there are many, the three methods discussed within the scope of this research shall be visualization, cognitive-behavioral therapy, and hypnotherapy.

\section{$\underline{\text { Visualization }}$}

Visualization is a mental imagery technique that allows one to bring about desired changes by "re-programming" the mind's beliefs. It has been marketed to the general public as a tool that can be used to manifest goals and create life changes, but it is also a skill that has been successfully utilized by athletes and creative performers. It involves the "mental or imaginary rehearsal of a physical skill without physical movement, using visual (seeing), aural (hearing), and kinesthetic (feeling/touch) senses to create or recreate an experience similar to a physical event.",217

The premise of visualization is actually scientific in nature: just as in situational perception, where the body's nervous system cannot tell the difference between real danger and that which is perceived, the central nervous system also cannot tell the difference between imagined execution and actual execution of an activity. ${ }^{218}$ This has been proven in a study conducted at Hunter College, where basketball players were asked to imagine making free-throw shots. The players' neuromuscular activities were monitored during the mental rehearsal, and the measurement of these showed that the neurological messages sent to activate muscles during actual free-throw shooting were activated in the same manner during visualization. ${ }^{219}$

\footnotetext{
${ }^{216}$ Connolly and Williamson, 224-225.

${ }^{217}$ David Buswell, Performance Strategies for Musicians (Hertfordshire: MX Publishing, 2006), 77.

${ }^{218}$ Kenneth Baum, The Mental Edge (New York: Berkeley Publishing Group, 1999), 28.

${ }^{219}$ Baum, 26.
} 
The efficacy of visualization has also been proven in studies; a one-week study at the Olympic Training Center in Colorado involving golfers showed those who did not visualize improved by eleven percent, those asked to visualize making a putt before they did so improved by thirty percent, and those who were asked to visualize missing a putt before they made one decreased in accuracy by twenty-one percent. ${ }^{220}$

Positive results were also achieved in studies with musicians. In an investigation using guided imagery, twenty-one musicians listened to a ten-minute recording that included suggestions of control over a performance, feeling relaxed on stage, feeling confident in the process, and having a friendly, supportive audience. The results showed a significant decrease in performance anxiety symptoms, with twenty of the twenty-one performers agreeing that the tape had an effect on their performance ability. ${ }^{221}$

The case above is an example of "guided imagery," which describes a concept developed in the first part of the twentieth century by German psychologist Hans Happich. ${ }^{222}$ The guide can be a therapist or a recorded voice giving instruction. Visualization is drawn from guided imagery and can be performed by an individual without assistance, but the techniques are executed in a similar manner. It is important that one be relaxed before visualization of a task takes place; if working with a therapist (or a recorded voice), the idea of a pleasant environment will be introduced to achieve a state of relaxation and a feeling of safety. Once a person reaches this state, visualization of the task can begin.

Many sources suggest that people imagine a movie screen on which they see themselves, but any method of imagining oneself in a situation of performing an activity is sufficient.

\footnotetext{
${ }^{220}$ Baum, 27.

${ }^{221}$ Mary Jane Esplen and Ellen Hodnett, “A Pilot Study Investigation Student Musicians' Experiences of Guided Imagery as a Technique to Manage Performance Anxiety," Medical Problems of Performing Artists 14, no. 3 (September 1999): 128-130.

${ }^{222}$ Patricia Monaghan and Eleanor G. Viereck, Meditation: The Complete Guide (Novato, CA: New World Library, 1999$), 322$.
} 
Specificity is imperative; every aspect of the activity should be imagined. If the goal is to work through a task that involves stress, such as public performance, then a situation that would involve a stressor, such as walking in front of an audience, can be introduced, and ideas are given (either from an outside source or from the individual) on how to perceive the stressor as nonthreatening. ${ }^{223}$ The task can be visualized first as being done under perfect circumstances, such as being alone, with optimal health. Stressors can be suggested in an incremental way, with a low stress factor introduced first (such as arriving at the performance venue), followed by higher stressors (such as being in front of an audience).

In his monograph Performance Strategies for Musicians, David Buswell lists the following as benefits of using visualization:

- Accelerates learning

- Makes learning new skills easier

- Helps with problem solving

- Can supplement physical rehearsal (or substitute for it when physical fatigue or illness is an issue)

- Helps to commit repertoire to memory

- Makes practice time more efficient

- Can heighten sensory awareness - helps make one more aware of things that may not get as much attention when physically performing/practicing

- Can help one become more interested or involved in the music

- Can build overall confidence and mental fortitude during performance

- Can help one to connect to the audience 224

\footnotetext{
${ }^{223}$ Dunkel, 19-20.
}

${ }^{224}$ Buswell, 82-84. 
Conductor and cellist David Aks, who teaches visualization to singers in the OperaWorks summer training programs, agrees that singers can use the technique to improve on almost anything, from musicality to performance anxiety. He explains how the technique also contributes to efficiency and productivity:

Singers who use visualization techniques learn music faster, make changes quicker, and are usually less easily frustrated when they practice. Concerning this last one: If they accept that most errors are merely the symptoms of faulty mental concepts, fixing the concept should take care of the error. One of the most important parts of practicing is to locate precisely the cause of the error. It can be very frustrating to work hard at correcting something when that's not the actual problem. ${ }^{225}$

Further correspondence from Aks concerning visualization can be found in Appendix I.

Bert Priest, a certified yoga instructor and musician who teaches in the United Kingdom, uses visualization in his teaching as well. He describes his thoughts about the using the method himself:

Another exercise I use is visualisation and I've found that I can learn bits of music without ever playing them. I do this during meditation, and I visualise myself playing a song and actually trigger the muscles that I would use when I was actually playing the song, except I'm only firing the nerves, as opposed to the full physical action - it's basically a muscle-memory technique. What I'm getting to here is that it works on a mental level too. Visualising oneself at a performance and not being anxious can certainly help reduce those pre-gig nerves. ${ }^{226}$

The amount of time it takes for visualization to become useful varies and is dependent upon the individual's commitment to practice, ability to focus, and level of specificity. Sometimes things can be visualized and an instant change can be observed, and other times a series of repetitions may be necessary over a period of time. A singer introduced to visualization commented on his experience:

\footnotetext{
${ }^{225}$ David Aks, e-mail message to the author, November 13, 2011.

${ }^{226}$ Bert Priest, e-mail message to the author, January 1, 2010.
} 
After imagining a certain phrase or aria about eighteen times, I was able to physically sing it the way I had imagined/visualized. Most importantly I was able to alleviate a heavy chest connection into my passaggio and top. I am a very visual person, so it helps me tremendously. ${ }^{227}$

For performers that do not have a strong visual orientation, the process may take longer to learn, but it is possible to develop this skill and to learn how to control the perspective from which the visualization takes place, including external and internal viewpoints. ${ }^{228}$

Visualization is mentioned in many sources as a method for coping with performance anxiety, and if one is seeking self-help, there are many sources available, including those that focus solely on the technique. Because the method can be applied to almost anything, it is not necessary to find a source that deals specifically with music, but because performance anxiety deals with adversity and stress, a source on visualization that addresses these issues (and there are many) may be most effective.

\section{Cognitive-Behavioral Therapy}

In order to control fear, one must know how the fear is kept alive and how it influences one's lifestyle and behavioral patterns. ${ }^{229}$ "Cognitive-behavioral therapy," commonly referred to as $\mathrm{CBT}$, is a general term that describes therapeutic approaches that work "to uncover irrational and problematic thinking styles that often accompany psychological stress. ${ }^{, 230}$ It is not a technique in itself, but rather a classification of psychotherapy, which utilizes (as its name implies) cognitive and behavioral techniques. Based on her research, Dianna T. Kenny describes six components of CBT that distinguish it from other forms of psychotherapy:

\footnotetext{
${ }^{227}$ Confidential e-mail message to the author, November 5, 2011.

${ }^{228}$ Buswell, 88-89.

${ }^{229}$ Herbert Fensterheim, Stop Running Scared! (New York: Dell Publishing, 1977), 40-41.

${ }^{230}$ Behavioral Associates, "What Is Cognitive Therapy?" Behavioral Associates Cognitive Behavioral Therapy, http://www.behavioralassociates.com/cbt.asp (accessed November 20, 2011).
} 
- CBT includes the use of homework and out-of-session activities

- Session activity is directed and pre-planned to focus on specific topics

- The role of the therapist is partly educational - during sessions, patients are taught techniques that allow them to form new thoughts and behaviors

- Sessions are focused mostly on future experiences rather than talking about the past

- Therapists explain their treatment techniques and why they are used

- Focus is on internal communication (self-talk) and thoughts ${ }^{231}$

Cognitive therapy is based on the principle that thoughts create moods, and that negative feelings stem from negative thoughts, not from external events. ${ }^{232}$ Feelings of anxiety can lead people to perceive a situation in only one way; cognitive therapy explores whether there are other ways to interpret the situation and asks them to validate the accuracy of their perception. It is not a series of "feel good" techniques; rather, it is intended to assist in the discernment between realistic thoughts (which lead to healthy feelings) and distorted, illogical, or unrealistic thoughts (which lead to unhealthy feelings). Examples of these would be healthy remorse versus neurotic guilt, or constructive anger versus destructive anger. ${ }^{233}$ Once the desired perception is discovered, any obstacles that may prevent that perception are identified and discussed. In this way, cognitive therapy gives one the power of information and choice, rather than succumbing to an initial perception that does not allow for alternatives. ${ }^{234}$

It is customary for relaxation exercises (either physical, mental, or both) to commence before beginning CBT to allow the patient to minimize any tension and to lower the metabolic,

\footnotetext{
${ }^{231}$ Kenny, The Psychology of Music Performance Anxiety, 178-179.

${ }^{232}$ David Burns, Ten Days to Self-Esteem: The Leader's Manual (New York: William Morrow, 1993), 77.

${ }^{233}$ Burns, 80-81.

${ }^{234}$ Paul M. Salkovskis, "The Cognitive Approach to Anxiety: Threat Beliefs, Safety-Seeking Behavior, and the Special Case of Health Anxiety and Obsessions," in Frontiers of Cognitive Therapy, Paul M. Salkovskis, ed. (New York: The Guilford Press, 1996), 49-50.
} 
respiratory, and heart rates. This is done because "cognitive techniques are more effective in management of stress reactivity when they are applied during the performer's relaxed state.,235 The following relaxation techniques are commonly used:

- Autogenic Training: Emphasis is placed on feelings of heaviness and warmth in the body by giving suggestive cue words

- Progressive Relaxation: Sitting in a chair, parts of the body are tensed and relaxed, with both sensations being acknowledged, as well as noticing the difference in feeling; eventually the tensing step is removed

- Imagery: Specific mental images are produced to create feelings of relaxation and safety $^{236}$

Once relaxed, different cognitive-behavioral techniques can be introduced. While there are many, the following describes some of the methods commonly discussed in sources concerning performance and anxiety. ${ }^{237}$

- Stress Inoculation: Stress/anxiety reactions are recognized to understand their affects. Then, after reaching a state of deep relaxation, imaginary stressors are introduced in order to become associated with the relaxed state

- Systematic Desensitization: Stressors are introduced in a gradual, step-by-step process, where the level of stress does not increase until the current level feels comfortable

- Rational-Emotive Therapy: Irrational emotions and thoughts experienced during anxious events are identified, evaluated, and shown to be unfounded

- Externalization of Voices: One person verbalizes negative thoughts while the other verbalizes positive ones - gives the patient ideas on positive alternatives to automatic negative reactions

- Cost/Benefit Analysis: Identification of a behavior, followed by making a list of the advantages and disadvantages of that behavior

\footnotetext{
${ }^{235}$ Pargman, 181.

${ }^{236}$ Pargman, 181-184.

${ }^{237}$ As with the other methods these techniques are only described in general terms, as it is not the purpose of this research to provide specific solutions.
} 
- Compassion-based Technique: The self is treated like a close friend and self-talk is created accordingly to support self-compassion, which is comprised of self-kindness, common humanity, and mindfulness

- Truth-based Technique: Beliefs are tested by looking for evidence or performing an experiment to test its validity

- Paradoxical magnification: A negative thought is taken to the extreme to illuminate its irrationality $^{238}$

CBT has been purported to achieve positive results in the treatment of depression and generalized anxiety. ${ }^{239}$ It has also been the subject of music performance anxiety studies, and the results are favorable. But, as Kenny explains, the studies are not particularly strong cases, for they are mostly based upon self-reports rather than clinical data and are in conjunction with other therapeutic modalities. ${ }^{240}$ Like many of the other studies looking for effective solutions, the subject count in these is typically small. But self-reports should not be ignored; if performers are reporting a reduction in trait anxiety and in music performance anxiety, regardless of whether the study was well organized or had a control group or yielded clinical results, to those that reported feeling more confident and less anxious, the method had a recordable influence and therefore should be explored as a possibility.

\footnotetext{
${ }^{238}$ Pargman, 186-190.

239 Julie Jaffee Nagel, “Treatment of Music Performance Anxiety via Psychological Approaches,” Medical Problems of Performing Artists 25, no. 4 (December 2010): 143.

${ }^{240}$ Kenny, The Psychology of Music Performance Anxiety, 187-188. Also Nagel, 143-144.
} 


\section{Hypnotherapy}

The existence of hypnosis extends back to the beginning of recorded history and can be connected with religious practices throughout the world. ${ }^{241}$ The precursor to modern hypnosis was created in the late 1700s by the Austrian physician Franz Friedrick Anton Mesmer, who used a technique he called "mesmerism" to cure people of their troubles. While his techniques were investigated and found to be faulty, he was successful in using what is called "hypnotic trance" to treat certain illnesses, and this method was adapted by James Braid a century later and completely separated from mesmerism. ${ }^{242}$

After Braid, hypnosis was employed by Sigmund Freud and then by Milton Erickson, who is credited with legitimizing hypnosis as a legitimate psychotherapeutic modality and developing much of what is referred to today as hypnotherapy. ${ }^{243}$ Hypnosis is often trivialized due to its popularity as an entertainment act; it should be noted that hypnotherapy is not the same as hypnosis used for entertainment purposes. Its use as it pertains to alleviating anxiety focuses on the control of concentration. ${ }^{244}$

In order for hypnotherapy to be successful, the participant must be willing and have a desire to enter a hypnotic state. An altered state is not achieved; one is not unconscious or under the control of a therapist, nor does anything occur that is not acceptable to the participant. It seeks to allow the participant to enter into a relaxed state where awareness is increased, and the trance state allows for behavioral changes and a reorganizing of perception. ${ }^{245}$ The subconscious mind is purported to contain collective information not typically accessed by the conscious mind;

\footnotetext{
${ }^{241}$ Creighton University Medical Center, "Origin of Hypnotherapy," Complementary and Alternative Medicine, http://altmed.creighton.edu/hypnotherapy/ (accessed November 23, 2011).

${ }^{242}$ Creighton University Medical Center, http://altmed.creighton.edu/hypnotherapy/; Pargman, 191.

${ }^{243}$ Pargman, 192.

244 Pargman, 192.

245 Jevon Dängeli, “The Truth About Hypnosis,” NLP Center, http://www.nlp-center.net/articles/the-truth-about-hypnosis.html (accessed November 24, 2011); Pargman, 193.
} 
in theory, this state of relaxation allows for information gathered in the unconscious mind to be accessed more freely, making way for the resolution of issues.

While hypnotherapy can take place in an office with a hypnotherapist, one can be taught to induce self-hypnosis as well. While Kenny criticizes hypnosis, stating that only one in eight people can enter a deep hypnotic trance, David Pargman notes that people enter into trance states all the time, giving the example of people who travel along a highway and suddenly come to realize that they don't know how much time has passed or to what they last paid attention. ${ }^{246}$

As Kenny states, only one study has attempted to survey the effect of hypnotherapy on music performance anxiety, and although it yielded impressive positive results, the study was seen as having a weak structure. ${ }^{247}$ Its methodology is worth mentioning however, because of its prevalence in sports psychology as well as in music performance literature.

Many hypnotherapists also employ neuro-linguistic programming techniques. In The Singer's Voice, licensed hypnotherapist Donna May states that hypnotherapy and neurolinguistic programming can both be useful modalities to singers, and she uses both when working with performers. ${ }^{248}$ Commonly known as NLP, neuro-linguistic programming was created in the 1970s by John Grinder (a linguistics professor) and Richard Bandler (a computing and mathematics student). The two sought the answer to why some people were highly successful in their chosen field as opposed to others, and they studied the association between language, the mind, and behavior. ${ }^{249}$ The result was a discipline consisting of analysis, techniques, and training that seeks to achieve excellence by modeling those who were highly successful already. ${ }^{250}$

\footnotetext{
${ }^{246}$ Kenny, The Psychology of Music Performance Anxiety, 198; Pargman, 194.

${ }^{247}$ Kenny, The Psychology of Music Performance Anxiety, 197-198.

${ }^{248}$ Michael S. Benninger and Thomas Murry, The Singer's Voice (San Diego: Plural Publishing, 2008), 113.

${ }^{249}$ Shlomo Vaknin, NLP for Beginners: Only the Essentials (Prague: Inner Patch Publishing, 2009), 21.

${ }^{250}$ Vaknin, 22.
} 
The term "neuro-linguistic programming" refers to the body's neurology and how it interprets experiences (neuro), how it relates to and interprets language symbols, both visual and aural (linguistic), and how these symbols and experiences can be used to achieve desired results (programming). NLP seeks to train the brain to function optimally in order to become successful at whatever one wants to do. ${ }^{251}$ The following are principle beliefs of NLP:

- The center of activity is oneself; one's current state (mental and physical processes) is a choice, and it can be changed

- Self-limiting beliefs, or presuppositions, can be identified and replaced

- Rapport is essential for good communication; one must establish mutual trust, respect, and understanding (with self as well as others)

- NLP actions are focused on obtaining an outcome; delving into content, such as one's personal issues or reasoning, is not necessary

- Paying attention to feedback is paramount, for each step is based upon the result of the previous one - the senses must be alert

- Flexibility is necessary; what works for one situation may not work for another, and one's first choice may not be best ${ }^{252}$

Using these principles, NLP seeks to model behavior that has already shown to be highly successful; by practicing different techniques, people form their thoughts and actions based on what is most effective in order to move toward a desired outcome. Some of these techniques use what are called "anchors," which are stimuli that initiate desired responses. ${ }^{253}$ Anchors can be internal or external, and can draw on any of the senses. All people experience these kinds of triggers, such as smelling something that reminds them of a memory or a certain person. They can be useful or pleasant, and they can also be undesirable, as in the case of military veterans

\footnotetext{
${ }^{251}$ Vaknin, 25.

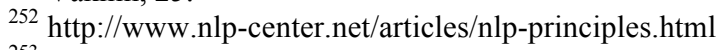

${ }^{253}$ Roger Ellerton, “Anchors,” NLP Center, http://www.nlp-center.net/articles/nlp-anchors.html (accessed November 24, 2011).
} 
who associate their war experiences with any helicopter's sound. According to NLP practices, unwanted anchors can be eliminated. ${ }^{254}$ Anchoring is one kind of technique; there are hundreds of different techniques that have been established by NLP practitioners.

NLP, like hypnosis, is not without its controversy. Because the concepts have not been thoroughly evaluated by the scientific community, its effectiveness is mostly subject to opinion, and many skeptics believe that it is a pseudoscience based upon unfounded beliefs. This is worsened by the many websites that, in order to sell products, make baseless claims about becoming wealthy or getting people to do what one wants.

Like physical musical practice, those who will find mental skill training, behavioral modification, and physiological adjustments to be successful are those who practice regularly and attempt to incorporate them into their daily living. Many of the methods share a focus; for example, attention to the breath is encountered in the Alexander Technique, Feldenkrais Method, yoga, and relaxation techniques. Since people tend to recommend coping strategies that work specifically for themselves, performers must take into account that what is effective can be unique and individual. It is imperative that performers seek to find the right kind of coping strategy or a combination thereof for their own individual needs, which may take time and persistence. It is also important that a proposed strategy be given a fair amount of time before a decision is made as to whether or not it is beneficial. A list of sources for further self study can be found in Appendix II.

${ }^{254}$ Ellerton, http://www.nlp-center.net/articles/nlp-anchors.html 


\section{CHAPTER 8}

\section{$\underline{\text { Conclusions }}$}

A survey of the available literature on music performance anxiety (MPA) shows that there have been numerous studies of its cases, symptoms, and possible coping strategies. Many have shown positive results when testing the coping strategies commonly known to alleviate the symptoms of performance anxiety, but many have been criticized for having a lack of structure, an insufficient subject group size, and imprecise research methodologies. Very few studies have been performed solely with singers as the subjects. While some of the studies included them,

those that did had a significantly smaller population of singers in proportion to the number of instrumentalists.

Because the voice is a living instrument and resides within the body, it is unlike any other instrument, and the effects of life itself - both from internal and external sources - are unique not only to the instrument but from one person to another. The effectiveness of the coping strategies discussed may be completely different for a singer as opposed to an instrumentalist; an example of this was seen in Chapter 6 concerning the use of beta-blockers. While several studies have suggested that they can be useful for instrumentalists without having a noticeable effect on performance, a study completed with only singers showed that a small dosage was ineffective and a larger dose worsened the effects of performance anxiety. Other than this, very little scholarship exists concerning this possible differentiation, with singers representing an inadequate number among studies of musicians. Further study is necessary to discover the efficacy of various interventions for singers. 
Studies are carried out in a finite amount of time, which includes a pre-study assessment, a study period (which can last for as little or as much time as the study can afford based on finances and availability of subjects), and a post-study assessment. The study periods vary in length, and while some take place with weekly sessions over a course of several months, most of the studies are quite limited in length. It takes years of training to build a vocal technique and performance artistry; it is probable that the true effectiveness of a coping strategy cannot be assessed within in a study that introduces it for such a limited amount of time. Perhaps one that followed a group of singers over the course of their undergraduate educations (typically four years) with comparative analysis provided by a control group of a similar size would provide more relevant and therefore more persuasive recommendations for coping with performance anxiety.

Pianist David Karp remarked, "It is as important for us to understand and help students with problems of performance anxiety as it is for us to understand and help with the musical and technical problems our students encounter." ${ }^{, 255}$ However, available evidence indicates that music performance anxiety is not a common topic of discussion within a college-level music program. Currently, there are no statistics as to how many music schools offer programs, workshops, courses, or lectures on music performance anxiety or any of the coping strategies. A survey designed to gather this information would assist in learning whether or not the research conducted on MPA thus far is supported by the educational curriculum currently offered to music students.

A larger study sample would also be beneficial. The largest study to date, and one that is often cited in research, was that performed by the International Conference of Symphony and Opera Musicians to determine the occupational challenges associated with the profession, in

${ }^{255}$ David Karp, ”Understanding Performance Anxiety," Clavier 27, no. 1 (January 1988): 18. 
which a survey of 2,212 musicians found that performance anxiety was the most frequently stated concern. ${ }^{256}$ This study, however, is the only one of its size, and it included only instrumentalists, all of whom were professional players.

The recorded percentages of musicians who experience performance anxiety are too varied in range, and no study has gathered relevant data concerning a large number of collegelevel musicians to give a more accurate percentage of those experiencing MPA. Those who give false information appear to do so because either they are ashamed or they are unaware that their symptoms are evidence of performance anxiety, further complicating calculations of the number of musicians who experience MPA. But with some studies showing one hundred percent of those surveyed experience performance anxiety, and other research citing only fifteen percent, there is an evident need for more conclusive, larger studies. ${ }^{257}$

For many, there is no cure for performance anxiety. While the known coping strategies may help to curb symptoms, there are many performers who struggle with the condition throughout their entire careers. The collegiate years are an especially vulnerable time for singers because not only are many of them evolving from novice performers into artists, but they are also developing from adolescents to adults. This time will encompass a myriad of new experiences, both positive and negative, which come with a new sense of independence, as well as the responsibilities associated with becoming an artist. It will gradually require a more sophisticated level of performance combined with the acquisition of advanced vocal technique, which may cause some to feel overwhelmed or to question what they have learned thus far. It is during these years that many singers will either gain or lose confidence in their performing

\footnotetext{
${ }^{256}$ Martin Fishbein, et al., "Medical Problems Among ICSOM: Overview of a National Survey, Medical Problems of Performing Artists 3, no. 1 (March 1988): 1-8.

${ }^{257}$ Joann Marie Kirchner, “A Qualitative Inquiry into Music Performance Anxiety," Medical Problems of Performing Artists 18 , no. 2 (June 2003): 78; Anne McGinnis and Leonard S. Milling, "Psychological Treatment of Musical Performance Anxiety:

Current Status and Future Directions," Psychotherapy: Theory, Practice, and Training 42, no. 5 (2005): 358.
} 
abilities, and because performance anxiety is so closely connected with self-esteem, the ability to gain confidence in one's skill as a singer as well as oneself should undoubtedly be part of a singer's instructional training.

Because some undesired behavior and low self-confidence might have roots in performance anxiety, it is productive for instructors to become familiar with the symptoms of the condition. It is not the instructor's job alone, however; singers must also become aware of any behaviors that may be a manifestation of performance anxiety. The effectiveness of any coping strategy that requires adaptive learning depends on many factors, including these listed by Pargman:

- Motivation for learning

- Previous experiences

- Commitment level to the process

- Sensitivity toward acquired information/willingness to accept feedback

- Form in which the feedback is made available

- One's physical and psychological ability to self-regulate ${ }^{258}$

A self-assessment of these factors can assist singers in finding a coping strategy that would be best suited to them. This analysis must include consideration of the possibility that, without knowing it, their current approach is impeding their improvement.

Encouraging awareness and communication about the disorder also removes the tendency to hide feelings about performance anxiety, which can lead to feelings of shame. ${ }^{259}$ Shame can

\footnotetext{
${ }^{258}$ Pargman, 176.
} 
lessen one's ability to be emotionally accessible, which is necessary in order for a performing artist to be successful. Perhaps more open communication on the subject would help to alleviate singers' inclinations to remain silent on the issue. One of the greatest advantages to this would be the heightened level of awareness concerning the epidemiology and prevalence of MPA, which, despite the multitude of information available, seems to be lacking among young singers. The more common and accepted this subject becomes among singing students, the less taboo it may seem to discuss it, and this could lead to a more open dialogue between students and instructors, resulting in students being willing to pursue productive interventions, while avoiding potentially harmful quick fixes, such as drug or alcohol abuse. If this information were incorporated into educational curriculum, the association of shame with music performance anxiety could be lessened as students learn reasoning skills and coping strategies with their colleagues.

Freud revealed that the mind's primal instincts "could never be eliminated, but can only at best be educated, modified, and diverted from their original primitive aims. ${ }^{260}$ Concerning music performance anxiety, students and instructors of singing can enhance their efficacy and success rate by continuing the acquisition of knowledge and the dissemination thereof.

\footnotetext{
${ }^{259}$ Thomas J. Scheff, "Shame and Conformity: The Deference-Emotion System," American Psychological Review 53, no. 3 (June 1988): 395-406.

${ }^{260}$ James Ching, Performer and Audience: An Investigation Into the Psychological Causes of Anxiety and Nervousness in Playing, Singing, or Speaking Before an Audience (Oxford: Hall the Publishers, 1947), 4.
} 


\section{APPENDIX I}

\section{Additional Correspondence}

This Appendix includes complete transcriptions of interviews and selected email

correspondence. The following is extracted from e-mail correspondence from Bert Priest to the

author:

Yoga has helped me greatly in many ways, not least for what you refer to as performance anxiety. Unfortunately, contemporary yoga has been hijacked by commercialism and is largely seen as a fitness activity, with often less emphasis on the more subtle side of the discipline.

Postures, also known as asanas, may be useful, especially for opening up the chest area and also for helping alleviate round-shouldered posture, which may be associated with performance anxiety. Breathing, also known as pranayama or breath-control, is a very important aspect of yoga that I've found very useful because it overrides the unconscious respiratory process that may well have become inhibited by long-term poor posture. Meditation is a wonderful tool to calm the mind and I've found it to be a great help in overcoming performance anxiety. I started singing backing vocals with a band a few years ago and it was a real challenge because, unlike playing drums exclusively, I had nothing to hide behind.

One of the tenets of yoga is 'letting go' and I find that this is a very useful tool in overcoming nerves and building confidence. One thing I've found very useful is to bring awareness to the concept of projection. It's so easy to strain and overplay just to try to be heard yet when we are relaxed, we can project with ease. And it's not just about technique; I feel it's more about 'living in it' and working with the space in-between whatever else is going on in the song/tune. This is where the more subtle aspects of yoga come to the fore, because relaxation can afford us a greater realisation of how what we do fits in with whatever else is going on.

One of the most important things I've learned from playing music and practicing yoga is the relationship between tension and release. I've found that music is all about creating tension and many, if not all, of the greatest compositions are built upon that creation of tension. In the same vein, the yoga postures involve the body building up a physical tension through postures and then dissipating it with relaxation.

'Yoga nidra' is, without doubt, one of the most powerful tools in yoga's armoury, yet relatively few teachers use it in class, or indeed use it themselves. Basically, it's a form of relaxation (but not strictly a meditation) where the consciousness is between waking and sleeping. The process involves bringing the awareness to each part of the body in turn and relaxing it. Of all the yoga practices, yoga nidra is probably the most suitable for helping with performance anxiety. It counteracts the stress response, one of the 
symptoms of this being something known as 'peripheral resistance'. This is where the 'fight or flight' response is activated and blood supply to unnecessary areas of the body is cut-off, enabling fresh blood to be fed to the muscles, either to run away or stay and fight - this is actually the fundamental cause of all hypertension.

When in stressful situations on a daily basis, the body sometimes stays in this mode, which is why people with highly stressful jobs often become ill because their vital organs are not being supplied with as much blood as they need. This may lead to chronic nervous tension, which doesn't help those who need to perform in front of people. That the awareness is brought to each part of the body means that those areas are fully and properly relaxed. There's nothing worse than feeling physically restricted or distracted from what you really need to be concentrating on during a performance. ${ }^{261}$

The following is from a written interview with certified yoga instructor Vida Alikani, who is also

formally trained as a dancer. KD refers to the author and VA to Alikani:

KD: Research has shown that yoga is known to reduce both trait and state anxiety, meaning anxiety occurring in the moment and overall anxiety. How can the practice of yoga be applied when one isn't in yoga class if she is feeling anxious?

VA: It's always amazing to me how calming and grounding a few minutes of meditation can be. Even if I don't intently "tune in" to the breath, something shifts: anxiety decreases, trust in my own impulses increases. I think in meditation we not only give our system a chance to rest from sensory stimulation, but we give our body/mind the message that it's ok to be ok right now, that it's ok to breathe and just be. Through this process we discover that it's possible to shift mental/emotional gears, that we're not bound to our anxiety, fear, etc. In terms of asana, postures done on the ground tend to induce a sense of safety and comfort. Seated forward bends have a pacifying effect on the nervous system. Doing just one or two postures can quiet the nervous system and bring relief.

KD: Are there types of yoga that are more beneficial than others for those who suffer from performance anxiety?

VA: I think Kundalini yoga can be helpful, because of its emphasis on breathing. It has specific "sets" and chants meant to bring about specific effects on the body/mind. It is an uplifting practice, and I've always come out of Kundalini class feeling light--physically and emotionally. I think a hatha practice is a good warm-up for doing a Kundalini practice. There's a lot of sitting in Kundalini, and the repeated breathing/moving exercises can be taxing if one goes into it cold. Restorative yoga is very useful too.

261 Bert Priest, e-mail message to the author, January 1-4, 2010. 
KD: Can you compare/contrast yoga practice and meditation?

VA: Asana practice can be thought of as a moving meditation that prepares the body/mind for seated meditation. It's easier to get quiet and still when you've engaged the body and breath for a while. Someone with anxiety might need to move and breathe first, and then meditate/do pacifying postures.

KD: What aspects of yoga do you think are helpful particularly for singers?

VA: Yoga's emphasis on finding the relationship between different parts of the body and creating a harmonious whole in each posture is useful to singers in that it helps them become more appreciative and aware of their instrument. It also helps them learn energyefficient ways to move. I think this physical awareness brings about non-physical benefits as well, such as an increased capacity to approach their relationships - with their creative process, their colleagues, their audience - from a more calm, present, compassionate state of mind. I also think that yoga's emphasis on being fully present for the experience, without being attached to a particular outcome, can lessen the fear of failure and foster a sense of joy and playfulness in the act of creating. ${ }^{262}$

The following is extracted from a written interview with conductor and cellist David Aks, who teaches visualization in the OperaWorks summer programs. KD refers to the author and DA to Aks:

KD: Do you think that visualization is a powerful tool for singers to use when they are faced with symptoms of performance anxiety? Why?

DA: Visualization can be very helpful in dealing with the performance anxiety that we all experience. First, doing a thorough amount of visualizing the piece(s) you need to sing will give you a greater sense of familiarity and ease that will sustain you when the nerves take over. Remember, the nervous system can't tell the difference between a real event and an imagined event, so if you run it perfectly in your imagination, your body thinks you did it...perfectly! You can also use visualization to set up a helpful mental approach to actually being on stage. You could start by imagining not being nervous on stage. But it might be more useful to imaging being nervous and fearful, and still doing great (thunderous applause, standing ovation, etc.).

\footnotetext{
${ }^{262}$ Vida Alikani, e-mail message to the author, August 11, 2011.
} 
KD: How long does one need to practice visualization before it becomes useful?

DA: The benefits of visualization can be seen right away, even after only one pass. But to be more effective, many more repetitions are needed, perhaps fifteen or twenty times through. The French educator Emil Coue said, "When the Imagination and the Will are in conflict, the Imagination always wins the day." So it would be a good idea for that image in your head to be something positive that you have chosen, rather than your habitual collection fears, mistakes and neuroses accumulated over a lifetime.

KD: How did you come to teach visualization?

DA: Sports psychologist Don Greene first introduced me to his idea of "mental practice." After that I became interested in visualization from observing and reading about worldclass athletes. Singing and athletics are really the same things: we are all attempting to do very precise movements with our bodies, just with different sets of muscles. But muscles are muscles, be they big quadriceps, or all the little ones surrounding our vocal folds.

KD: What differences have you seen in singers that have tried visualization?

DA: Singers who use visualization techniques learn music faster, make changes quicker, and are usually less easily frustrated when they practice. Concerning this last one: If they accept that most errors are merely the symptoms of faulty mental concepts, fixing the concept should take care of the error. One of the most important parts of practicing is to locate precisely the cause of the error. It can be very frustrating to work hard at correcting something when that's not the actual problem.

KD: What kinds of things can a singer improve by using visualization?

DA: The list is limitless. Anything you might work on, you can work on more efficiently and effectively using visualization. For example: rhythm, pitch, dynamics, diction, foreign languages, high notes, vocal technique, negative self-talk, fear of certain notes or passages (or pieces), stage fright, confidence, career advancement, etc... as I said, just about anything. ${ }^{263}$

263 David Aks, e-mail message to the author, November 13, 2011. 


\section{APPENDIX II}

Self-Help Sources for Further Study

The following is a list of sources the reader may find useful for further self-education concerning some of the solutions discussed with the scope of this research. It is not intended to be a comprehensive list, as there are many additional sources that may be consulted.

\section{$\underline{\text { Alexander Technique }}$}

An Alexander Approach to Singing (Singers') Technique by Ethan Kind (Amazon Digital Services, 2011)

The Alexander Technique and the Art of Teaching Voice: Singing and Speaking with an Energetic, Free, and Beautiful Voice by Maria Weiss (VDM Verlag Dr. Müller, 2009)

Singing with Your Whole Self: The Feldenkrais Method and Voice by Samuel H. Nelson and Elizabeth Blades-Zeller (Scarecrow Press, 2002)

Voice and the Alexander Technique by Jane Heinrich (Mornum Time Press, 2011)

$\underline{\text { Biofeedback }}$

Stress Test Biofeedback Card and Booklet by Alfred A. Barrios (thermal biofeedback - available from Amazon.com)

\section{Cognitive-Behavioral Techniques}

The Audition Process: Anxiety Management and Coping Strategies by Stuart Dunkel (Pendragon Press, 1989)

Coaching the Artist Within: Advice for Writers, Actors, Visual Artists, and Musicians from America's Foremost Creativity Coach by Eric Maisel (New World Library 2005)

Creativity for Life: Practical Advice on the Artist's Personality and Career from America's Foremost Creativity Coach by Eric Maisel (New World Library, 2007)

Fearless Creating: A Step-by-Step Guide to Starting and Completing Your Work of Art by Eric Maisel (Tarcher, 1995) 
Fearless Presenting: ASelf-Help Guide or Anyone Who Speaks, Sells, or Performs in Public by Eric Maisel (Back Stage Books, 1997)

Feeling Good: The New Mood Therapy by David Burns

(William Morrow, 1999)

Fight Your Fear and Win: Secen Skills for Performing Your Best Under Pressure - at Work, in Sports, on Stage by Don Greene (Broadway, 2002)

Mastering Creative Anxiety: 24 Lessons for Writers, Painters, Musicians, and Actors from America's Foremost Creativity Coach by Eric Maisel (New World Library, 2011)

Overcoming Performance Anxiety by Rod Farnbach and Eversley Farnbach (Simon and Schuster, 2001)

Performance Success: Performing Your Best Under Pressure by Don Greene (Routledge, 2001)

\section{Feldenkrais Method}

Singing with Your Whole Self: The Feldenkrais Method by Samuel H. Nelson (Scarecrow Press, 2002)

\section{Hypnotherapy}

A Practical Guide to Self-Hypnosis by Melvin Powers

(Fili-Quarian Classics, 2010)

Instant Hypnosis: How to Hypnotize Yourself with Your Eyes Open by Forbes Robbins Blair (Sourcebooks, Inc., 2004)

\section{$\underline{\text { Yoga }}$}

30 Essential Yoga Poses: For Beginning Students and Their Teachers by Judith Hanson Lasater (Rodmell Press, 2003)

Musician's Yoga: A Guide to Practice Performance and Inspiration by Mia Olson

(Berklee Press, 2009)

Yoga for Anxiety: Meditations and Practices for Calming the Body and Mind by Mary Nurrie Stearns and Rick Nurrie Stearns (New Harbinger Publications, 2010)

Yoga for Singers: Freeing Your Voice and Spirit Through Yoga by Linda Lister (Lulu.com) 
Yoga and the Quest for the True Self by Stephen Cope (Bantam, 2000)

Yoga Journal's YOGA Step by Step (The Total Guide to Beginning Your Home Practice) with Natasha Rizopoulos (Set of 3 DVDs; Bayview Entertainment/Widowmaker, 2007)

Yoga Nidra: A Meditative Practice for Deep Relaxation and Healing by Richard Miller (Sounds True, Inc., 2010)

YogaSing: Yoga for Singers and Performers with Suzanne Jackson (DVD)

(A.D.O Entertainment, 2006)

\section{Additional Performance Strategy Educational Sources and Workbooks}

The Artist's Way by Julia Cameron

(Penguin Group, 2002)

The Perfect Wrong Note: Learning to Trust Your Musical Self by William Westney

(Amadeus Press, 2003)

Performance Strategies for Musicians by David Buswell

(MX Publishing, 2006)

The Psychology of Music Performance Anxiety by Dianna T. Kenny

(Oxford University Press, 2011)

Stress and Motor Performance Under Pressure by David Pargman

(Mouvement Publications,1986)

Musical Excellence: Strategies and Techniques to Enhance Performance edited by Aaron

Williamson (Oxford University Press, 2004)

Performance Anxiety: A Workbook for Actors, Singers, Dancers, and Anyone Who Performs in Public by Eric Maisel (Back Stage Books, 2005)

Ten Days to Self-Esteem by David Burns

(William Morrow, 1999)

Toxic Criticism: Break the Cycle with Friends, Family, Coworkers, and Yourself by Eric Maisel (McGraw-Hill 2006) 


\section{BIBLIOGRAPHY}

Abascal, Kathy, and Eric Yarnell. "Nervine Herbs for Treating Anxiety," Alternative \& Complementary Therapies 10, no. 6 (December 2004): 309-315.

Abel, Jennifer L., and Kevin T Larkin. "Anticipation of Performance Among Musicians: Physiological Arousal, Confidence, and State-anxiety." Psychology of Music 18, no. 2 (1990): 171-182.

Al-Nasir, Jamie. "Anxiety - Evidence of Involvement of the Neurotransmitter GABA (Gamma-Amino-Butyric-Acid) and Other Implicated Neurotransmitters." Jamie AlNasir. http://www.al-nasir.com/www/Jamie/Articles/Pharmacy/ anxiety_gaba_neurotransmitters.shtml (accessed November 30, 2011).

Alexander, F. Matthias. Constructive Conscious Control of the Individual. London: Methuen, 1932.

American Nutraceutical Association. "What is a Nutraceutical?" American Nutraceutical Association. http://www.ana-jana.org/nut_info_details.cfm?NutInfoID=4 (accessed November 17, 2011).

American Psychological Association. "Why Sleep is Important and What Happens When You Don't Get Enough.” APA. http://www.apa.org/topics/sleep/why.aspx (accessed December 1, 2011).

American Society for the Alexander Technique, "The Alexander Technique." American Society for the Alexander Technique, http://www.amsatonline.org (accessed November 10, 2011).

Bahrke, Michael S., and William P. Morgan. "Anxiety Reduction Following Exercise and Meditation." Cognitive Therapy and Research 2, no. 4 (1978): 323-333.

Balandra, Valerie, and David Sheiderer. "The Four Major Neurotransmitters." Integrative Psychiatry. http://www.integrativepsychiatry.net/neurotransmitter.html (accessed November 30, 2011).

Ballenger, James C., Jonathan R. Davidson, Yves Lecrubier, David J. Nutt, Julio Bobes, Deborah C. Beidel, Yusuke Ono, and Herman G. Westenberg. "Consensus Statement on Social Anxiety Disorder from the International Consensus Group on Depression and Anxiety." Journal of Clinical Psychiatry 59, supplement 17 (1998): 54-60.

Bandler, Richard, and John Grinder. Reframing: Neuro-linguistic Programming and the Transformation of Meaning. Moab, UT: Real People Press, 1982. 
Barnes, Rob. Positive Teaching, Positive Learning. New York: Routledge, 1999.

Baum, Kenneth. The Mental Edge. New York: Berkeley Publishing Group, 1999.

Beck, Aaron T. "Beyond Belief: A Theory of Modes, Personality, and Psychopathology." In Frontiers of Cognitive Therapy, edited by Paul M. Salkovskis, 1-25. New York: The Guilford Press, 1996.

Beck, Judith S. Cognitive Therapy: Basics and Beyond. New York: Guillford Press, 1995.

Behavioral Associates. "What Is Cognitive Therapy?" Behavioral Associates Cognitive Behavioral Therapy. http://www.behavioralassociates.com/cbt.asp (accessed November 20, 2011).

Benninger, Michael S., and Thomas Murry. The Singer's Voice. San Diego: Plural Publishing, 2008 .

Blanc, Pamela. "Bringing the Semi-Supine to Life." Pamela Blanc: Lessons in the Alexander Technique. http://www.pamelablanc.com (accessed November 12, 2011).

_. "The Alexander Technique/Respiratory Re-Education and the Art of Breathing." Pamela Blanc: Lessons in the Alexander Technique. http://www.pamelablanc.com (accessed November 12, 2011).

Blanchard, Bonnie. Making Music and Having a Blast! Bloomington: Indiana University Press, 2009.

Bonetti, Ruth. "Conquering the Shakes - Without Beta Blockers." Ruth Bonetti. http:www.musicabonetti.com/ruth-pdf/ConquerShakes.pdf (Accessed December 1, 2011).

Bonsor, Kevin. "How Marijuana Works." How Stuff Works. http://science.howstuffworks.com/marijuana1.htm (accessed November 15, 2011).

Book, Sarah W., and Carrie L. Randall. "Social Anxiety Disorder and Alcohol Use." Under "Publications," National Institute on Alcohol Abuse and Alcoholism. http://pubs.niaaa.nih.gov/publications/arh26-2/130-135.htm (accessed November 12, 2011).

Booth, Eric. The Music Teaching Artist's Bible. New York: Oxford University Press, 2009.

Boston Singers' Resource. "Performance Anxiety." Career Services Center of New England Conservatory. http://www.bostonsingersresource.com/vocalhealthperfanxiety.asp (accessed June 1, 2009). 
Braiker, Harriet B. "The Power of Self-Talk.” Psychology Today 1 (December 1989): 23-27.

Brandfonbrener, Alice G. "Performance Anxiety: Different Strokes for Different Folks." Medical Problems of Performing Artists 14, no. 3 (September 1999): 101-102.

Bracha, H. Stefan, Tyler C. Ralston, Jennifer M. Matsukawa, Andrew E. Williams, and Adam S. Bracha. "Does 'Fight or Flight' Need Updating?" Psychosomatics 45, no. 5 (September 2004): 448-449.

Brodsky, Warren. "Music Performance Anxiety Re-conceptualized: A Critique of Current Research Practices and Findings." Medical Problems of Performing Artists 11, no. 3 (September 1996): 88-98.

Brontons, Melissa. "Effects of Performing Conditions on Music Performance Anxiety and Performance Quality." Journal of Music Therapy 31, no. 1 (March 1994): 63-81.

Brown, Barbara B. Stress and the Art of Biofeedback. New York: Harper \& Row, 1977.

Brown, Richard P., and Patricia L. Gerbarg. "Sudarshan Kriya Yogic Breathing in the Treatment of Stress, Anxiety, and Depression: Part II - Clinical Applications and Guidelines." Journal of Alternative and Complementary Medicine 11, no. 4 (August 2005): 711-717.

Brugués, Ariadna Ortiz. "Music Performance Anxiety - Part 1. A Review of Its Epidemiology." Medical Problems of Performing Artists 26, no. 2 (June 2011): 102-105.

Bruser, Madeline. The Art of Practicing: A Guide to Making Music from the Heart. New York: Bell Tower, 1997.

Bupa. "Beta-blockers.” Bupa Healthcare. http://www.bupa.co.uk/individuals/healthinformation/directory/b/beta-blockers?intcmp=heart-circulation\%3abeta-blockers (accessed November 15, 2011).

Burns, David D. Ten Days to Self-Esteem: The Leader's Manual. New York: William Morrow, 1993.

- When Panic Attacks: The New, Drug-Free Anxiety Therapy That Can Change Your Life. New York: Morgan Road Brooks, 2006.

Buswell, David. Performance Strategies for Musicians. London: MX Publishing, 2006.

Cannon, Walter B. Bodily Changes in Pain, Hunger, Fear, and Rage: An Account of Recent Researches Into the Function of Emotional Excitement. 2nd ed. New York: AppletonCentury-Crofts, 1929. 
Ching, James. Performer and Audience: An Investigation Into the Psychological Causes of Anxiety and Nervousness in Playing, Singing, or Speaking Before an Audience. Oxford: Hall the Publishers, 1947.

Clark, Duncan B., and W. Stewart Agras. "The Assessment and Treatment of Performance Anxiety in Musicians." American Journal of Psychiatry 148, no. 5 (May 1991): 598-605.

Clarke, Eric F. "Understanding the Psychology of Performance." In Musical Performance: A Guide to Understanding. Cambridge: Cambridge University, 2002.

Cohen, Bennet J., and Judith R.F. Kupersmith. "A Study of SCL-90 Scores of 87 Performing Artists Seeking Psychotherapy." Medical Problems of Performing Artists 1, no. 3 (December 1986): 140-142.

Coplan, Jeremy D., and R. Bruce Lydiard. "Brain Circuits in Panic Disorder." Biological Psychiatry 44, no. 12 (1998): 1264-1276.

Corredor, José M. Conversations with Pablo Casals. New York: E.P. Dutton \& Co., 1956.

Cox, Richard H. Conquer Stage Fright: A Field Guide to Excellence in Performance. San Jose, CA: Resource Publications, 2010.

- Managing Your Head and Body So You Can Become a Good Musician: The Psychology of Musical Competence - A Student-Musician's Field Guide for Performance and Freedom from Performance Anxiety. Colorado Springs: Colorado School of Professional Psychology Press, 2006.

Cratty, Bryant J. Social Psychology in Athletics. Ithaca, NY: Mouvement Publications, Inc., 1984.

Crego, Nancy. "What Is the Alexander Technique?" Nancy Crego: Alexander Technique. http://www.at-toledo.com (accessed November 10, 2011).

- "A Collection of the Saying and Aphorisms of F.M. Alexander." Nancy Crego: Alexander Technique. http://www.at-toledo.com/aphorisms/index.html (accessed December 2, 2011).

Creighton University Medical Center. "Origin of Hypnotherapy." Complementary and Alternative Medicine. http://altmed.creighton.edu/hypnotherapy/ (accessed November 23, 2011).

Cyphert, Dale. "Managing Stage Fright." University of Northern Iowa College of Business Administration. http://business.uni.edu/buscomm/Presentations/stagefright.html (accessed November 30, 2011). 
Dängeli, Jevon. “The Truth About Hypnosis.” NLP Center. http://www.nlp-center.net/articles/the-truth-about-hypnosis.html (accessed November 24, 2011).

Deen, Diana Rhea. "Awareness and Breathing: Keys to the Moderation of Musical Performance Anxiety." PhD diss., University of Kentucky, 1999.

Deforest, George Robert. "The Effects of Pedagogical Variables on Musical Performance Anxiety." PhD diss., Baylor University, 1998.

Denholm, Jack S. "An Investigation of the Affects of State Anxiety on Athletic Performance." Master's thesis, Mankato State University, 1993.

Desforges, Charles W. "Understanding Learning for Teaching." Westminster Studies in Education 12, no. 1 (1989): 17-29.

Dews, C.L. Barney, and Martha S. Williams. "Student Musicians' Personality Styles, Stresses, and Coping Patterns." Psychology of Music 17, no. 1 (1989): 37-47.

Diaz, Geórgia. "Voice work in the Alexander Technique." Geórgia Diaz. http://www.bodyandmind-at.nl/06e-media\&articles.html (accessed November 30, 2011).

Dishman, Rod K., Richard A. Washburn, and Gregory W. Heath. Physical Activity Epidemiology. Champaign: Human Kinetics, 2004.

Dogle, Dale O. "Toward Effective Treatment for Music Performance Anxiety." Psychotherapy: Theory, Research and Practice 19, no. 3 (Fall 1982): 368-375.

Drugs.com. "What Is Cannabis?” Drugs.com. http://www.drugs.com/cannabis.html (accessed November 15, 2011).

Duarte, Fernando. "The Principles of the Alexander Technique Applied to Singing: The Significance of the 'Preparatory Set'." Journal of Research in Singing 5, no. 1 (December 1981): 3-21.

Dunkel, Stuart Edward. The Audition Process: Anxiety Management and Coping Strategies. Stuyvesant, NY: Pendragon Press, 1989.

Dunsby, Jonathan. Performing Music: Shared Concerns. New York: Oxford University Press, 1995.

Dweck, Carol S. "Motivational Processes Affecting Learning." American Psychologist 41, no. 10 (October 1986): 1040-1048. 
Eccles, Jacquelynne S. "School and Family Effects on the Ontogeny of Children's Interests, SelfPerceptions, and Activity choices." In Nebraska Symposium on Motivation, edited by Janis E. Jacobs, 145-208. Lincoln: University of Nebraska Press, 1993.

Ellerton, Roger. “Anchors.” NLP Center. http://www.nlp-center.net/articles/nlp-anchors.html (accessed November 24, 2011).

Ely, Mark C. "Stop performance anxiety!” Music Educators Journal 78 no. 2 (October 1991): 35-39.

Emmons, Shirlee, and Alma Thomas. Power Performance for Singers: Transcending the Barriers. New York: Oxford University, 1998.

__. "Shirlee Emmons: The Various Faces of Performance Anxiety." Shirlee Emmons. http://www.shirlee-emmons.com/anxiety (Accessed September 16, 2011).

Enright, Patrick. "Even Stars Get Stage Fright.” Msnbc.com, September 12, 2007. http://www.msnbc.msn.com/id/20727420/ns/health-mental_health/t/even-stars-get-stagefright/ (accessed November 30, 2011).

Esplen, Mary Jane, and Ellen Hodnett. "A Pilot Study Investigating Student Musicians' Experiences of Guided Imagery as a Technique to Manage Performance Anxiety." Medical Problems of Performing Artists 14, no. 3 (September 1999): 127-132.

Esposito, Janet E. Getting Over Stage Fright. St. Peters, MO: Love Your Life Publishing, Inc., 2009.

- In the Spotlight: Overcome Your Fear of Public Speaking and Performing. Bridgewater, CT: In the Spotlight, 2000.

Eysenck, Hans J. "The Conditioning Model of Neurosis." Behavioral and Brain Sciences 2, no. 2 (June 1979): 155-166.

Farnbach, Rod, and Eversley Farnbach. Overcoming Performance Anxiety. Pymble, AU: Simon \& Schuster, 2001.

Fehm, Lydia, and Katja Schmidt. "Performance Anxiety in Gifted Adolescent Musicians." Journal of Anxiety Disorders 20, no. 1 (2006): 98-109.

Felsky, Antoinette. The Musician's Mind. New York: Pioneer Publishing Company, 1921.

Fensterheim, Herbert. Stop Running Scared! New York: Dell Publishing, 1977.

Fiore, Neil. Awaken Your Strongest Self: Break Free of Stress, Inner Conflict, and SelfSabotage. New York: McGraw-Hill, 2007. 
- The Now Habit: A Strategic Program for Overcoming Procrastination and Enjoying Guilt-free Play. New York: Tarcher/Penguin, 2007.

Fishbein, Martin, Susan E. Middlestadt, Victor Ottati, Susan Strauss, and Alan Ellis. "Medical Problems Among ICSOM Musicians: Overview of a National Survey." Medical Problems of Performing Artists 3, no. 1 (January 1988): 1-7.

Freymuth, Malva Susanne. Mental Practice and Imagery for Musicians: A Practical Guide for Optimizing Practice Time, Enhancing Performance, and Preventing Injury. Boulder: Integrated Musicians Press, 1999.

Galatas, Ruth Ann. "A Survey of Techniques in Imagery Training for the Treatment of Performance Anxiety." PhD diss., University of Miami, 1989.

Gates, George A., and Phillip Montalbo. "The Effect of Low-Dose Beta-Blockage on Performance Anxiety in Singers." Journal of Voice 1, no. 1 (March 1987): 105-108.

Giunta, John P. "Yoga for Musicians.” Yoga for Musicians. http://specialmind.com/yogamus.htm (accessed December 3, 2011).

Goode, Michael I. Stage Fright in Music Performance and Its Relationship to the Unconscious. Oak Park, IL: Trumpetworks Press, 2003.

Gorrie, Jon. Mind and Body: A Theory for Understanding Levels of Musical Performance. N.p.: CreateSpace, 2011.

- Performing in The Zone: Unleash Your True Performing Potential! N.p.: CreateSpace, 2009.

Gramer, Margit, and Karin Saria. "Effects of Social Anxiety and Evaluative Threat on Cardiovascular Responses to Active Performance Situations.” Biological Psychology 74, no. 1 (January 2007): 67-74.

Gray, Jeffrey A. The Psychology of Fear and Stress, 2nd ed. Cambridge: Cambridge University Press, 1988.

Green, Barry. The Inner Game of Music. Garden City, NY: Doubleday, 1986.

- The Mastery of Music: Ten Pathways to True Artistry. New York: Broadway Books, 2003.

Greenwald, Anthony G., and Mahzarin R. Banaji. "Implicit Social Cognition: Attitudes, SelfEsteem, and Stereotypes.” Psychological Review 102, no. 1 (January 1995): 4-27.

Greene, Don. Audition Success: An Olympic Sports Psychologist Teaches Performing Artists How to Win. New York: Routledge, 2001. 
—. Fight Your Fear and Win: Seven Skills for Performing Your Best Under Pressure. New York: Broadway Books, 2001.

- Performance Success Performing Your Best Under Pressure. New York: Routledge, 2002.

Grishman, Alan. "Musicians' Performance Anxiety: The Effectiveness of Modified Progressive Muscle Relaxation in Reducing Physiological, Cognitive, and Behavioral Symptoms of Anxiety." PhD diss., University of Pittsburgh, 1989.

Guillory, Shelly. "Foods That Trigger Anxiety." Livestrong.com. http://www.livestrong.com/article/273839-foods-that-trigger-anxiety/ (accessed December 1, 2011).

Gupta, Nidhi, Shevta Khera, R.P. Vempati, Ratna Sharma, and R. L. Bijlani, "Effect of Yoga Based Lifestyle Intervention on State and Trait Anxiety," Indian Journal of Physiology and Pharmacology 50, no.1 (January-March 2006): 41-47.

Hamann, Donald L. "An Assessment of Anxiety in Instrumental and Vocal Performances." Journal of Research in Music Education 30, no. 2 (Summer 1982): $77-90$.

Hamann, Donald L., and Martha Sobaje. "Anxiety and the College Musician: A Study of Performance Conditions and Subject Variables." Psychology of Music 11, no. 1 (April 1983): 37-50.

Hanton, Sheldon, and Declen Connaughton. "Perceived Control of Anxiety and Its Relationship to Self-Confidence and Performance." Research Quarterly for Exercise and Sport 73, no. 1 (2002): 87-97.

Harby, Karla, Kathrin Kucharski, Sarah Tuck, and Julia Vasquez. "Beta Blockers and Performance Anxiety in Musicians.” Ethan Winer. http://www.ethanwiner.com/BetaBlox.html (accessed December 2, 2011).

Hart, Leslie A. Human Brain and Human Learning. New York: Longman, 1983.

Hatfield, Heather. "How to Sleep Like an Olympic Athlete." WebMD. http://www.webmd.com/sleep-disorders/guide/sleep-like-an-olympian (accessed December 1, 2011).

Hays, Kate F. "Performance Anxiety." In Performance Psychology in Action, edited by Kate F. Hays, 101-120. Washington, D.C.: American Psychological Association, 1994.

Heinrich, Jane. Voice and Alexander Technique: Active Explorations for Speaking \& Singing. Berkeley: Mornum Time Press, 2005. 
Henderson, William Hayes. "Factors Related to Performance Anxiety as Experienced by Professional Musicians.” PhD diss., University of Southern California, 1985.

Hingley, Virginia Dee. "Performance Anxiety in Music: A Review of the Literature (Stage Fright, Stress).” PhD diss., University of Washington, 1985.

Hipple, John. “Is There More to Stage Fright Than Just Anxiety?” Brass Bulletin 109 (1st Quarter 2000): 68-73.

Hoesman, Beth. The Effects of Biofeedback Training and Muscle Relaxation on Performance Anxiety in Musicians. Albion, MI: Albion College, 1981.

Hudson, Barbara. "The Effects of the Alexander Technique on the Respiratory System of the Singer/Actor I: F.M. Alexander and Concepts of His Technique that Affect Respiration in Singer/Actors.” Journal of Singing 59, no. 1 (September-October 2002): 9-17.

. "The Effects of the Alexander Technique on the Respiratory System of the Singer/Actor II: Implications for Training Respiration in Singer/Actors Based on Concepts of the Alexander Technique." Journal of Singing 59, no. 2 (NovemberDecember 2002): 105-110.

Humphreys, Tony. The Power of Negative Thinking. Dublin: Gill \& Macmillan, 1996.

Hunnicut, Heather W., and A. Scott Winter. "Musical Performance Anxiety: Adapting Psychotherapy Techniques of Desensitization to the Voice Studio, Part I." Journal of Singing 67, no. 3 (January/February 2011): 331-336.

Hunt, Ernest H. The Cure of Nervousness and Stage Fright. Reprint. Whitefish, MT: Kessinger Publishing, 2010.

- How to Win the War on Nerves. London: Rider, 1940.

Iyengar, Bellur Krishnamachar Sundararaja. Light on Yoga: The Bible of Modern Yoga - Its Philosophy and Practice - by the World's Foremost Teacher. New York: Schoeken Books, 1979.

Jackson, Suzanne. "YogaSing." YogaSing.com: Yoga for Singers and Performers. http://www.yogasing.com (accessed November 15, 2009).

Jain, Sanjiv, Kristy Janssen, and Sharon DeCelle. "Alexander Technique and Feldenkrais Method: A Critical Overview." Physical Medicine and Rehabilitation Clinics of North America 15 (2004): 811-825.

Javanbakht, M., Kenari R. Hejazi, and Majid Ghasemi. "Effects of Yoga on Depression and Anxiety of Women." Complementary Therapies in Clinical Practice 15, no. 2 (May 2009): 102-104. 
Jones, Frank Pierce. Freedom to Change: The Development and Science of the Alexander Technique. Berkeley: Mornum Time Press, 1997.

Judy, Stephanie. Making Music for the Joy of It: Enhancing Creativity, Skills, and Musical Confidence. New York: St. Martin's Press, 1990.

Khan, April. "Anxiety and Eating.” Livestrong.com. http://www.livestrong.com/article/331540-anxiety-eating/ (accessed December 1, 2011).

Karp, David. ’Understanding Performance Anxiety." Clavier 27, no. 1 (January 1988): 16-19.

Kearns, Hugh, Angus Forbes, and Maria Gardiner. "A Cognitive Behavioral Coaching Intervention for the Treatment of Perfectionism and Self-Handicapping in a Non-Clinical Population," Behavior Change 24, no. 3 (2007): 157-159.

Kemp, Anthony. The Musical Temperament. Oxford: Oxford University Press, 1996.

Kenny, Dianna T. "Music Performance Anxiety: Its Origins, Phenomenology, Assessment and Treatment," Context: Journal of Music Research 31 (2006): 51-64.

- The Psychology of Music Performance Anxiety. New York: Oxford University Press, 2011.

Kenny, Dianna T., and Margaret S. Osborne. "Development and Validation of a Music Performance Anxiety Inventory for Gifted Adolescent Musicians." Journal of Anxiety Disorders 19, no. 7 (2005): 725-751.

-. "Music Performance Anxiety: New Insights from Young Musicians." Advances in Cognitive Psychology 2, no. 2-3 (2006): 103-112.

Kesselring, Jürg. "Music Performance Anxiety.” In Music, Motor Control, and the Brain, edited by Jürg Kesselring, 309-318. Oxford: Oxford University Press, 2006.

Khalsa, Sat Bir, and Steven Cope. "Effects of Yoga Lifestyle Intervention on PerformanceRelated Characteristics of Musicians: A Preliminary Study." Medical Science Monitor 12, no. 8 (Aug 2006): 325-331.

Khalsa, Sat Bir, Stephanie M. Shorter, Steven Cope, Grace Wyshak, and Elyse Sklar. "Yoga Ameliorates Performance Anxiety and Mood Disturbance in Young Professional Musicians.” Applied Psychological Biofeedback 34, no. 4 (December 2009): 279-289.

Klickstein, Gerald. The Musician's Way: A Guide to Practice, Performance, and Wellness. New York: Oxford University Press, 2009.

Krauss, David R. Peak Performance. Englewood Cliffs, NJ: Prentice-Hall, 1980. 
Lafosse, Leopold. "An Introduction to Sports Psychology, Mental Training, and Musical Performance." In Fluting and Dancing: Articles and Reminiscences for Betty Bang Mather on Her 65th Birthday, edited by David Lasocki, 146-153. New York: McGinnis \& Mars, 1992.

Leblanc, Albert. “A Theory of Music Performance Anxiety.” In Indiana Symposium on Research in Social Psychology of Music, edited by University of Northern Colorado School of Music, Center for Research in Music Learning and Teaching, edited by Franz L. Roehmann and Frank R. Wilson, 60-68. Greenley: University of Northern Colorado, 1995.

Lederman, Richard J. "Medical Treatment of Performance Anxiety: A Statement in Favor." Medical Problems of Performing Artists 14, no. 3 (September 1999): 117-121.

Lehman, Andreas C. Psychology for Musicians: Understanding and Acquiring the Skills. New York: Oxford University Press, 2007.

Lehrer, Paul. "The Causes and Cures of Performance Anxiety: A Review of the Psychological Literature." In The Biology of Music Making: Proceedings of the 1984 Denver Conference, edited by Franz L. Roehmann and Frank R. Wilson, 32-46. St. Louis: MMB Music, 1988.

Levitt, Joel H. "Conquering Anxiety, Depression, and Fatigue Without Drugs - the Role of Hypoglycemia," Alternative Mental Health. http://www.alternativementalhealth.com/articles/hypoglycemia.htm (accessed November 19, 2011).

Lewis, Barbara. "Feldenkrais Method - Some Tips and Insight for Singers from an Interview with Alan Fraser." Singing Tips with Barbara Lewis. http://singing-tips-with-barbara-lewis.com (accessed November 6, 2011).

Lewis, Pamela Payne. "The Alexander Technique: Its Relevance for Singers and Teachers of Singing." PhD diss., Carnegie-Mellon University, 1980.

Lieberman, Julie Lyonn. You Are Your Instrument: The Definitive Musician's Guide to Practice and Performance. New York: Huiksi Music, 1991.

Lloyd, Gwyneth. "The Application of the Alexander Technique to the Teaching and Performing of Singing: A Case Study Approach.” Master's thesis, University of Stellenbosch, 1986.

Loehr, James E., and Jeffery A. Migdow. Breathe In, Breathe Out: Inhale Energy and Exhale Stress by Guiding and Controlling Your Breathing. Alexandria, VA: Time-Life Books, 1999. 
Lowenstein, Marisa. "Stretching Your Abilities: Yoga for Musicians." Star Polish: Helping Artists Help Themselves, March 9, 2001.

http://www.starpolish.com/features/columns/article.asp?ID=46 (accessed December 31, 2009).

Love, Roger. Set Your Voice Free. Boston: Little, Brown, 1999.

Maisel, Eric. A Life in the Arts: Practical Guidance and Inspiration for Creative and Performing Arts. New York: Putnam, 1994.

—. Affirmations for Artists. New York: Putnam, 1996.

- Coaching the Artist Within: Advice for Writers, Actors, Visual Artists, and Musicians from America's Foremost Creativity Coach. Novato, CA: Publishers Group West, 2005.

-. Fearless Creating: A Step-by-Step Guide To Starting and Completing Your Work of Art. New York: Putnam, 2005.

- Fearless Presenting: A Self-help Workbook for Anyone Who Speaks, Sells, or Performs in Public. New York: Backstage Books, 1997.

- Mastering Creative Anxiety: 24 Lessons for Writers, Painters, Musicians, and Actors from America's Foremost Creativity Coach. Novato, CA: New World Library, 2011.

- Performance Anxiety. New York: Backstage Books, 2005.

- Staying Sane in the Arts: A Guide for Creative and Performing Artists. New York: Putnam, 1992.

- Toxic Criticism: Break the Cycle with Friends, Family, Coworkers, and Yourself. New York: McGraw-Hill, 2007.

Maltz, Maxwell. Psycho-Cybernetics. New York: Prentice-Hall, 1960.

Marsh, Herbert W. "Big Fish Little Pond Effect on Academic Self-Concept: Cross-Cultural and Cross-Disciplinary Generalizability." Australian Association for Research in Education. www.aare.edu.au/05pap/mar05389.pdf (Accessed December 1, 2011).

McCoy, Lorraine Hough. "Musical Performance Anxiety Among College Students: An Integrative Approach.” Ph D diss., Northern Illinois University, 1998.

McKercher, Charlotte, F. Martin, and K.C. Kirkby. "Attentional Bias in Music Performance Anxiety?" Australian Journal of Psychology Supplement (2003): 196-197. 
McKinney, James. Diagnosis and Correction of Vocal Faults (Long Grove, IL: Waveland Press, 2005.

McVitamins. "Potassium.” McVitamins. http://www.mcvitamins.com/Vitamins/potassium.htm (accessed November 19, 2011).

McWilliams, John Roger, and Peter McWilliams. You Can't Afford the Luxury of a Negative Thought. London: Thorsons, 1991.

Mental Health Foundation. "How to Overcome Fear and Anxiety." Mental Health Foundation Publications.

http://www.mentalhealth.org.uk/publications/overcome-fear-anxiety (accessed November 11, 2011).

Miller, Diane K., and Judith R.F. Kupersmith. "Louisville-PACH: Psychiatric Problems of Performing Artists." Medical Problems of Performing Artists 5, no. 1 (March 1990): $19-22$.

Miller, Staci Renee, and Kris Chesky, “The Multidimensional Anxiety Theory: An Assessment of and Relationships Between Intensity and Direction of Cognitive Anxiety, Somatic Anxiety, and Self-Confidence over Multiple Performance Requirements among College Students." Medical Problems of Performing Artists 19, no. 1 (March 2004): 12-20.

Minocha, Anil. "Whole Fruit Versus Fruit Juice." Digestion, Health, and Nutrition: Dr. Anil Minocha, A Gastroenterologist and Nutritionist. http://minochahealth.typepad.com/gut/2010/08/fruit-juice.html (accessed November 19, 2011).

Moliterno, Mark. "What is YogaVoice?" Facebook, November 19, 2009. https://www.facebook.com/note.php?note_id=201188711411(accessed August 12, 2011).

Monaghan, Patricia, and Eleanor G. Viereck. Meditation: The Complete Guide. Novato, CA: New World Library, 1999.

Mor, Shulamit, Hy I. Day, and Gordon L. Flett. "Perfectionism, Control, and Components of Performance Anxiety in Professional Artists." Cognitive Therapy and Research 19, no. 2: 207-225.

Morehouse, Lawrence E., and Leonard Gross. Maximum Performance. New York: Simon \& Schuster, 1977.

Morgan, Dagmar. "Singing the Praises of Yoga." The Muse's Muse, November 22, 2002. http://www.musesmuse.com/00000337.html (accessed December 31, 2009). 
Morgan, William P. "Anxiety Reduction Following Acute Physical Activity.” Psychiatric Annals 9, no. 3 (March 1979): 36-45.

Mortensen, Kurt W. Maximum Influence: The 12 Universal Laws of Power Persuasion. New York: Amacom, 2004.

Nagel, Julie Jaffee. "Treatment of Music Performance Anxiety via Psychological Approaches," Medical Problems of Performing Artists 25, no. 4 (December 2010): 141-148.

Nagel, Julie Jaffee, David P. Himle, and James D. Papsdorf. "Cognitive-Behavioural Therapy for Musical-Performance Anxiety.” Journal of Consulting and Clinical Psychology 50, no. 3 (1982): 353-362.

Natural Healing for All. "Types of Biofeedback.” Natural-healing-for-all.com. http://www.natural-healing-for-all.com/biofeedback-2.html (accessed December 2, 2011).

Nelson, Samuel H., and Elizabeth Blades-Zeller. Singing with Your Whole Self: The Feldenkrais Method and Voice. Lanham: Scarecrow Press, 2002.

Nichols, Diane. "The Demons Within: Confronting Performance Anxiety." Chamber Music Magazine 12, no. 6 (December 1995): 20-23, 34-40.

Niemann, Brand Keola, Rosalie R. Pratt, and Michael Maughan. "Biofeedback Training, Selected Coping Strategies, and Music Relaxation Interventions to Reduce Debilitative Musical Performance Anxiety." International Journal of Arts Medicine 2, no. 2 (Fall 1993): 7-15.

Nordqvist, Christian. "What is Anxiety? What Causes Anxiety? What To Do About It." Medical News Today, February 9, 2009. http://www.medicalnewstoday.com/releases/7603.php (accessed November 30, 2011).

Paprocki, Daniel A. "It's All In The Mind: Performance Anxiety and Sport Training." The Clarinet 26, no. 2 (March 1999): 74-79.

Pargman, David. Managing Performance Stress: Models and Methods. New York: Routledge, 2006.

—. Stress and Motor Performance. Ithaca, NY: Mouvement Publications, 1986.

Parncutt, Richard, and Gary E. McPherson, eds. The Science and Psychology of Music Performance: Creative Strategies for Teaching and Learning. New York: Oxford University Press, 2002. 
Pediatric Neurotransmitter Disease Association. "What are neurotransmitters?" PNDA. http://www.pndassoc.org/site/c.iuLWJdMRKpH/b.689419/k.8000/What_Are_Neurotrans mitters.htm (accessed November 30, 2011).

Picard, André. "Qualitative Pedagogical Inquiry into Cognitive Modulation of Musical Performance Anxiety." Bulletin of the Council for Research in Music Education 140 (Spring 1999): 62-76.

Ponasik, Jill Anna. "Continuing Education: One More Conversation about the Feldenkrais Method with Master Teacher Maxine Davis.” Classical Singer, January 2009, 14-17.

—. "Learning to Let Go: A Discussion about the Inner Game of Singing with Feldenkrais Teacher Maxine Davis," Classical Singer, December 2008, 22-24.

ProCon.org. "Should Marijuana Be a Medical Option?" ProCon.org. http://medicalmarijuana.procon.org/ (accessed November 15, 2011).

Quinn, Elizabeth. "Sleep Deprivation Can Hinder Athletic Performance." About.com Sports Medicine. http://sportsmedicine.about.com/cs/conditioning/a/aa062800a.htm (accessed December 1, 2011).

Rack, John Edward. "Performance Anxiety in Student Musicians: A Correlational Study." PhD diss., Pennsylvania University, 1995.

Ragone, Imogen. “Alexander Technique Self-Help Information.” Alexander Technique with Imogen Ragone. http://www.imogenragone.com (accessed November 10, 2011).

Reese, Doug. "Change For the Better.” To The Next Level Sports Network. $\mathrm{http} / / / \mathrm{www}$. tothenextlevel.org/docs/features/change_for_the_better/default.asp (accessed November 30, 2011).

Rickover, Robert. "What Can Go Wrong with Alexander Technique Lessons?" AltMD.com Health and Wellness Community, http://www.altmd.com/Articles/What-Can-Go-Wrongwith-Alexander-Technique-Lessons (accessed December 2, 2011).

Rife, Nora Anne, Leah Blumberg Lapidus, and Zachary M. Shnek. "Musical Performance Anxiety, Cognitive Flexibility, and Field Independence in Professional Musicians." Medical Problems of Performing Artists 15, no. 4 (December 2000): 161-166.

Riffe, Jane Beerbower. "The Effects of Diaphragmatic Breathing on Stage Fright and Musical Performance in College Music Students." PhD diss., West Virginia University, 1987.

Ristad, Eloise. A Soprano on Her Head: Right-Side-Up Reflections on Life and Other Performances. Moab, UT: Real People Press, 1982. 
Ritterman, Janet. “On Teaching Performance.” In Musical Performance: A Guide to Understanding, edited by John Rink, 75-88. Cambridge: Cambridge University, 2002.

Robin, Mitchell W., and Rochelle Balter. Performance Anxiety: Overcoming Your Fear in the Workplace, Social Situations, Interpersonal Communications, and the Performing Arts. Holbrook, MA: Adams Publishing, 1995.

Roland, David. The Confident Performer. Portsmouth, NH: Heinemann, 1998.

Rosen, Charles. "The Aesthetics of Stage Fright." In Critical Entertainments: Music Old and New. Cambridge: Harvard University Press, 2000.

Runck, Bette. "What Is Biofeedback?" Arizona Behavioral Health Associates, P.C. http://www.psychotherapy.com/bio.html (accessed November 10, 2011).

Sagolla, Lisa Jo. "Keeping Up with Alexander." American Society for the Alexander Technique, http://www.amsatonline.org (accessed November 10, 2011).

Salkovskis, Paul M. "The Cognitive Approach to Anxiety: Threat Beliefs, Safety-Seeking Behavior, and the Special Case of Health Anxiety and Obsessions." In Frontiers of Cognitive Therapy, edited by Paul M. Salkovskis, 48-74. New York: The Guilford Press, 1996.

Salmon, Paul G. Notes from the Green Room: Coping With Stress and Anxiety in Musical Performance. San Francisco: Jossey-Bass, 1998.

Sataloff, Robert Thayer, Deborah Caputo Rosen, and Steven Levy. "Medical Treatment of Performance Anxiety: A Comprehensive Approach." Medical Problems of Performing Artists 14, no. 3 (September 1999): 122-126.

—_. "Performance Anxiety: What Singing Teachers Should Know." Journal of Singing 56, no. 5 (2000): 33-40.

Savage, Dylan. "An Answer to Performance Anxiety: Don Greene." American Music Teacher (February/March 2009): 26-29.

Schaffer, Fred, Judy Crawford, and Randy Neblett. "Biofeedback Certification 101." Biofeedback 36, no. 2 (2008): 49-51.

Schiraldi, Glenn R. 10 Simple Solutions for Building Self-Esteem. Oakland: New Harbinger Publications, 2007.

Sinden, Lisa Marie. "Music Performance Anxiety: Contributions of Perfectionism, Coping Style, Self-efficacy, and Self-esteem.” PhD diss., Arizona State University, 1999. 
Smith, Melinda, Lawrence Robinson, and Jeanna Segal, "Anxiety Medication: What You Need to Know About Drugs for Anxiety." Helpguide.org. http://helpguide.org/mental/anxiety_medication_drugs_treatment.htm (accessed November 12, 2011).

Soen, Evelyn Lee. "Yoga Within the Music Studio." American Music Teacher (August/September 2004): 36-40.

Stacken, Jesse. "Yoga for Musicians: The Benefit of Daily Yoga Practice," Bloomingdale School of Music. http://www.bsmny.org/features/yoga/index.php (accessed December 31, 2009).

Stanton, Harry E. "Research Note: Alleviation of Performance Anxiety Through Hypnotherapy." Psychology of Music 21 (January 1993): 78-82.

Stedman, Sarah Elizabeth. "Singing and Self: The Psychology of Performing." PhD diss., Northwestern University, 1985.

Steptoe, Andrew. "Negative Emotions in Music Making: The Problem of Performance Anxiety." In Music and Emotion - Theory and Research, edited by Patrik N. Juslin and John A. Sloboda, 291-307. Oxford: Oxford University Press, 2001.

—. "Stress, Coping, and Stage Fright in Professional Musicians." Psychology of Music 17, no. 1 (1989): 3-12.

Stoddard, Mark. Marketing Singers - Creating a Perpetual Job Machine. Lindon, UT: Alexander Press, 2007.

Streifel, Sebastian. "Ethics and the Performing Arts," Biofeedback 30, no. 3/4 (2002): 6-7.

Sweeney, Gladys Maria. "The Separate and Combined Effects of Cue-Controlled Relaxation and Cognitive Restructuring in the Treatment of Musical Performance Anxiety." Journal of Counseling Psychology 29 (1982): 486-497.

Tamborino, Robert Anthony. "An Examination of Performance Anxiety Associated with Solo Performance of College-level Music Majors.” PhD diss., Indiana University, 2001.

Taylor, C. Barr, James F. Sallis, and Richard Needle. "The Relation of Physical Activity and Exercise to Mental Health." Public Health Reports 100, no. 2 (March-April 1985): 195202.

Test Medical Symptoms. "Performance Anxiety Symptoms." Test Medical Symptoms at Home, Inc. http://www.testsymptomsathome.com/sym_performance.asp (accessed November 30, 2011). 
Traverse, James. "Performance Anxiety: Mental Impotence." Being Yoga. http://www.beingyoga.com/Performance\%20Anxiety.htm (accessed November 30, 2011).

Tschaikov, Basil. Physical and Emotional Hazards of a Performing Career: A Special Issue of the Journal of Musical Performance. London: Taylor \& Francis, 2001.

University of Maryland Medical Center. "Biofeedback." http://www.umm.edu/altmed/articles/biofeedback-000349.htm (accessed November 12, 2011).

Vaknin, Shlomo. NLP for Beginners. Lexington: Inner Patch Publishing, 2009.

Valentine, Elizabeth. "The Fear of Performance." In Musical Performance: A Guide to Understanding, edited by John Rink, 168-184. Cambridge: Cambridge University, 2002.

Valentine, Elizabeth, David F.P. Fitzgerald, Tessa L. Gorton, Jennifer A. Hudson, and Elizabeth R.C. Symonds. "The Effect of Lessons in the Alexander Technique on Music Performance in High and Low Stress Situations." Psychology of Music 23, no. 2 (October 1995): 129-141.

Walker, C. Eugene. Learn to Relax: Proven Techniques for Reducing Stress, Tension, and Anxiety - and Promoting Peak Performance. New York: Wiley, 2001.

Wehrenberg, Margaret. The 10 Best-Ever Anxiety Management Techniques: Understanding How Your Brain Makes You Anxious, and What You Can Do to Change It. New York: W. W. Norton, 2008.

Werner, William. Effortless Mastery: Liberating the Musician Within. Portland: Amadeus, 2003.

Wesner, Robert B., Russell Noyes, Jr., and Thomas L. Davis. "The Occurrence of Performance Anxiety Among Musicians." Journal of Affective Disorders 18, no. 3 (March 1990): $177-185$.

Westney, William. The Perfect Wrong Note: Learning to Trust Your Musical Self. Pompton Plains, NJ: Amadeus Press, 2003.

Whitten, Sarah. "Yoga and Singing." Boston Singers' Resource. http://www.bostonsingersresource.com/yogaandsinging.asp (accessed December 31, 2009).

Whykes, Susan. Mind Over Matter: A Handbook for Musicians to Help You Overcome Performance Anxiety. Bloomington: AuthorHouse, 2006. 
Williamson, Aaron, ed. Musical Excellence: Strategies and Techniques to Enhance Performance. Oxford: Oxford University Press, 2004.

Wilson, Edward O. Sociobiology: The New Synthesis. Cambridge: Belknap Press of Harvard University Press, 1975.

Wilson, Glenn D. "Performance Anxiety." In The Social Psychology of Music, edited by David John Hargreaves and Adrian C. North, 229-245. New York: Oxford University Press, 1997.

Wilson, Glenn D., and David Roland. "Performance Anxiety." In The Science and Psychology of Music Performance: Creative Strategies for Teaching and Learning, edited by Richard Parncutt and Gary McPherson, 47-61. New York: Oxford University Press, 2002.

Wolfson, Amy R., and Mary A. Carskadon. "Understanding Adolescents' Sleep Patterns and School Performance: A Critical Appraisal.” Sleep Medicine Reviews 7, no. 6 (2003): 491-506.

Wormhoudt, Pearl Shinn. With a Song in my Psyche: On the Psychology of Singing and Teaching Singing. N.p.: Xlibris, 2001.

Wright, Martin Wallace. "Waiting in the Wings: The Relationship Between Performance Anxiety and Identity." Master's thesis, Simon Frasier University, 1999.

Wulf, Gabriele. "Attention and Motor Skill Learning." Human Kinetics. http://www.humankinetics.com/products/all-products/attention-and-motor-skill-learning (accessed November 30, 2011).

Yogananda, Paramahansa. The Essence of Self-Realization. Nevada City: Crystal Clarity Publishers, 1990.

Zinn, Marcie L. "Development of a Self-report Inventory to Assess Cognitive Dysfunction in Musicians." PhD diss., Illinois Institute of Technology, 2004.

Zuckerman, Marvin. "The Search for High Sensation.” Psychology Today 11, no. 9 (1978): 38-99. 